\title{
UCRL-TR-213206
}

LAWRENCE LIVERMORE N A TIO N A L LABORATORY

\section{An Earth Penetrating Modeling Assessment}

Eugene Stokes, Paul Yarrington, Lew Glenn

June 23, 2005 
This document was prepared as an account of work sponsored by an agency of the United States Government. Neither the United States Government nor the University of California nor any of their employees, makes any warranty, express or implied, or assumes any legal liability or responsibility for the accuracy, completeness, or usefulness of any information, apparatus, product, or process disclosed, or represents that its use would not infringe privately owned rights. Reference herein to any specific commercial product, process, or service by trade name, trademark, manufacturer, or otherwise, does not necessarily constitute or imply its endorsement, recommendation, or favoring by the United States Government or the University of California. The views and opinions of authors expressed herein do not necessarily state or reflect those of the United States Government or the University of California, and shall not be used for advertising or product endorsement purposes.

This work was performed under the auspices of the U.S. Department of Energy by University of California, Lawrence Livermore National Laboratory under Contract W-7405-Eng-48. 
Defense Threat Reduction Agency

\title{
An Earth Penetration Modeling Assessment
}

\author{
Prediction of Lateral Loading for Oblique Impact Conditions
}

\author{
Eugene Stokes \\ Defense Threat Reduction Agency \\ 8725 John J Kingman Rd \\ Fort Belvoir VA 22060-6201 \\ Paul Yarrington \\ Sandia National Laboratories \\ PO BOX 5800 \\ Albuquerque, NM 87185 \\ Lew Glenn \\ Lawrence Livermore National Laboratory \\ 7000 East Avenue \\ Livermore, CA 94550
}

June 2005

Technical Report 



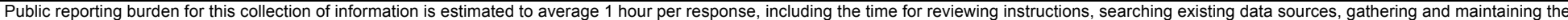

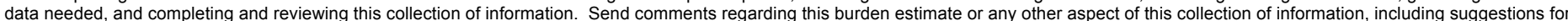

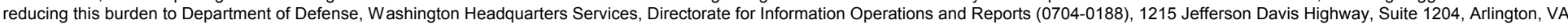

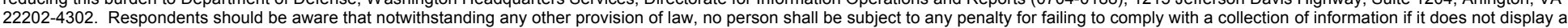
currently valid OMB control number. PLEASE DO NOT RETURN YOUR FORM TO THE ABOVE ADDRESS.

\begin{tabular}{l|l|l} 
1. REPORT DATE $(D D-M M-Y Y Y Y)$ & 2. REPORT TYPE & 3. DATES COVERED (FrOm - To)
\end{tabular}

$\begin{array}{ll}\text { xx-06-2005 } & \text { Review Draft }\end{array}$

4. TITLE AND SUBTITLE

An Earth Penetration Modeling Assessment

Prediction of Lateral Loading for Oblique Impact Conditions

$\mathrm{xx}-04-2004$ to $\mathrm{xx}-07-2004$

5a. CONTRACT NUMBER

5b. GRANT NUMBER

5c. PROGRAM ELEMENT NUMBER

6. AUTHOR(S)

Stokes, Eugene

Yarrington, Paul

5d. PROJECT NUMBER

Glenn, Lew

5e. TASK NUMBER

5f. WORK UNIT NUMBER

7. PERFORMING ORGANIZATION NAME(S) AND ADDRESS(ES)

DEFENSE THREAT REDUCTION

AGENCY

8725 JOHN J KINGMAN RD

FORT BELVOIR VA 22060-6201
SANDIA NATIONAL LABORATORIES

PO BOX 5800

ALBUQUERQUE, NM 87185
8. PERFORMING ORGANIZATION REPORT NUMBER

LAWRENCE LIVERMORE NATIONAL LABORATORY

7000 EAST AVENUE

LIVERMORE, CA 94550

10. SPONSOR/MONITOR'S ACRONYM(S)

DTRA, SNL

11. SPONSOR/MONITOR'S REPORT NUMBER(S)

\section{SPONSORING / MONITORING AGENCY NAME(S) AND ADDRESS(ES)}

Defense Threat Reduction Agen SANDIA NATIONAL LABORATORIES

Cy

8725 JOHN J KINGMAN RD

FORT BELVOIR VA 22060-6201
PO BOX 5800

ALBUQUERQUE, NM 87185

\section{DISTRIBUTION / AVAILABILITY STATEMENT}

TBD

\section{SUPPLEMENTARY NOTES}

Prepared in cooperation with Sandia National Laboratories

\section{ABSTRACT}

Documentation of a study to assess the capability of computer codes to predict lateral loads on earth penetrating projectiles under conditions of non-normal impact. Calculations simulated a set of small scale penetration tests into concrete targets with oblique faces at angles of 15 and 30 degrees to the line-of-flight. Predictive codes used by the various calculational teams cover a wide range of modeling approaches from approximate techniques, such as cavity expansion, to numerical methods, such as finite element codes.

The modeling assessment was performed under the auspices of the Phenomenology Integrated Product Team (PIPT) for the Robust Nuclear Earth Penetrator Program (RNEP). Funding for the penetration experiments and modeling was provided by multiple earth penetrator programs.

15. SUBJECT TERMS

Earth Penetrator, RNEP, Obl ique Impact, Modeling and Simulation,

16. SECURITY CLASSIFICATION OF:

a. REPORT

UNCLASSIFIED b. ABSTRACT UNCLASSIFIED c. THIS PAGE

UNCLASSIFIED

\begin{tabular}{l|l}
\hline 17. LIMITATION & 18. NUMBER \\
OF ABSTRACT & OF PAGES \\
Unclassified & \\
Unlimited & \\
& \\
\hline
\end{tabular}

19a. NAME OF RESPONSIBLE PERSON Eugene Stokes

19b. TELEPHONE NUMBER (include area code)

703-325-6414 


\begin{abstract}
Documentation of a study to assess the capability of computer codes to predict lateral loads on earth penetrating projectiles under conditions of non-normal impact. Calculations simulated a set of small scale penetration tests into concrete targets with oblique faces at angles of 15 and 30 degrees to the line-of-flight. Predictive codes used by the various calculational teams cover a wide range of modeling approaches from approximate techniques, such as cavity expansion, to numerical methods, such as finite element codes.

The modeling assessment was performed under the auspices of the Phenomenology Integrated Product Team (PIPT) for the Robust Nuclear Earth Penetrator Program (RNEP). Funding for the penetration experiments and modeling was provided by multiple earth penetrator programs.
\end{abstract}




\section{CONVERSION TABLE}

Conversion factors for U.S. Customary to metric (SI) units of measurement

\begin{tabular}{|c|c|c|}
\hline \multirow[t]{2}{*}{$\begin{array}{l}\text { MULTIPLY } \\
\text { TO GET }\end{array}$} & $\begin{array}{r}\longrightarrow \mathrm{BY} \longrightarrow \\
\mathrm{BY} \rightleftharpoons \\
\end{array}$ & $\begin{aligned} & \longrightarrow \text { TO GET } \\
& \text { DIVIDE } \\
&\end{aligned}$ \\
\hline & $1.000000 \times E-10$ & meters $(\mathrm{m})$ \\
\hline atmosphere (normal) & $1.01325 \times E+2$ & kilo pascal $(\mathrm{kPa})$ \\
\hline bar & $1.000000 \times E+2$ & kilo pascal $(\mathrm{kPa})$ \\
\hline barn & $1.000000 \times E-28$ & meter $^{2}\left(\mathrm{~m}^{2}\right)$ \\
\hline British thermal unit (thermochemical) & $1.054350 \times \mathrm{E}+3$ & joule $(\mathrm{J})$ \\
\hline calorie (thermochemical) & 4.184000 & joule $(\mathrm{J})$ \\
\hline cal (thermochemical $/ \mathrm{cm}^{2}$ ) & $4.184000 \times E-2$ & mega joule $/ \mathrm{m}^{2}\left(\mathrm{MJ} / \mathrm{m}^{2}\right.$ \\
\hline curie & $3.700000 \times E+1$ & 1-giga becquerel (GBq) \\
\hline degree (angle) & $1.745329 \times \mathrm{E}-2$ & radian $(\mathrm{rad})$ \\
\hline degree Fahrenheit & $t^{\circ} k=\left(t^{\circ} f+459.67\right) / 1.8$ & degree kelvin $(\mathrm{K})$ \\
\hline electron volt & $1.602177 \times \mathrm{E}-19$ & joule $(\mathrm{J})$ \\
\hline erg & $1.000000 \times \mathrm{E}-7$ & joule $(\mathrm{J})$ \\
\hline erg/second & $1.000000 \times \mathrm{E}-7$ & watt $(\mathrm{W})$ \\
\hline foot & $3.048000 \times E-1$ & meter $(\mathrm{m})$ \\
\hline foot-pound-force & 1.355818 & joule $(\mathrm{J})$ \\
\hline gallon (U.S. liquid) & $3.785412 \times E-3$ & meter $^{3}\left(m^{3}\right)$ \\
\hline inch & $2.540000 \times \mathrm{E}-2$ & meter $(\mathrm{m})$ \\
\hline jerk & $1.000000 \times E+9$ & joule $(\mathrm{J})$ \\
\hline $\begin{array}{l}\text { joule/kilogram }(\mathrm{J} / \mathrm{kg}) \text { radiation dose } \\
\text { absorbed }\end{array}$ & 1.000000 & $\stackrel{2}{2}$ Gray (Gy) \\
\hline kilotons & 4.184 & terajoules \\
\hline kip (1000 lbf) & $4.448222 \times E+3$ & newton $(\mathrm{N})$ \\
\hline kip/inch ${ }^{2}(\mathrm{ksi})$ & $6.894757 \times E+3$ & kilo pascal (kPa) \\
\hline ktap & $1.000000 \times E+2$ & newton-second $/ \mathrm{m}^{2}\left(\mathrm{~N}-\mathrm{s} / \mathrm{m}^{2}\right)$ \\
\hline micron & $1.000000 \times E-6$ & meter $(\mathrm{m})$ \\
\hline mil & $2.540000 \times E-5$ & meter $(\mathrm{m})$ \\
\hline mile (international) & $1.609344 \times E+3$ & meter $(\mathrm{m})$ \\
\hline ounce & $2.834952 \times \mathrm{E}-2$ & kilogram (kg) \\
\hline pound-force (Ibs avoirdupois) & 4.448222 & newton $(\mathrm{N})$ \\
\hline pound-force inch & $1.129848 \times \mathrm{E}-1$ & newton-meter (N-m) \\
\hline pound-force/inch & $1.751268 \times E+2$ & newton/meter $(\mathrm{N} / \mathrm{m})$ \\
\hline pound-force/foot ${ }^{2}$ & $4.788026 \times \mathrm{E}-2$ & kilo pascal (kPa) \\
\hline pound-force/inch ${ }^{2}(\mathrm{psi})$ & 6.894757 & kilo pascal $(\mathrm{kPa})$ \\
\hline pound-mass (Ibm avoirdupois) & $4.535924 \times E-1$ & kilogram $(\mathrm{kg})$ \\
\hline pound-mass-foot ${ }^{2}$ (moment of inertia) & $4.214011 \times \mathrm{E}-2$ & kilogram-meter ${ }^{2}\left(\mathrm{~kg}-\mathrm{m}^{2}\right)$ \\
\hline pound-mass/foot ${ }^{3}$ & $1.601846 \times E+1$ & kilogram $/$ meter $^{3}\left(\mathrm{~kg} / \mathrm{m}^{3}\right)$ \\
\hline rad (radiation dose absorbed) & $1.000000 \times E-2$ & 르ay (Gy) \\
\hline roentgen & $2.58 \times E-4$ & coulomb/kilogram (C/kg) \\
\hline shake & $1.000000 \times E-8$ & second (s) \\
\hline slug & $1.459390 \times E+1$ & kilogram $(\mathrm{kg})$ \\
\hline torr $\left(\mathrm{mm} \mathrm{Hg}, 0^{\circ} \mathrm{C}\right)$ & $1.33322 \times E-1$ & kilo pascal $(\mathrm{kPa})$ \\
\hline
\end{tabular}

${ }^{1}$ Becquerel $(\mathrm{Bq})$ is the $\mathrm{SI}$ unit of radioactivity; $1 \mathrm{~Bq}=1$ event/s

${ }^{2}$ Gray (Gy) is the SI unit of absorbed radiation 


\section{Table of Contents}

ABSTRACT $\quad$ iii

CONVERSION TABLE

FIGURES vii

TABLES $\quad$ ix

1 Introduction. 1

2 Experimental Plan. 1

3 Participants. 2

4 Data Comparison Approach.

5 Results. 3

$5.1 \quad$ Test Results. 3

5.2 Calculational Results. $\quad 4$

5.3 Comparisons of Peak Axial Accelerations. 4

5.4 Comparisons of Peak Z-Lateral Accelerations. 4

6 Conclusions and Recommendations 5

7 References. $\quad 7$

Appendix A . Prediction Code Descriptions. A-1

A.1 PENCURV+ - Joe Renick. A-1

A.2 Abaqus (6.4.1)/Spherical Cavity Expansion (SCE), Richard W. Macek. A-2

A.3 ALE3D - Gregg Kay. A-2

A.4 DYNA3D - Gregg Kay. A-4

A.5 PENCURV - Todd Broyles. A-4

A.6 PRESTO - Mike Chiesa. $\quad$ A-6

A.7 PRESTO v1.07 - PRESTO/SCE Simulations, Henry Duong and Don Longcope. A-6

A.8 Zapotec v1.4 - Jeromy Hollenshead. A-7

A.9 EMU 2.6c Peridynamic - Stewart Silling. A-9

Appendix B Additional Validation Metrics. $\quad$ B-1

B.1 Windowed accelerations. B-1

B.2 Temporal moments. B-8

Appendix C Graphical Representation of Penetrator Rest Position. C-1 
Appendix D Lateral Acceleration in the Y-Direction $\quad$ D-1

Appendix E Test Variables $\quad$ E-1

E.1 Material Properties E-1

E.2 Variables/uncertainties $\quad$ E-1 


\section{FIGURES}

Figure 1. Penetrator design. $\quad$

Figure 2. Typical hydrostat for the 3.7ksi concrete target material. $\quad 10$

Figure 3. Typical shear failure envelope for the 3.7ksi concrete target material.

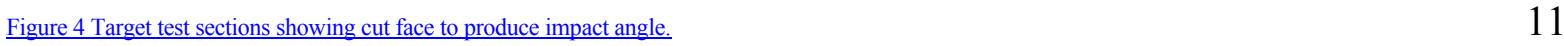

Figure 5. Top view of test geometry showing impact angle (angle of obliquity).

Figure 6. Slant view of test geometry showing impact angle (angle of obliquity).

Figure 7. Test-to-test measured accelerations, 15 degrees obliquity. $\quad 13$

Figure 8. Test-to-test measured accelerations, 30 degrees-obliquity.

Figure 9. SNL-03-12; X, Y, Z accelerations(286 m/s velocity; 30degrees-obliquity).

Figure 10. SNL-03-14; X, Y, Z accelerations(347 m/s velocity; 15degrees-obliquity). $\quad 14$

Figure 11. SNL-03-15; X, Y, Z accelerations(334 m/s velocity; 30degrees-obliquity).

Figure 12. SNL-03-16; X, Y, Z accelerations (372 m/s velocity; 15 degrees-obliquity).

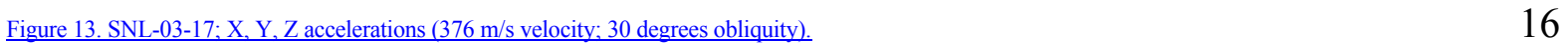

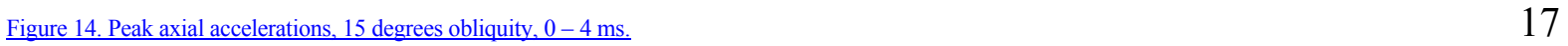

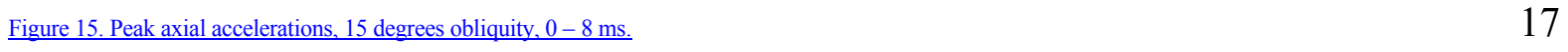

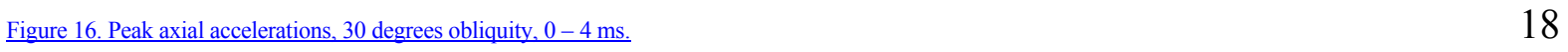

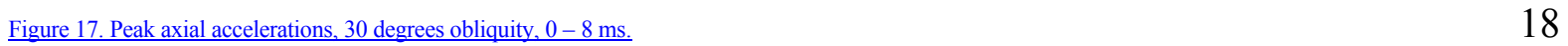

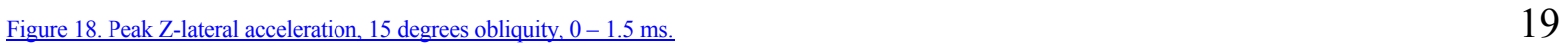

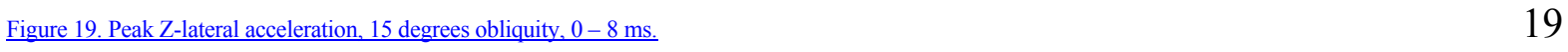

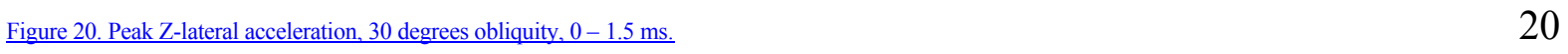

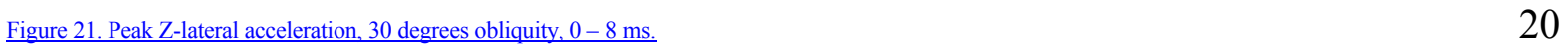

$\begin{array}{lc}\text { Figure B-1. Windowed acceleration metric. } & \text { B-1 }\end{array}$

$\begin{array}{ll}\text { Figure B-2. Windowed metric SNL-03-12 } & \text { B-2 }\end{array}$

$\begin{array}{ll}\text { Figure B-3. Windowed metric SNL-03-14 } & \text { B-2 }\end{array}$

$\begin{array}{ll}\text { Figure B-4. Windowed metric SNL-03-15 } & \text { B-2 }\end{array}$

$\begin{array}{ll}\text { Figure B-5. Windowed metric SNL-03-16 } & \text { B-2 }\end{array}$

$\begin{array}{ll}\text { Figure B-6. Windowed metric SNL-03-17. } & \text { B-2 }\end{array}$

$\begin{array}{ll}\text { Figure B-7. SNL-03-12 raw windowed metric. } & \text { B-3 }\end{array}$

$\begin{array}{ll}\text { Figure B-8. SNL-03-14 raw windowed metric. } & \text { B-4 }\end{array}$ 


\section{TABLES}

$\underline{\text { Table 1. Impact conditions. }}$

Table 2. Calculational teams.

Table C-1. SNL-03-12, penetration data.

C-2

Table C-2. SNL-03-14, penetration data.

C-2

Table C-3. SNL-03-15, penetration data. C-3

Table C-4. SNL-03-16, penetration data. C-3

$\underline{\text { Table C-5. SNL-03-17, penetration data. }}$ C-4

$\underline{\text { Table D-1. Peak Y-lateral accelerations for all tests and predictors. }}$

D-1

$\underline{\text { Table E-1. WES experimental variable control and measurement precision. }}$

E-1 


\section{An Earth Penetration Modeling Assessment}

\section{Prediction of Lateral Loading for Oblique Impact Conditions}

\section{Introduction.}

This report documents a study to assess the capability of computer codes to predict lateral loads on earth penetrating projectiles under conditions of non-normal impact.

In any earth penetration event, the projectile will generally strike the target with some nonzero angle of obliquity, due to effects of winds, target surface irregularities, etc. It is well known that such "non-normal" impact conditions produce large lateral forces and accelerations that can threaten the survivability of the earth penetrator (EP) case and internal components. Consequently, it is important for design engineers to know how accurately the penetration analysis tools can predict lateral loads on a given EP system.

For the present study, calculations of EP response to oblique impact events were performed by nine teams using a variety of analysis methods. The calculations simulated a set of small scale penetration tests into concrete targets conducted under a separate program. An independent assessment group then performed the necessary data processing and analysis for comparing the calculational results with the test data. Results of the oblique impact experiments were withheld until predictions of the expected accelerations of the events had been submitted by the calculational teams to the independent assessment group. Thus, the process provided an assessment of the "predictive" capability of the codes, in that the calculations were done in a "blind" mode, i.e. without knowledge of the test results.

\section{Experimental Plan.}

The test data for the present code benchmarking study was obtained under a program funded through the Department of Energy (DOE)/Department of Defense (DoD) and the Office of Munitions Memorandum of Understanding (MOU). Specifically, the data was generated as part of a broader penetration test program (Frew and Averett, 2004; Frew and Gilchrist, 2004) that was planned and conducted under the Penetration Technology Technical Coordination Group (TCG-11) of the MOU Program.

The TCG-11 penetration tests were conducted at the US Army Engineering Research and Development Center (ERDC). The penetrator design used in the tests is shown in Figure 1. The projectile had a 3 caliber radius head $(\mathrm{CRH})$ ogival nose, with a nominal outside

1 The study reported here began under the auspices of the Phenomenology Integrated Product Team (PIPT) for the Robust Nuclear Earth Penetrator Program; however, funding for the various participants in the program was provided by multiple EP technology programs within the National Nuclear Security Administration (NNSA) and DoD communities. 
diameter of 3.15 inches and nominal length of 20.9 inches. The penetrator case was made of steel, and the unit had a total weight of 29.3 pounds, including internal instrumentation. A 3 AMP-C triaxial accelerometer was mounted forward in the body, as indicated by callout Number 2 in Figure 1. It should be noted that the sensing element of the accelerometer was actually located at the forward end of the 3AMP-C instrumentation package.

The target material for the tests was a concrete mix of nominal $3.7 \mathrm{ksi}$ unconfined compressive strength. A representative hydrostat and shear failure envelope for the target material are shown in Figures 2 and 3, respectively. This data was available to the calculational teams for the purpose of determining material property constants, since some of the modeling techniques were able to use material property data directly to set certain model parameters.

In addition to the material property tests, a set of normal penetration tests were conducted earlier under the MOU Program with the same target material and penetrator design as were used in the oblique impact tests. Acceleration history from the normal impact tests was also available to the calculational teams for use in adjusting and calibrating parameters in the computational models for the oblique impact study.

Five tests were included in the oblique impact series. The impact conditions for these tests are summarized in Table 1 . The impact velocity ranged from $938 \mathrm{ft} / \mathrm{s}$ to $1234 \mathrm{ft} / \mathrm{s}$, so all tests were at roughly the same impact velocity. Two tests were conducted at an impact angle of 15 degrees and three tests at an impact angle of 30 degrees. Angles of pitch and yaw were well controlled by the test setup, and were less than one degree in all cases. Thus, it was possible to get estimates of data variability by comparing test results at nominally similar test conditions for each angle of obliquity.

The targets for the oblique impact tests were cast in thin-walled steel culverts cut at the desired impact angle as illustrated in Figure 4. The projectile impact velocity was aligned with the axis of the cylinder, as shown in Figures 5 and 6.

\section{Participants.}

Table 2 lists the calculational teams that participated in the study. The table lists the organization, principal investigator, and code for each team. The codes used by the various calculational teams cover a wide range of modeling approaches from approximate techniques, such as cavity expansion, to numerical methods, such as finite element codes. In some cases, the same basic modeling technique was used by different teams but with different assumptions and choices for input parameters. Descriptions of the various codes used in the study are provided in Appendix A.

\section{Data Comparison Approach.}


An independent assessment group collected the calculational results from each of the calculational teams and also obtained data packages on the test results from the MOU TCG-11 Project Team. The independent assessment group performed all necessary data processing and analysis for comparing test and calculational results. For the present study, the Defense Threat Reduction Agency (DTRA) contract organization Northrop Grumman Information Technology (NGIT), served in that independent assessment role.

Data reporting formats and post processing guidelines were specified to facilitate analysis and the comparison of code predictions with test results. Accelerations were monitored in the body-centered reference frame of the penetrator, corresponding to the location of the forward-mounted accelerometer in the test article. Accelerations were reported at $10 \mu \mathrm{s}$ intervals, and the data was filtered at $2 \mathrm{kHz}$ with a two-pass, four-pole Butterworth filter using MATLAB ${ }^{\circledR 2}$.

The primary metric for comparison of test and calculational results was lateral acceleration, although additional metrics are discussed in Appendix B. Penetrator rest angle and nose position are metrics that have been of interest in the TCG-11 MOU community, and these are discussed for the present study in Appendix C.

Since the test configuration was arranged to achieve symmetry with respect to the $\mathrm{Y}$ direction, the focus here will be on lateral accelerations in the Z-direction. Indeed, all results show much lower acceleration in the Y-direction. Furthermore, the Z-lateral accelerations are of greatest interest, since the largest overall accelerations were seen in that direction, as expected. For completeness, however, results and discussion of Ydirection accelerations are provided in Appendix D.

The first peak in the acceleration histories will be used to compare test and calculational results. For the test configuration here, the first peaks occurred in the first 1 millisecond of the event and were the highest acceleration levels experienced by the projectile. The first peaks were easily identified in each of the individual test and calculational results.

\section{Results.}

\subsection{Test Results.}

Overlays of the axial and lateral acceleration data for the tests at 15 degrees and 30 degrees obliquity are shown in Figures 7 and 8, respectively. The degree of test-to-test variability is evident in these results. While scatter in peak axial acceleration is relatively small, variations in the first peak of the Z-lateral accelerations are $\sim \pm 30$ percent for the 15 degrees obliquity shots and $\sim \pm 20$ percent for the 30 degrees obliquity events.

2 MATLAB Version 5, R11, The Math Works, Inc, 1984-1999. 
It should be noted that the tests that were considered in this study were conducted under very carefully controlled conditions on impact and target parameters (experimental variables are discussed in Appendix E). Nevertheless, a relatively large scatter is seen in the lateral acceleration data. The cause of this is not well understood.

\subsection{Calculational Results.}

The filtered acceleration history from calculations for each of the oblique impact tests are shown in Figures 9 through 13. Each figure also includes the experimental data for the corresponding test. Considerable variation is seen in the results predicted by the various calculational methods.

\subsection{Comparisons of Peak Axial Accelerations.}

Figure 14 compares peak axial accelerations for the test data with the predicted results for the tests at 15 degrees obliquity. Figure 15 shows the same information on a time scale that is expanded to $8 \mathrm{~ms}$. The icon labels in Figure 14 refer to the test numbers, e.g., $14 \equiv$ SNL-03-14.

Figures 16 and 17 provide the same peak axial acceleration comparisons for the tests at 30 degrees obliquity.

Shown on the peak axial acceleration plots of Figures 14 through 17 are lines of \pm 15 percent and \pm 30 percent error with respect to the midpoint of the data. One general conclusion that can be drawn from these comparisons is that with few exceptions, the codes were able to predict axial accelerations to within \pm 15 percent of the test data. This might not be surprising, however, since axial acceleration data from normal impact tests with the same projectile and target material were available to the calculational teams for calibrating the calculational models, as noted above. Indeed, test and calculational results indicate that the axial acceleration levels are relatively independent of speed and obliquity for this series of tests, so the opportunity to calibrate models to axial acceleration for normal impact tests was an advantage here that would not generally be available for predicting lateral loads.

\subsection{Comparisons of Peak Z-Lateral Accelerations.}

Figure 18 shows the peak Z-lateral accelerations $v s$. time for the tests at 15 percent obliquity, and Figure 19 provides an expanded view of the same data. Again, the icon labels in Figure 18 refer to the test numbers, e.g., $12 \equiv$ SNL-03-12.

Figures 20 and 21 provide the corresponding Z-lateral acceleration information for the tests at 30 degrees obliquity.

Dotted lines on Figures 18 through 21 show the data scatter for the Z-lateral 
accelerations. For the tests at 15 degrees obliquity, the data scatter (i.e. [max-min] /2) was $\sim 1300$ g's, with a data midpoint value (i.e. $[\max +\min ] / 2$ ) of $\sim 4000$ g's.

For the tests at 30 degrees obliquity, the data scatter was $\sim 1500 \mathrm{~g}$ 's, with a midpoint value of $\sim 7000$ g's.

It can be seen that most of the predictions fell within the data scatter band (i.e. $4000 \pm$ $1300 \mathrm{~g}$ 's) for the tests at 15 degrees obliquity, and almost all of the predictions fell within \pm 50 percent of the scatter band (i.e. within the range: $4000 \pm 1950$ g's) for events at that impact angle.

For the tests at 30 degrees obliquity, a few of the calculations were within the data scatter band (i.e. $7000 \pm 1500$ g's). The majority of the predictions, however, fell outside the data scatter, but again within \pm 50 percent of the scatter band (i.e. within the range: $7000 \pm$ 2250 g's).

As can be seen from figures 18 and 20, the calculators generally predicted significantly less test-to-test scatter than was measured in the experiments.

As indicated in Table 1, two separate sets of predictions were made using PENCURV. The variants of PENCURV employed by Sandia and DTRA for this study predict accelerations only at the penetrator center-of-mass. The DTRA (Renick) predictions did not include any coordinate transformations to account for the difference in the accelerometer/center-of-mass location. The SNL-B (Broyles) set of predictions did attempt to account for the difference in the location of measurement. Appendix A provides more detail regarding these issues.

It should be noted that predictions of Z-lateral accelerations by the LANL team were within the data scatter for all cases.

\section{Conclusions and Recommendations}

The goal of this study was to provide information to the penetrator design community on uncertainty levels to be associated with predictions of EP response. The assessment process was structured to assess the capability of current analysis methods to predict lateral loads on earth penetrating projectiles under oblique impact conditions. In particular, test results were withheld from distribution until the calculational teams had submitted the results of their calculations. In that sense, the calculational results provided actual predictions of the events.

One overarching conclusion from the study was that measured variability in lateral accelerations for penetration events involving impact into hard, brittle geologic media can be quite large. Indeed, the data scatter in peak lateral accelerations was on the order of $\sim \pm$ 30 percent about the midpoint for impacts at 15 degrees obliquity and $\sim 20$ percent about the midpoint for impacts at 30 degrees obliquity. The reasons for the relatively large data 
scatter are: 1) geology, 2) small asymmetries in impact conditions. Data are insufficient to resolve these issues.

In general, the calculational predictions of axial acceleration were within \pm 15 percent of the measured values. Of course, the computational models had been calibrated to earlier normal impact penetration data, so the relatively good agreement on axial accelerations is more likely a reflection of the insensitivity of axial loads to angle of impact than it is of predictive capability of the codes. In any case, \pm 15 percent would appear to be a reasonable estimate of the accuracy for most of the current modeling tools in predicting peak axial loads under impact conditions to \pm 30 degrees obliquity, at least when the models have been calibrated to normal impact data for the target material in question.

For predictions of lateral accelerations, most of the calculational methods gave predictions that were within \pm 50 percent the data scatter band, and some methods gave predictions that were considerably closer than that. Indeed, the calculations of the LANL team fell within the data scatter for all events in the test suite. As noted above, however, there was large scatter in the test data for lateral accelerations ( \pm 32 percent for the 15 degrees obliquity shots and \pm 21 percent for the 30 degrees obliquity events). So, based on the results presented here, overall uncertainty in estimates of lateral accelerations would be about a factor of two.

We would note that for the test conditions considered here, the peak lateral accelerations occurred early in the penetration event, as the nose of the projectile was becoming embedded in the target. Other earth penetration studies have indicated that angle of attack can lead to large lateral accelerations that occur later in the event. Such effects (e.g. tail slap) were not evaluated in the present study, since the tests and calculations were setup to keep the angle of attack (pitch and/or yaw) as close to zero as possible. Additional benchmarking and code validation studies should be undertaken to address predictive capability of the computational methods under these conditions. 


\section{References.}

Frew, Danny and Seth Gilchrist. Oblique Penetration Experiments into Low Strength Concrete Targets. Sandia National Laboratory. April 28, 2004, updated June 14, 2004.

Frew, D. J., and J. G. Averett. "Oblique penetration of concrete targets with deceleration-time measurements" to be submitted to International Journal of Impact Engineering. (2004). 
Table 1. Impact conditions.

\begin{tabular}{|c|c|c|c|}
\hline Shot Number & $\begin{array}{c}\text { Velocity } \\
\mathbf{m} / \mathbf{s}(\mathbf{f t} / \mathbf{s})\end{array}$ & $\begin{array}{c}\text { Angle of } \\
\text { Obliquity }\end{array}$ & $\begin{array}{c}\text { Pitch/Yaw } \\
\text { (deg) }\end{array}$ \\
\hline SNL-03-12 & $286(938)$ & $30^{\circ}$ & $0.3 \mathrm{D} / 0.5 \mathrm{R}$ \\
\hline SNL-03-14 & $347(1138)$ & $15^{\circ}$ & $0.2 \mathrm{U} / 0.3 \mathrm{~L}$ \\
\hline SNL-03-15 & $334(1096)$ & $30^{\circ}$ & $0.0 / 0.3 \mathrm{R}$ \\
\hline SNL-03-16 & $372(1220)$ & $15^{\circ}$ & $0.4 \mathrm{D} / 0.6 \mathrm{R}$ \\
\hline SNL-03-17 & $376(1234)$ & $30^{\circ}$ & $0.5 \mathrm{D} / 0.1 \mathrm{~L}$ \\
\hline
\end{tabular}

Table 2. Calculational teams.

\begin{tabular}{|c|c|c|}
\hline Organization & Investigator & Code \\
\hline DTRA & Renick, NGIT & PENCURV+ \\
\hline LANL & Macek, LANL & ABAQUS(6.4.1)/SCE \\
\hline LLNL-A & Kay, LLNL & ALE3D \\
\hline LLNL-D & Kay, LLNL & DYNA3D \\
\hline SNL B & Broyles, SNL & PENCURV \\
\hline SNL-C & Chiesa, SNL & Presto \\
\hline SNL-D & Duong/Longcope, SNL & Presto v1.07 \\
\hline SNL-H & Hollenshead. SNL & Zapotec v1.4 \\
\hline SNL-S & Silling, SNL & Emu 2.6c Peridynamic \\
\hline
\end{tabular}




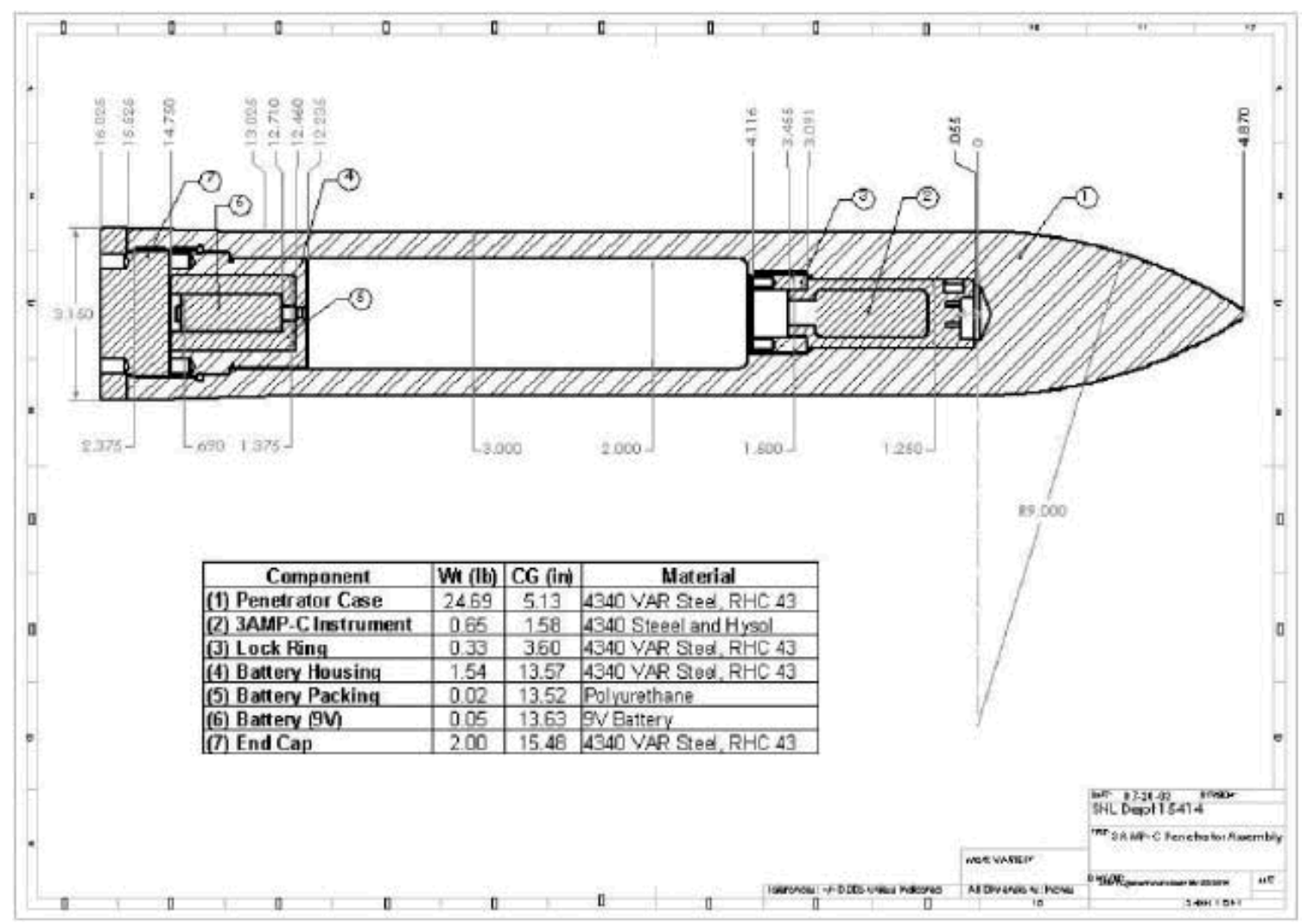

Figure 1. Penetrator design. 


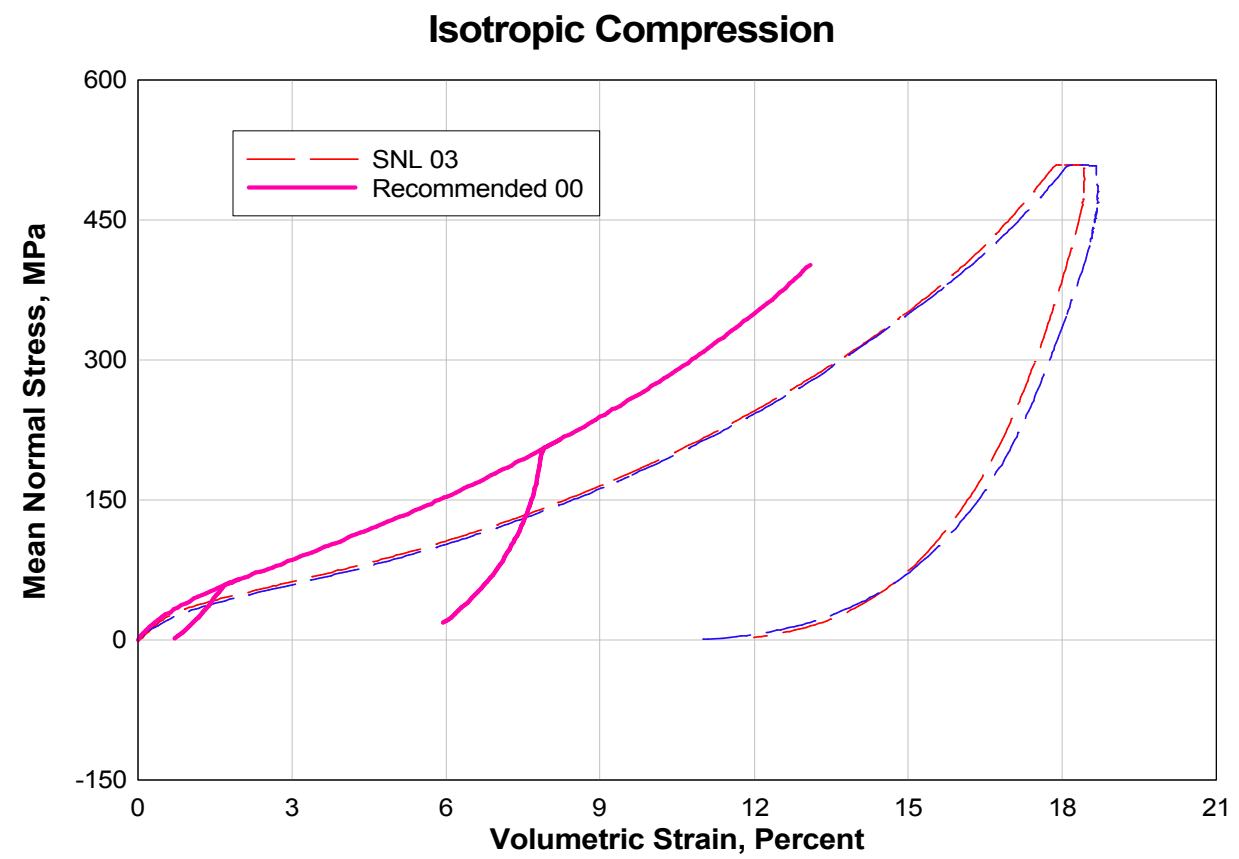

Figure 2. Typical hydrostat for the $3.7 \mathrm{ksi}$ concrete target material.

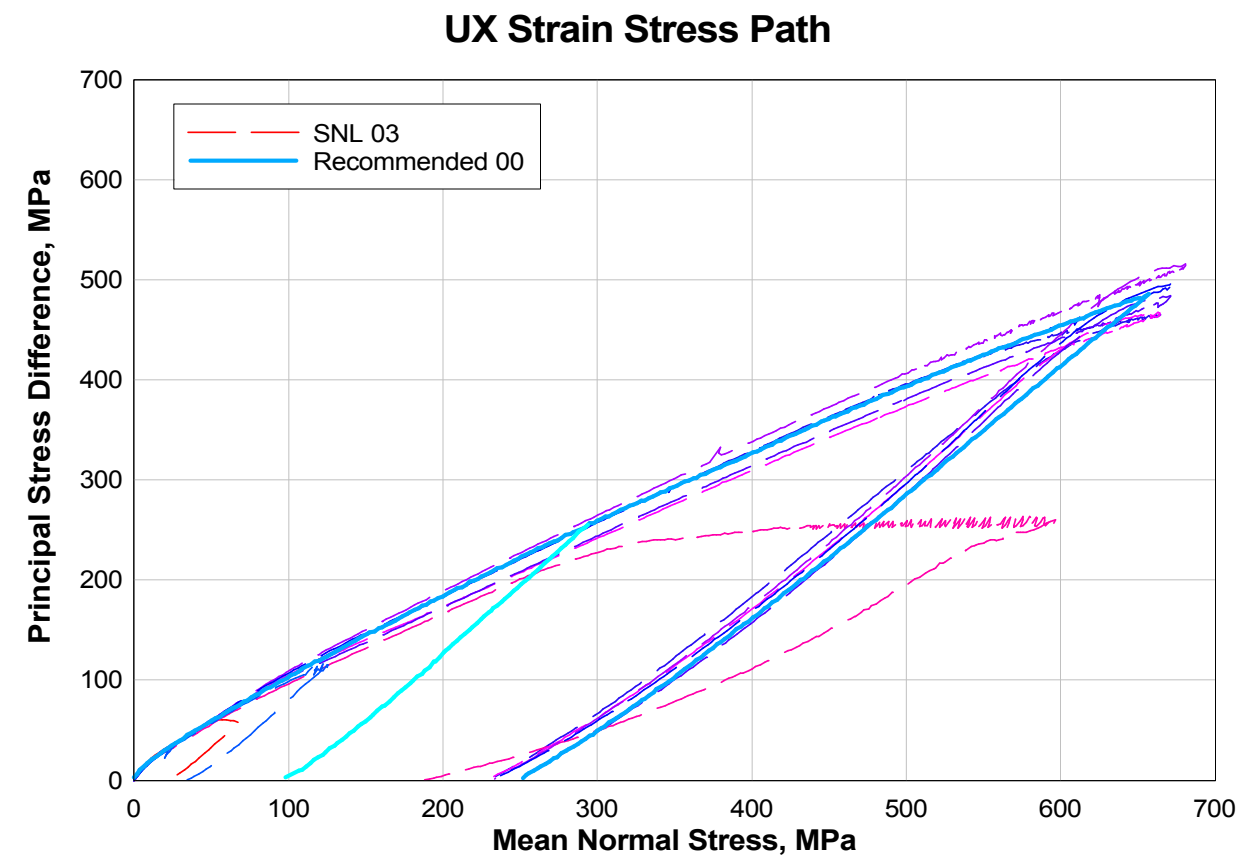

Figure 3. Typical shear failure envelope for the $3.7 \mathrm{ksi}$ concrete target material. 


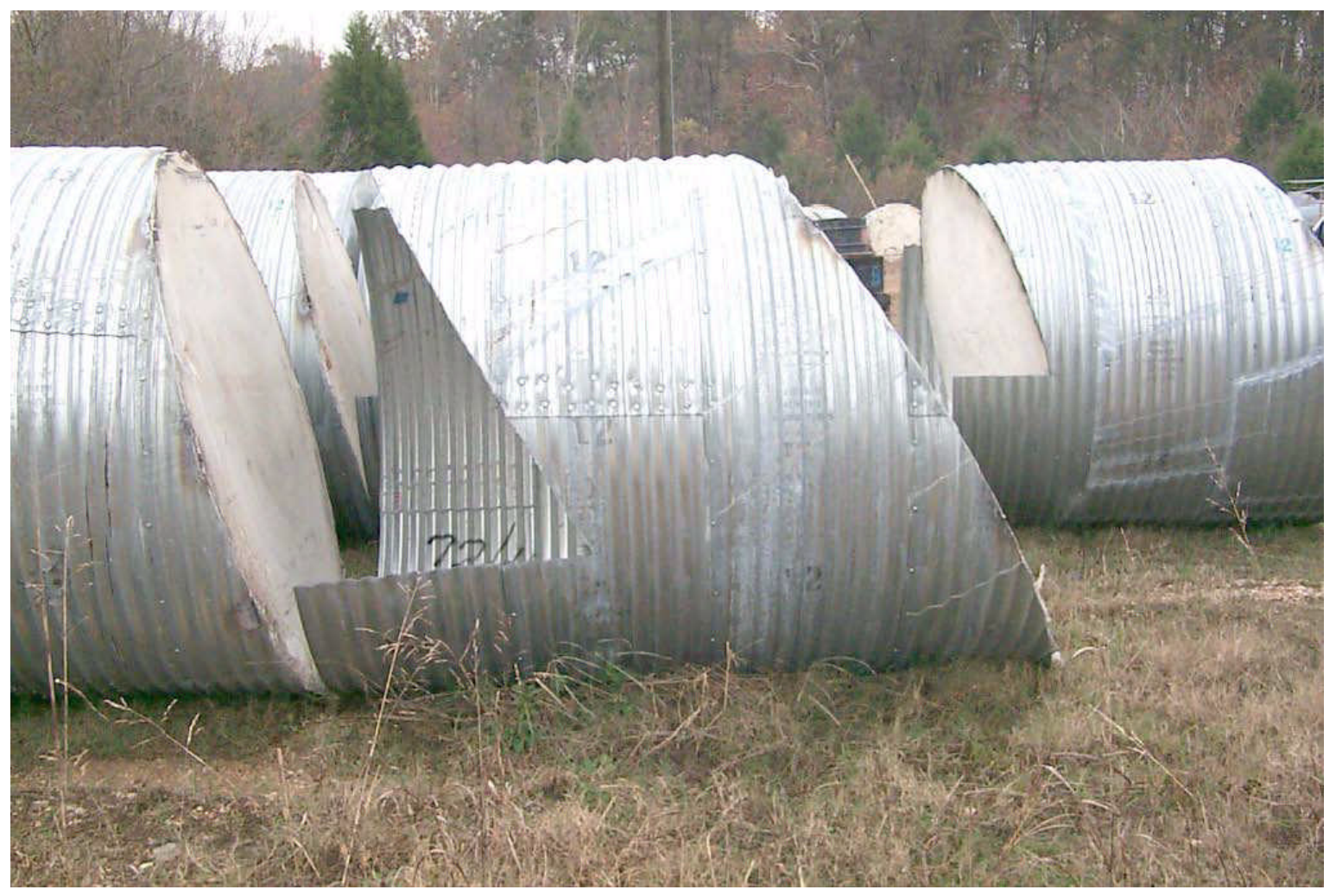

Figure 4 Target test sections showing cut face to produce impact angle. 


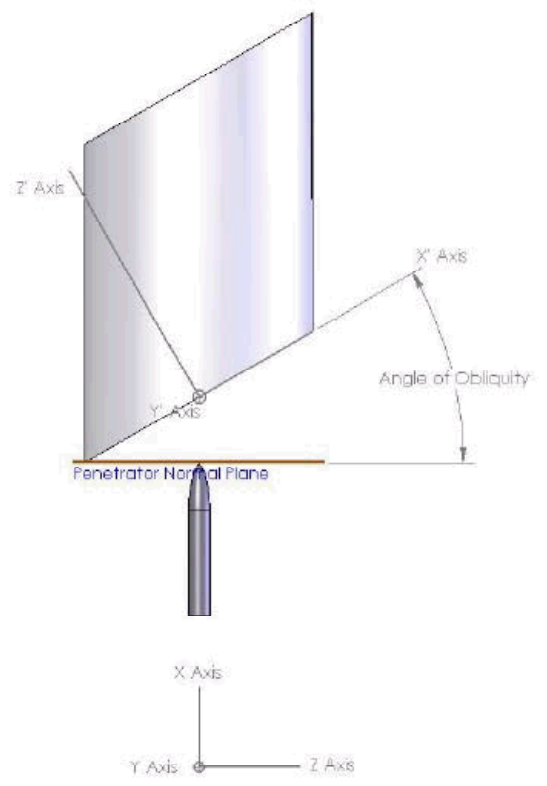

Figure 5. Top view of test geometry showing impact angle (angle of obliquity).

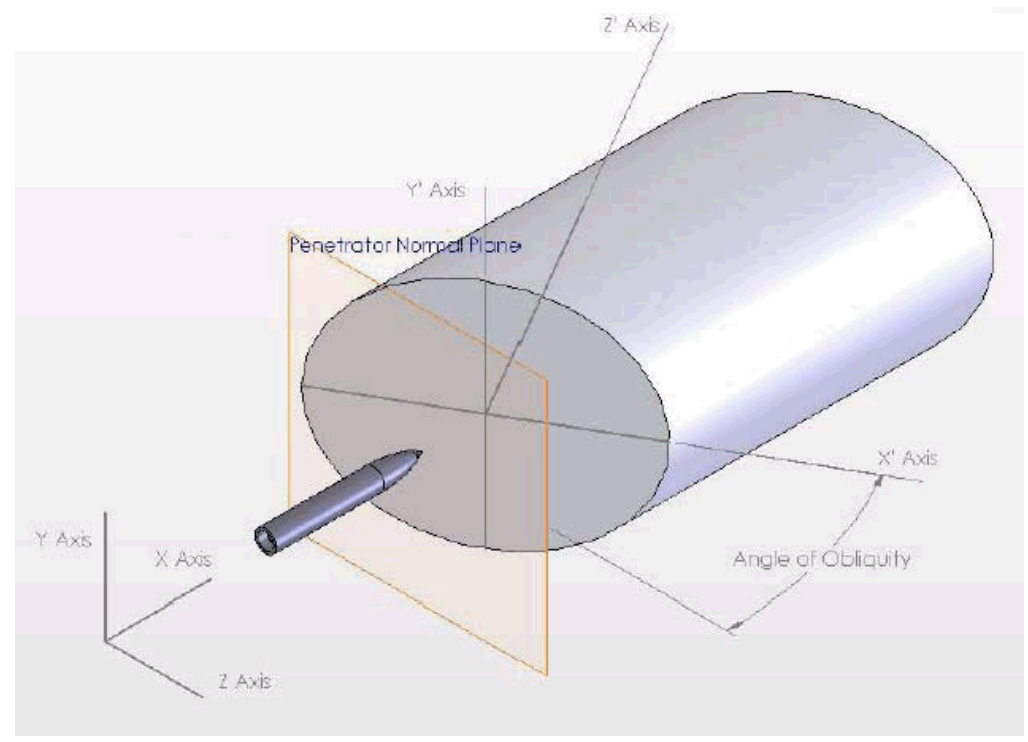

Figure 6. Slant view of test geometry showing impact angle (angle of obliquity). 

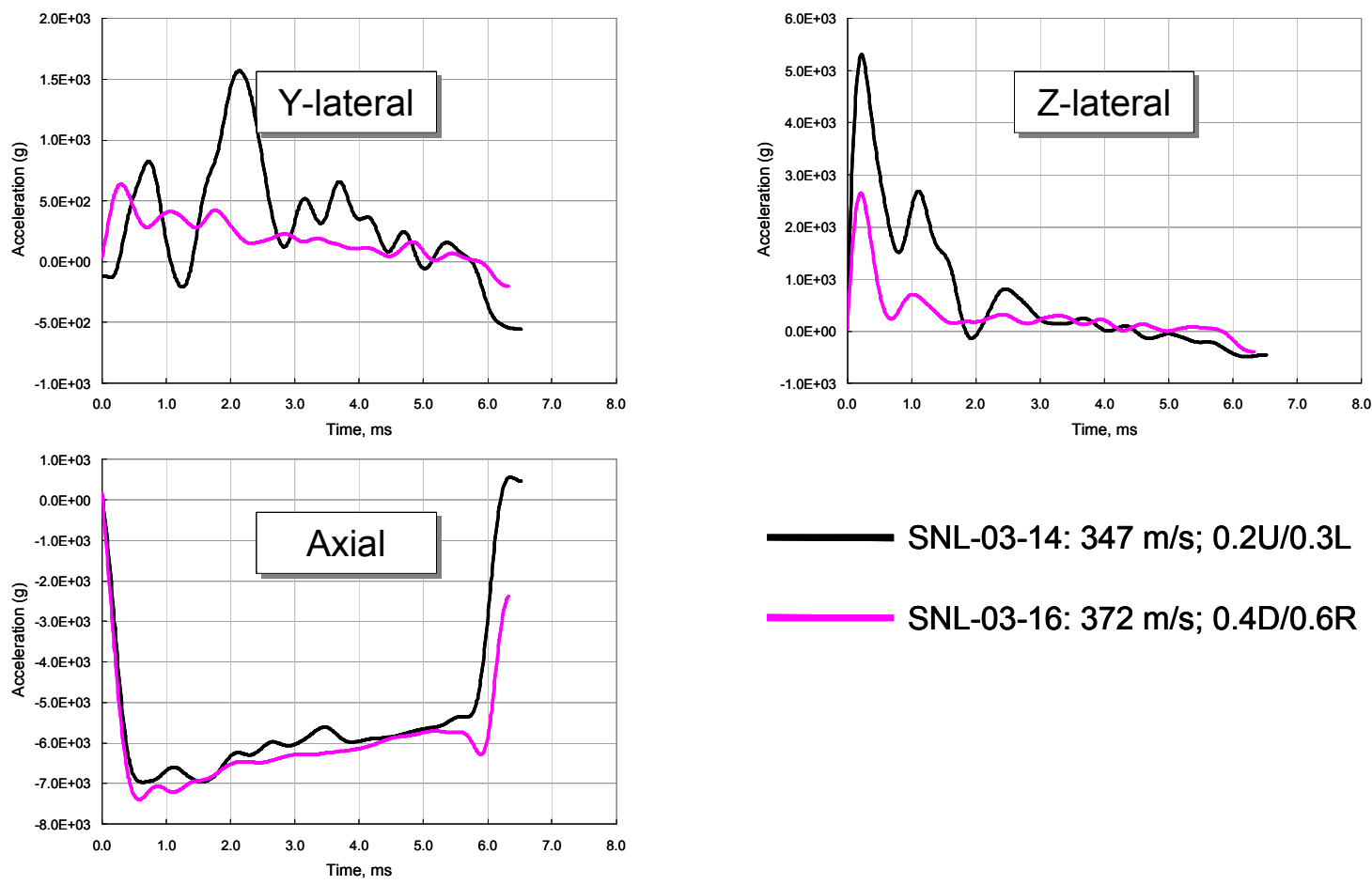

SNL-03-14: $347 \mathrm{~m} / \mathrm{s} ; 0.2 \mathrm{U} / 0.3 \mathrm{~L}$

SNL-03-16: $372 \mathrm{~m} / \mathrm{s} ; 0.4 \mathrm{D} / 0.6 \mathrm{R}$

Figure 7. Test-to-test measured accelerations, 15 degrees obliquity.
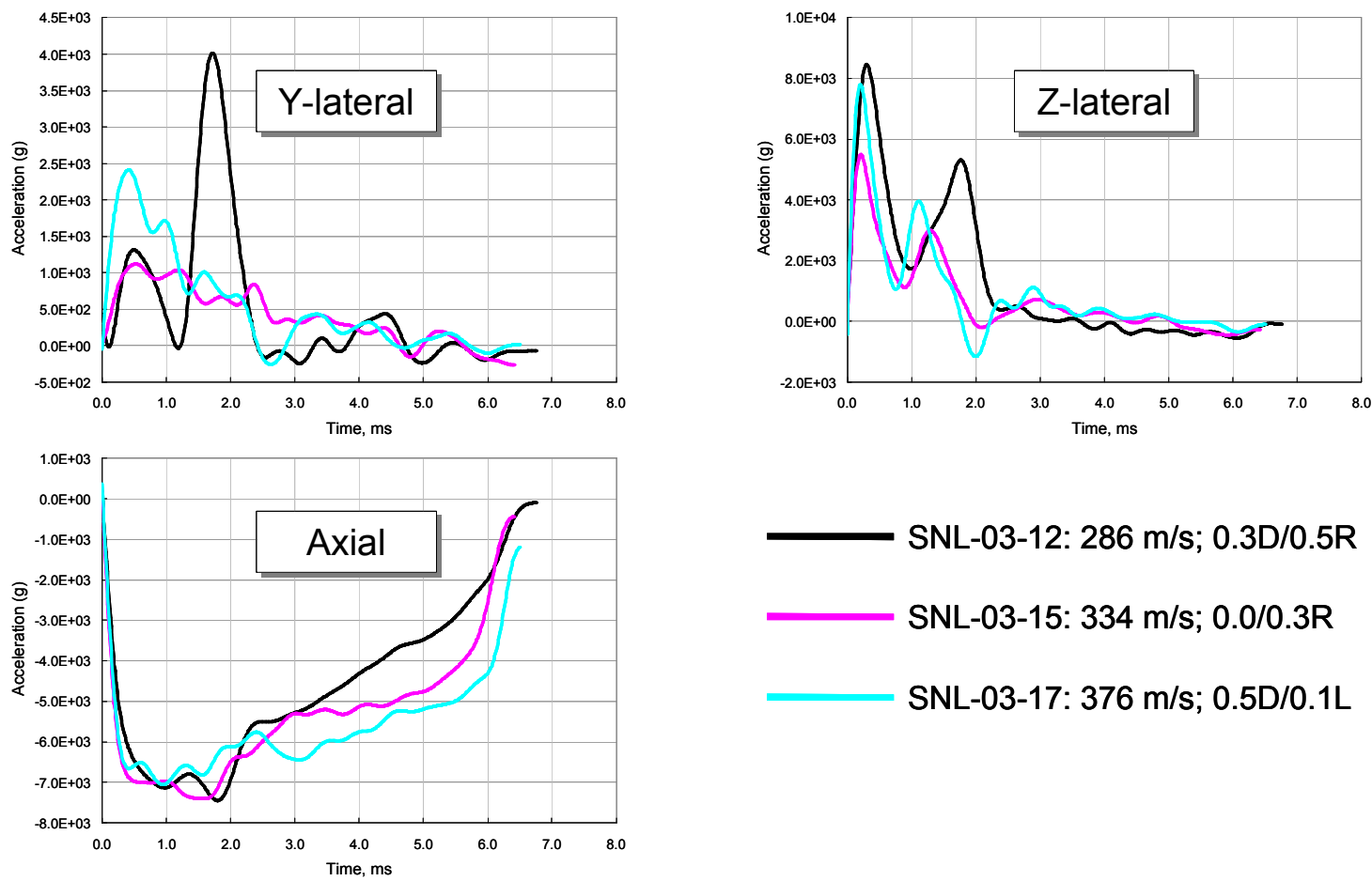

SNL-03-12: $286 \mathrm{~m} / \mathrm{s} ; 0.3 \mathrm{D} / 0.5 \mathrm{R}$

SNL-03-15: $334 \mathrm{~m} / \mathrm{s} ; 0.0 / 0.3 R$

SNL-03-17: 376 m/s; 0.5D/0.1L

Figure 8. Test-to-test measured accelerations, 30 degrees obliquity. 

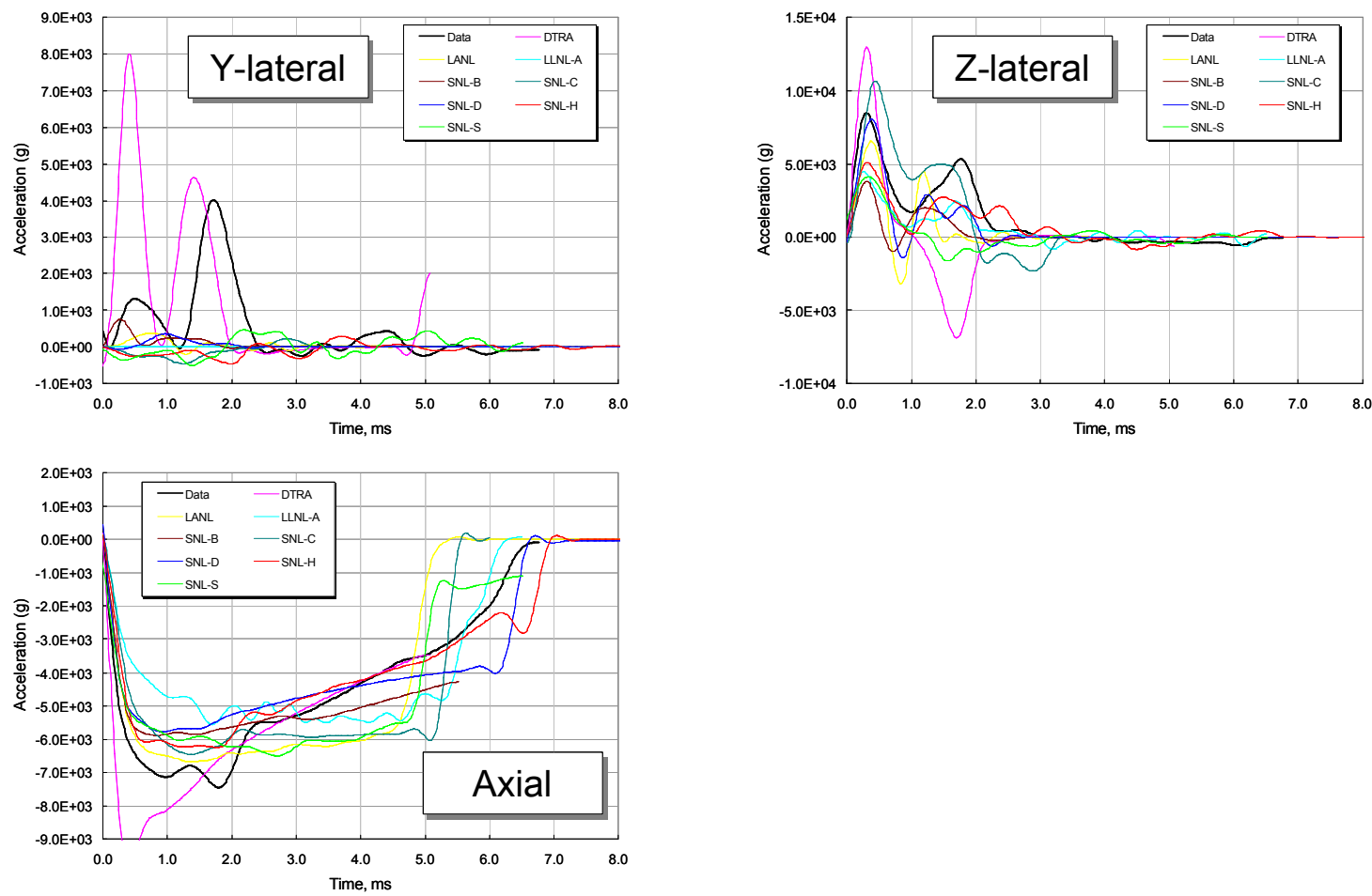

Figure 9. SNL-03-12; X, Y, Z accelerations(286 m/s velocity; 30degrees obliquity).
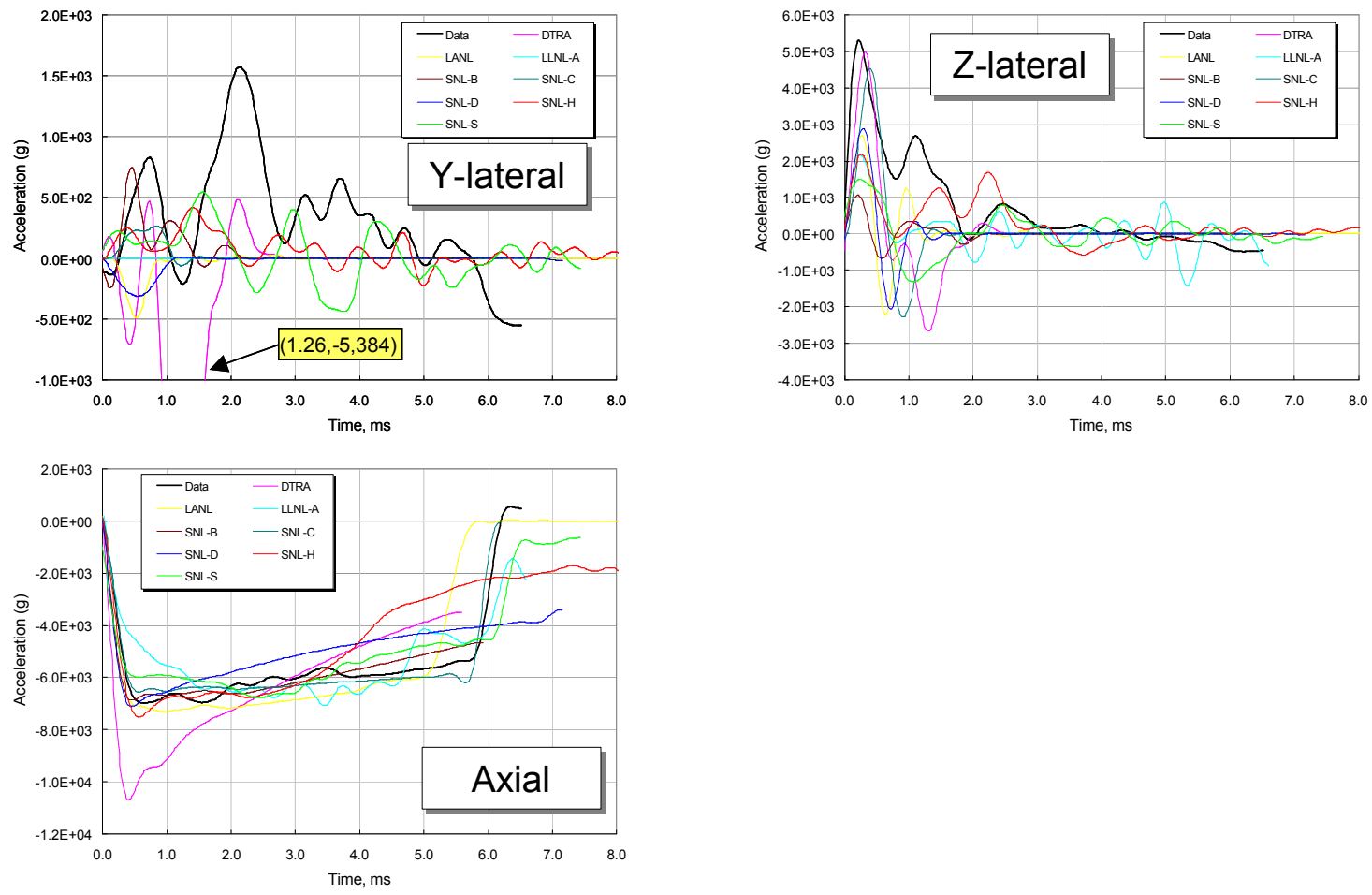

Figure 10. SNL-03-14; X, Y, Z accelerations(347 m/s velocity; 15degrees obliquity). 

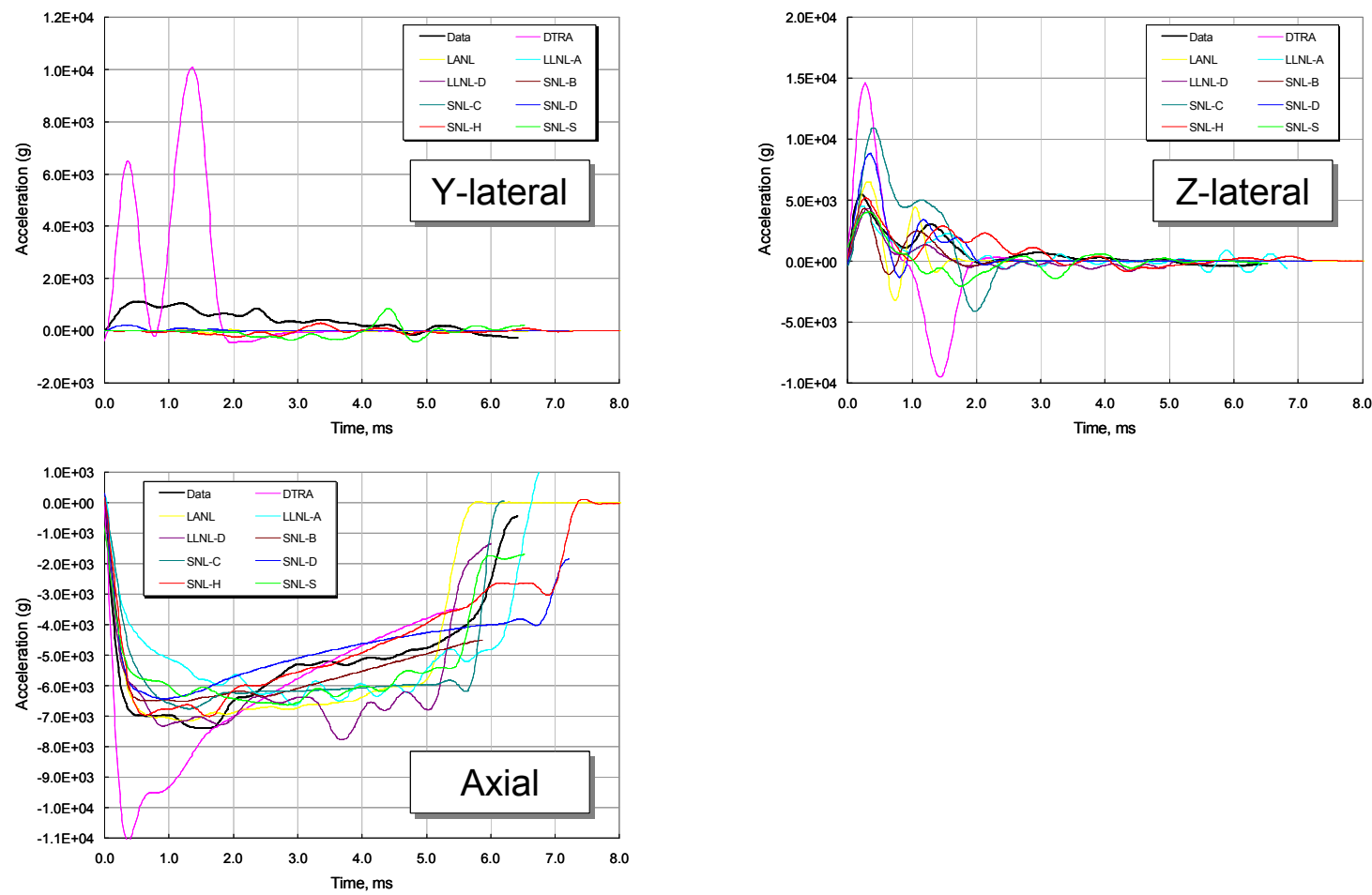

Figure 11. SNL-03-15; X, Y, Z accelerations(334 m/s velocity; 30degrees obliquity).
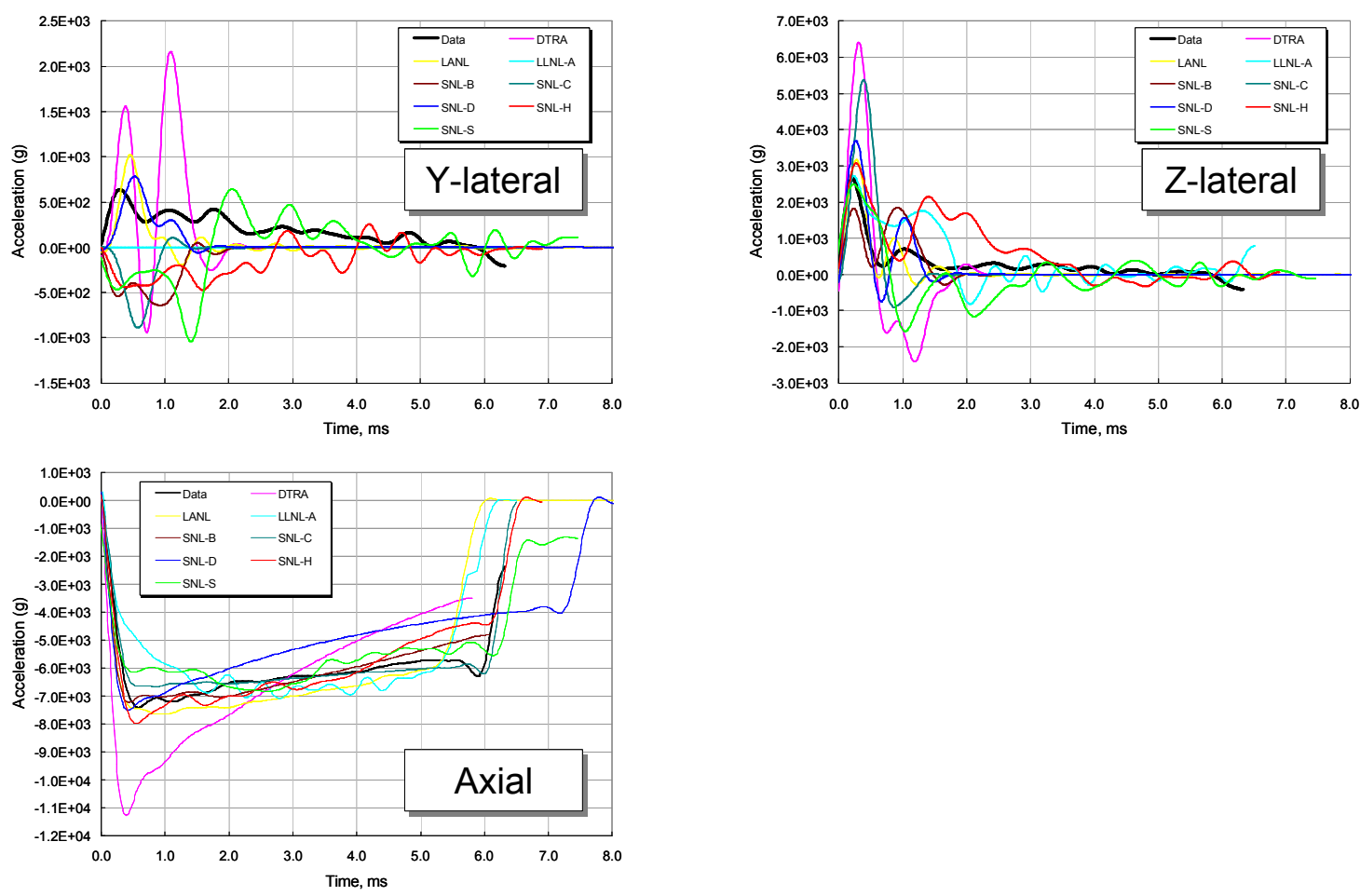

Figure 12. SNL-03-16; X, Y, Z accelerations (372 m/s velocity; 15 degrees obliquity). 

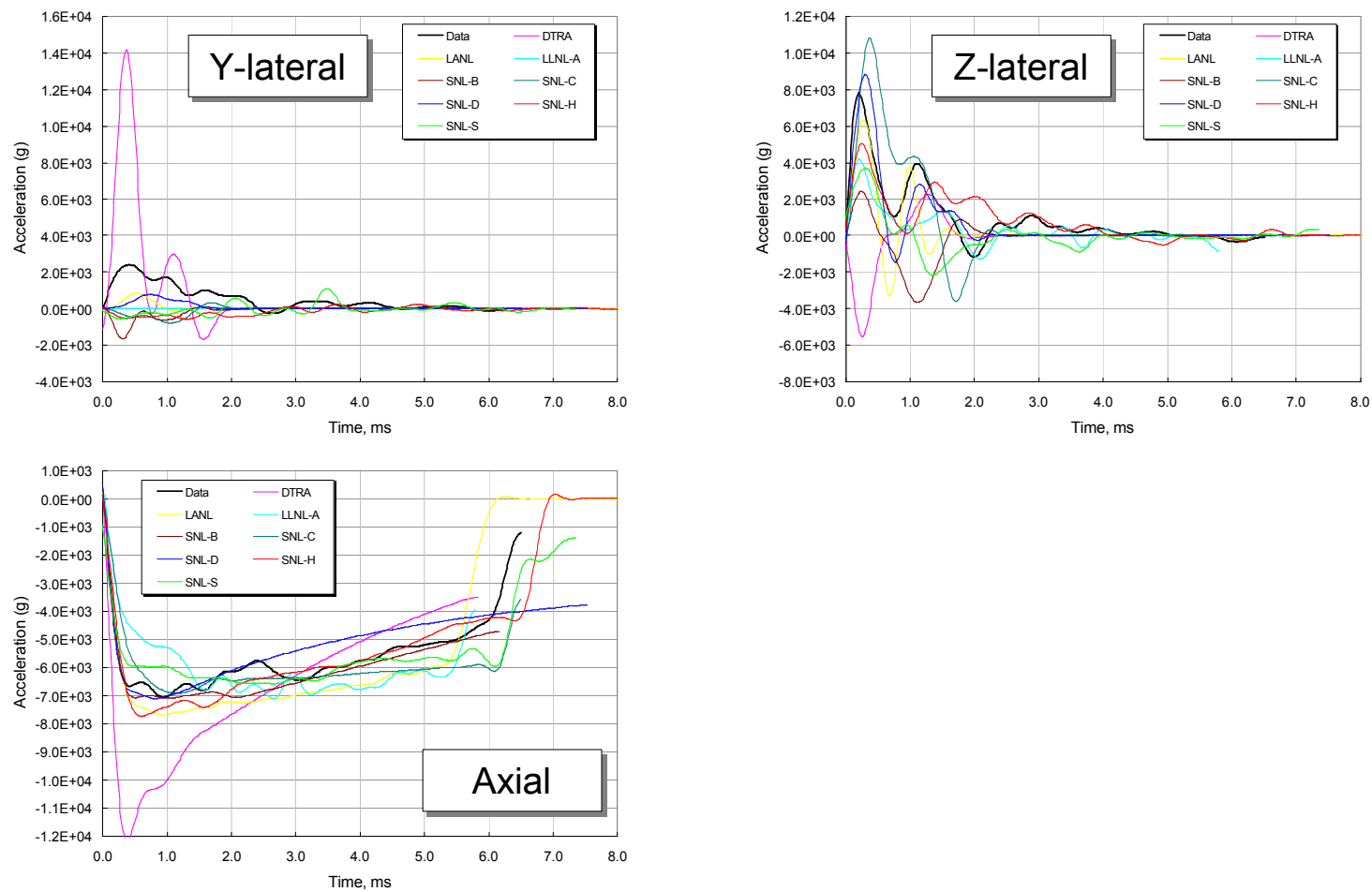

Figure 13. SNL-03-17; X, Y, Z accelerations (376 m/s velocity; 30 degrees obliquity). 


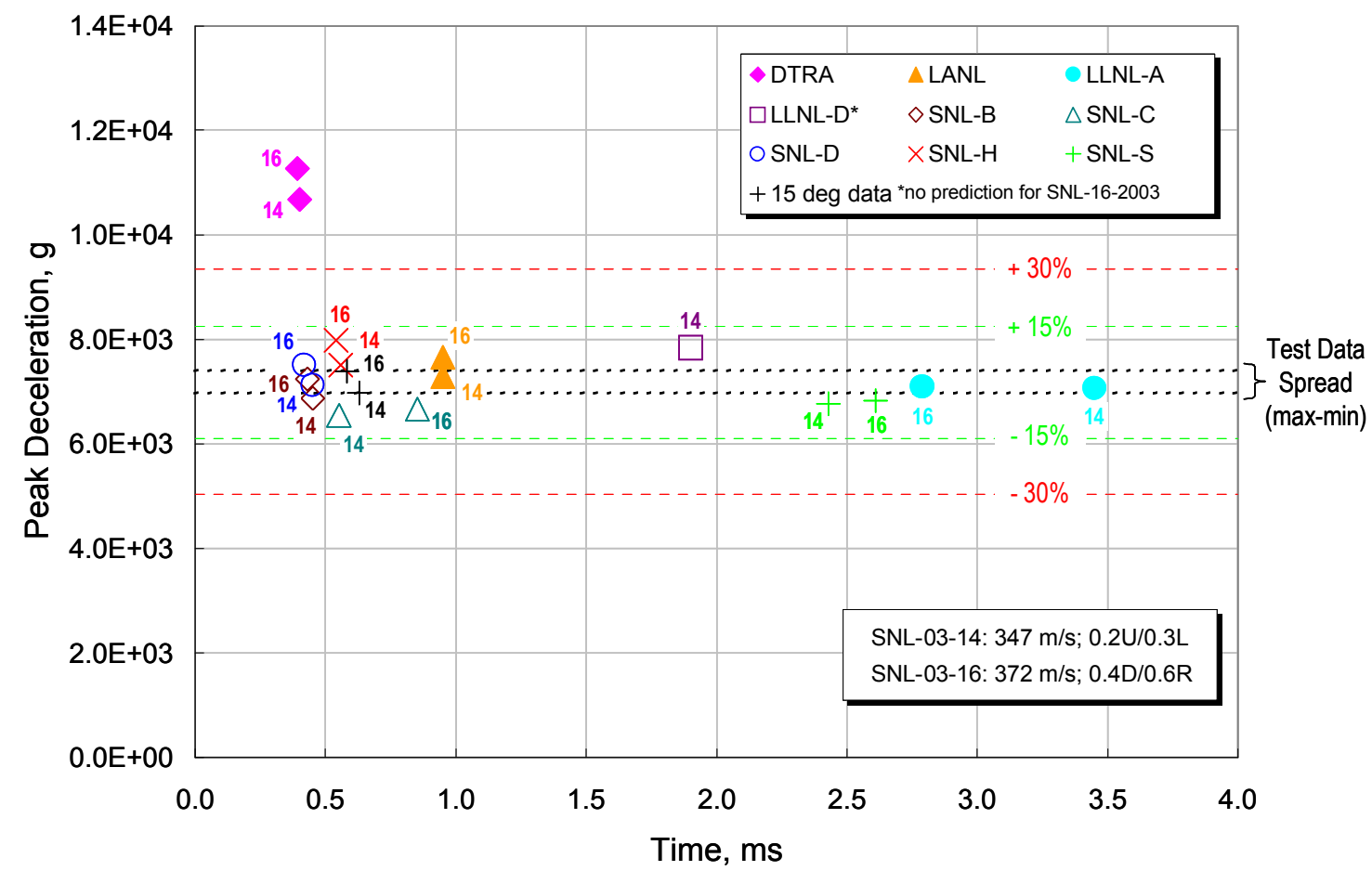

Figure 14. Peak axial accelerations, 15 degrees obliquity, $0-4 \mathrm{~ms}$.

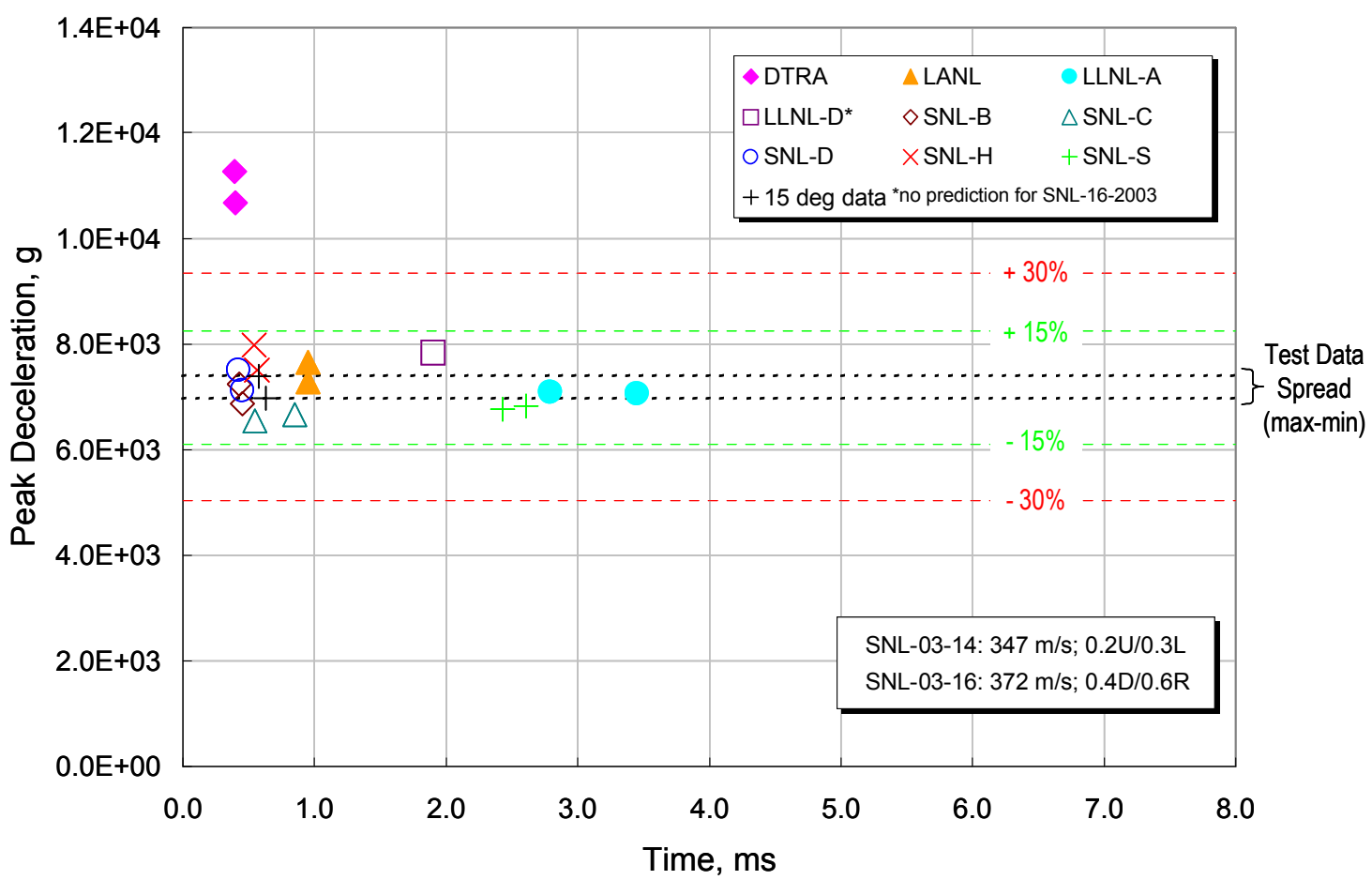

Figure 15. Peak axial accelerations, 15 degrees obliquity, $0-8 \mathrm{~ms}$. 


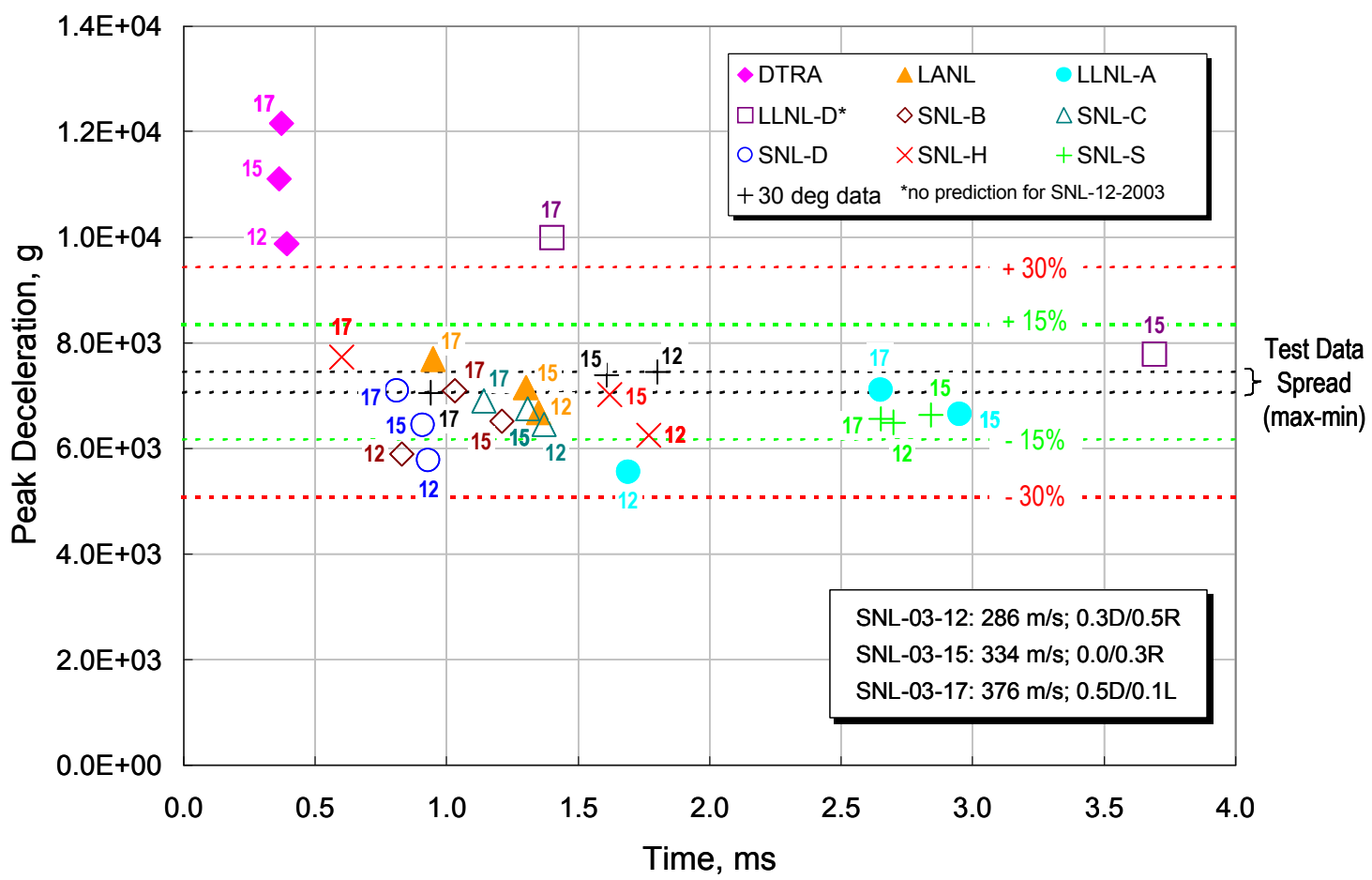

Figure 16. Peak axial accelerations, 30 degrees obliquity, $0-4 \mathrm{~ms}$.

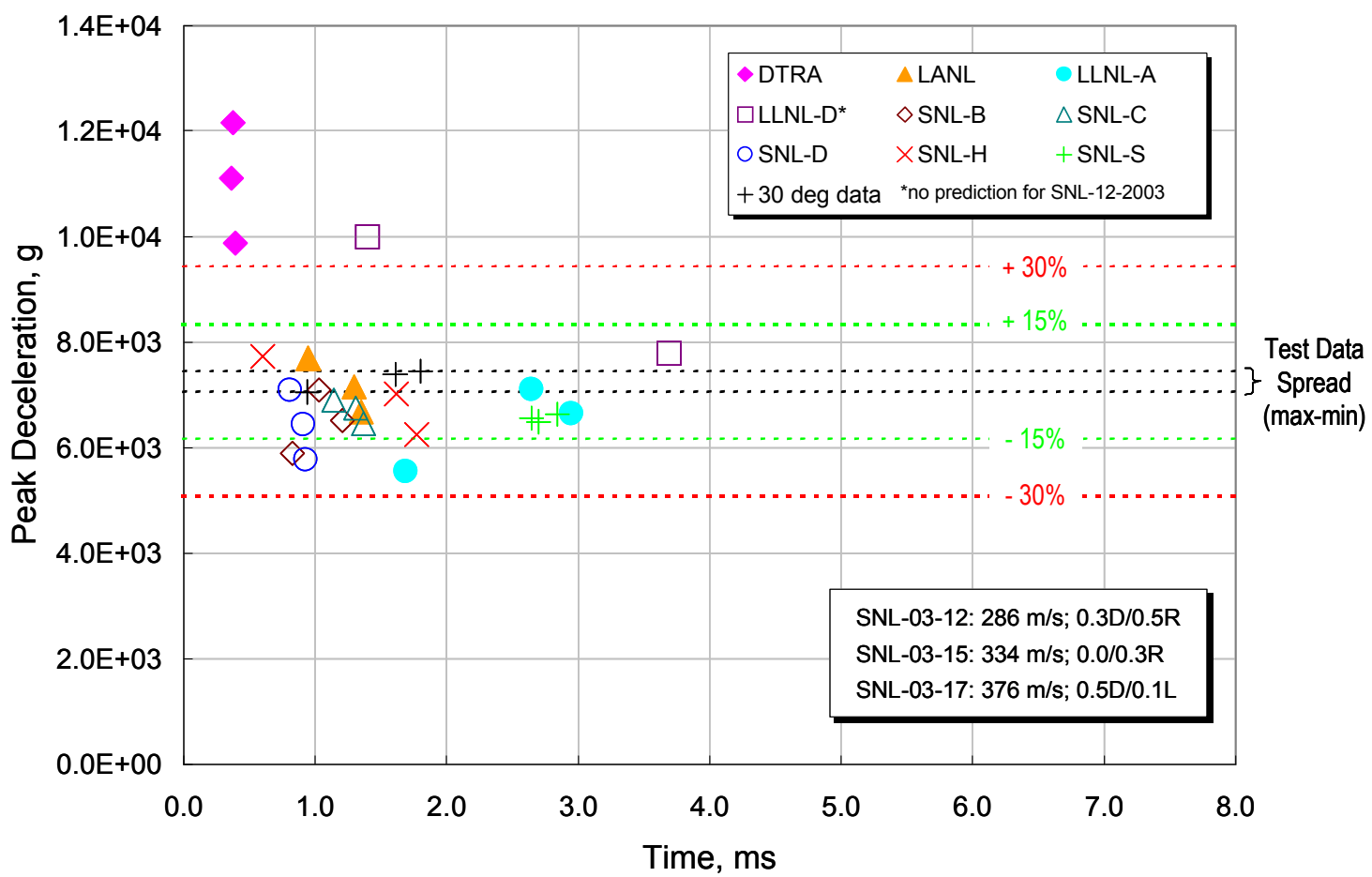

Figure 17. Peak axial accelerations, 30 degrees obliquity, $0-8 \mathrm{~ms}$. 


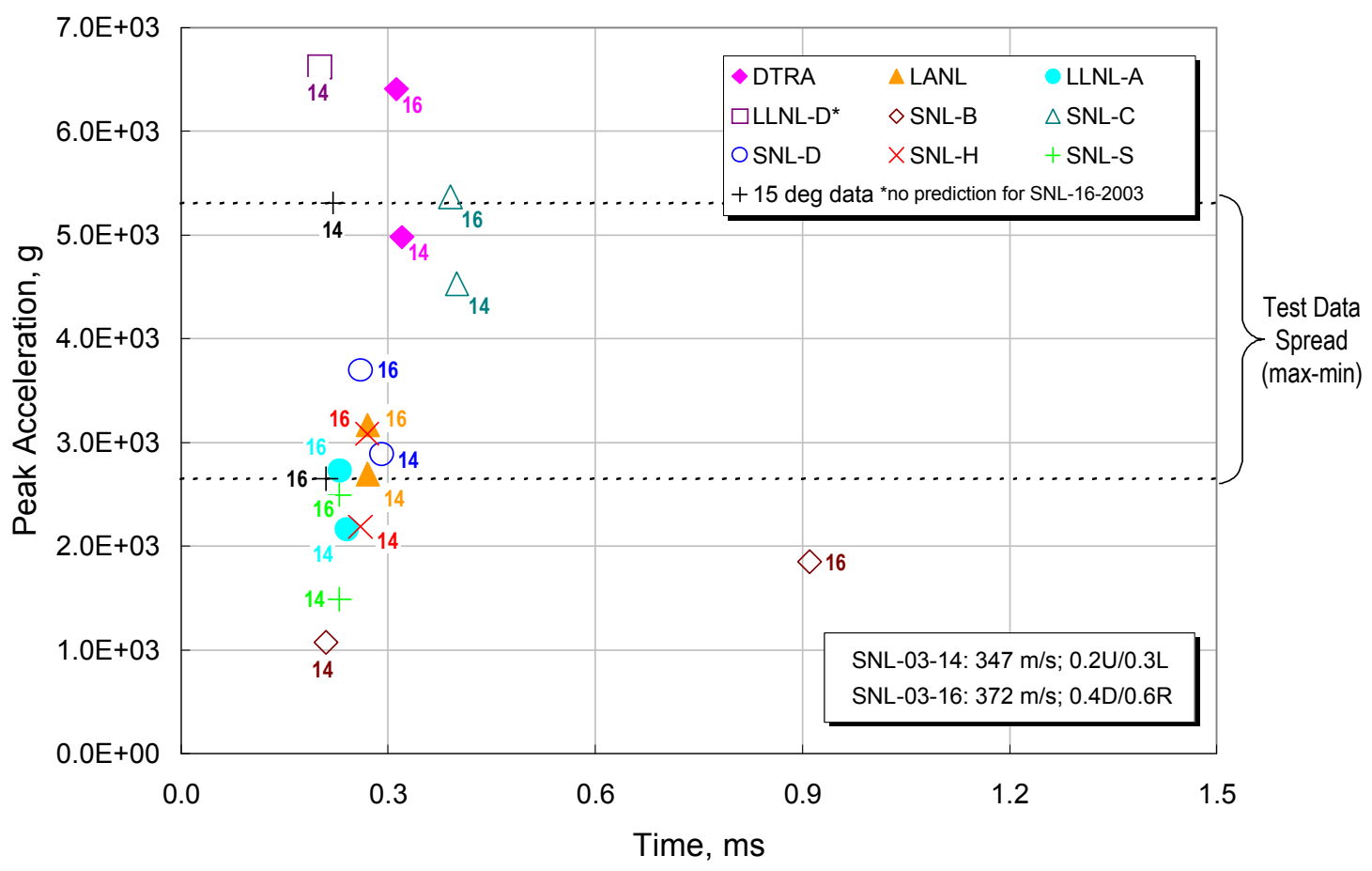

Figure 18. Peak Z-lateral acceleration, 15 degrees obliquity, $0-1.5 \mathrm{~ms}$.

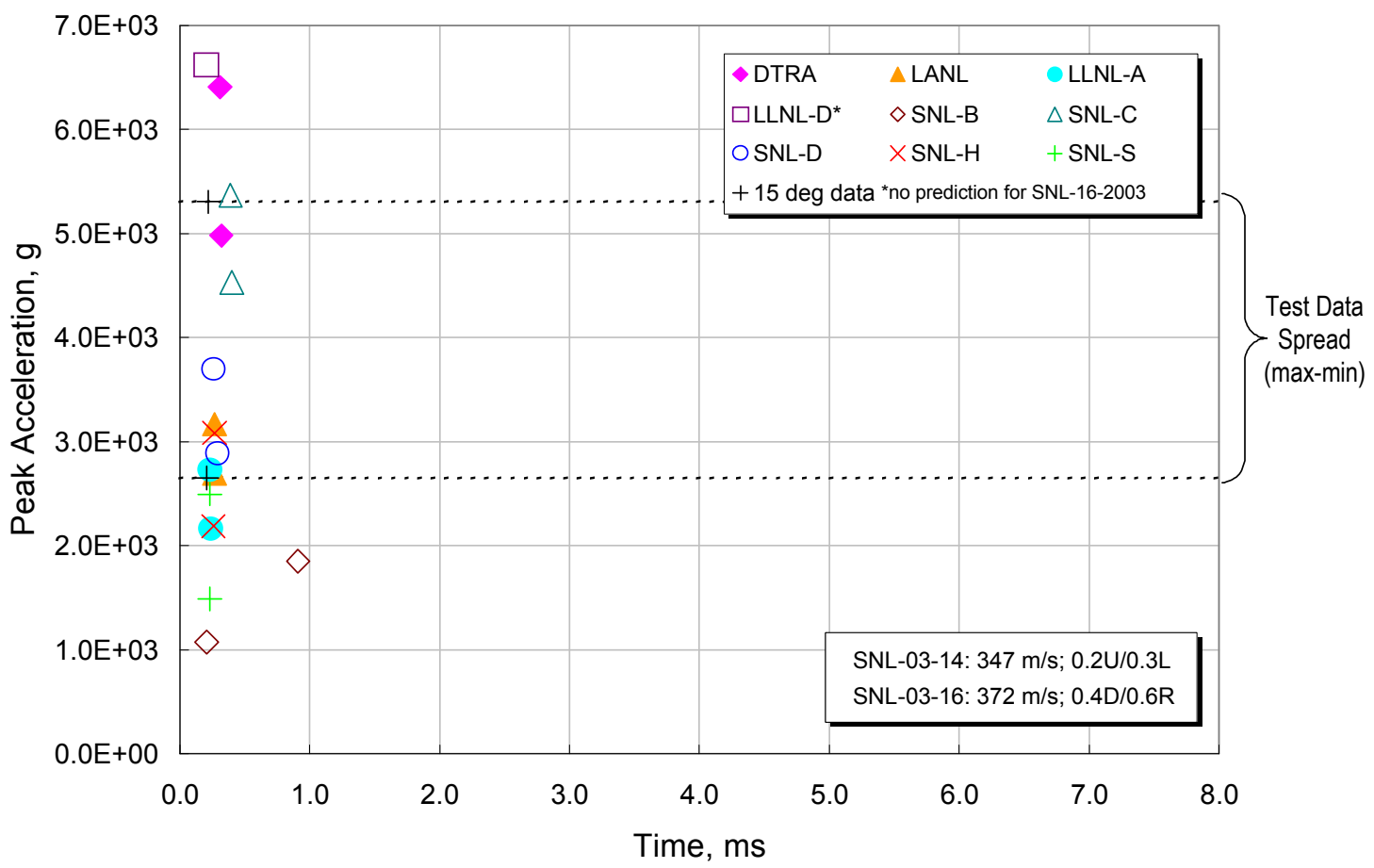

Figure 19. Peak Z-lateral acceleration, 15 degrees obliquity, 0 - 8 ms. 


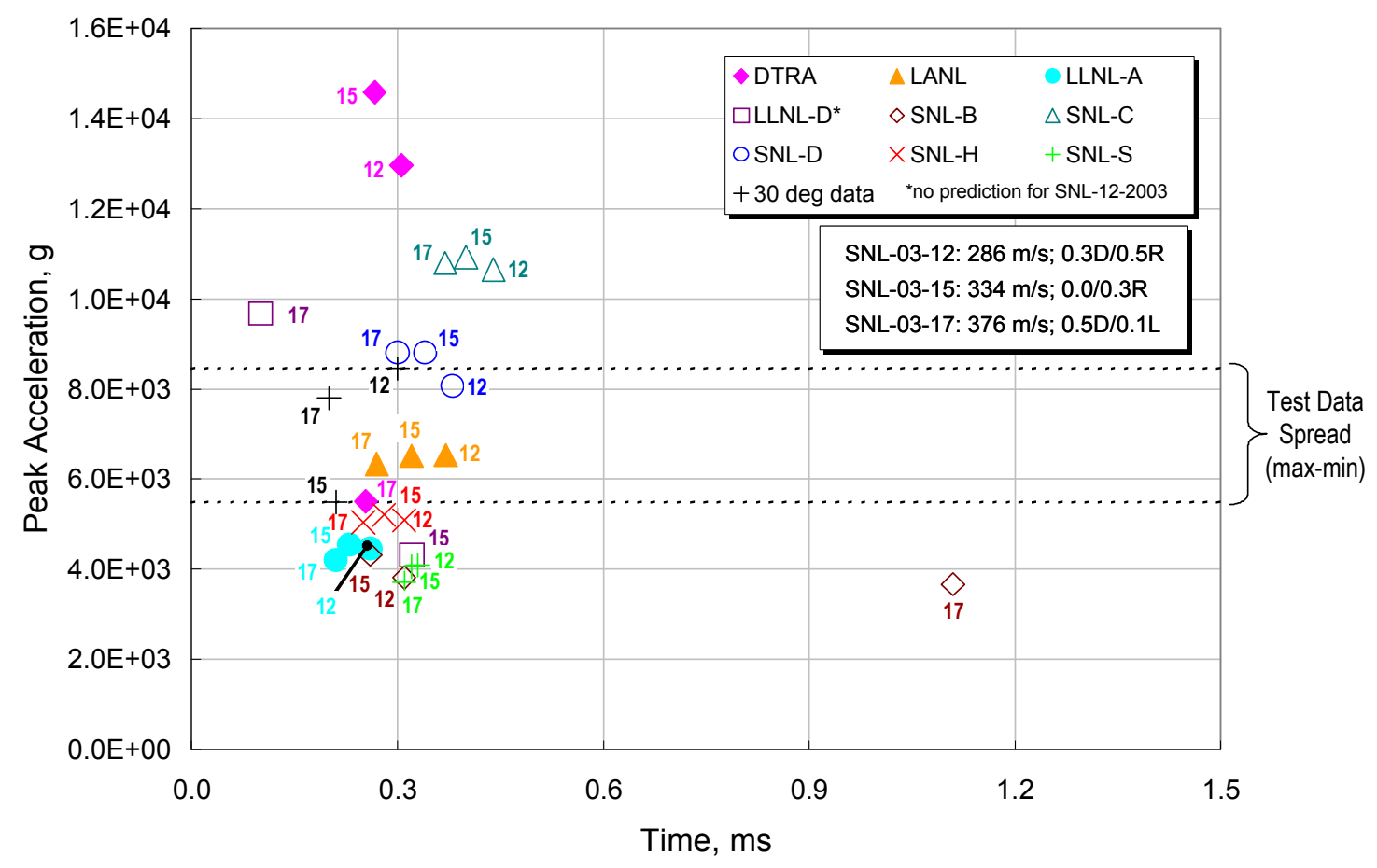

Figure 20. Peak Z-lateral acceleration, 30 degrees obliquity, $0-1.5 \mathrm{~ms}$.

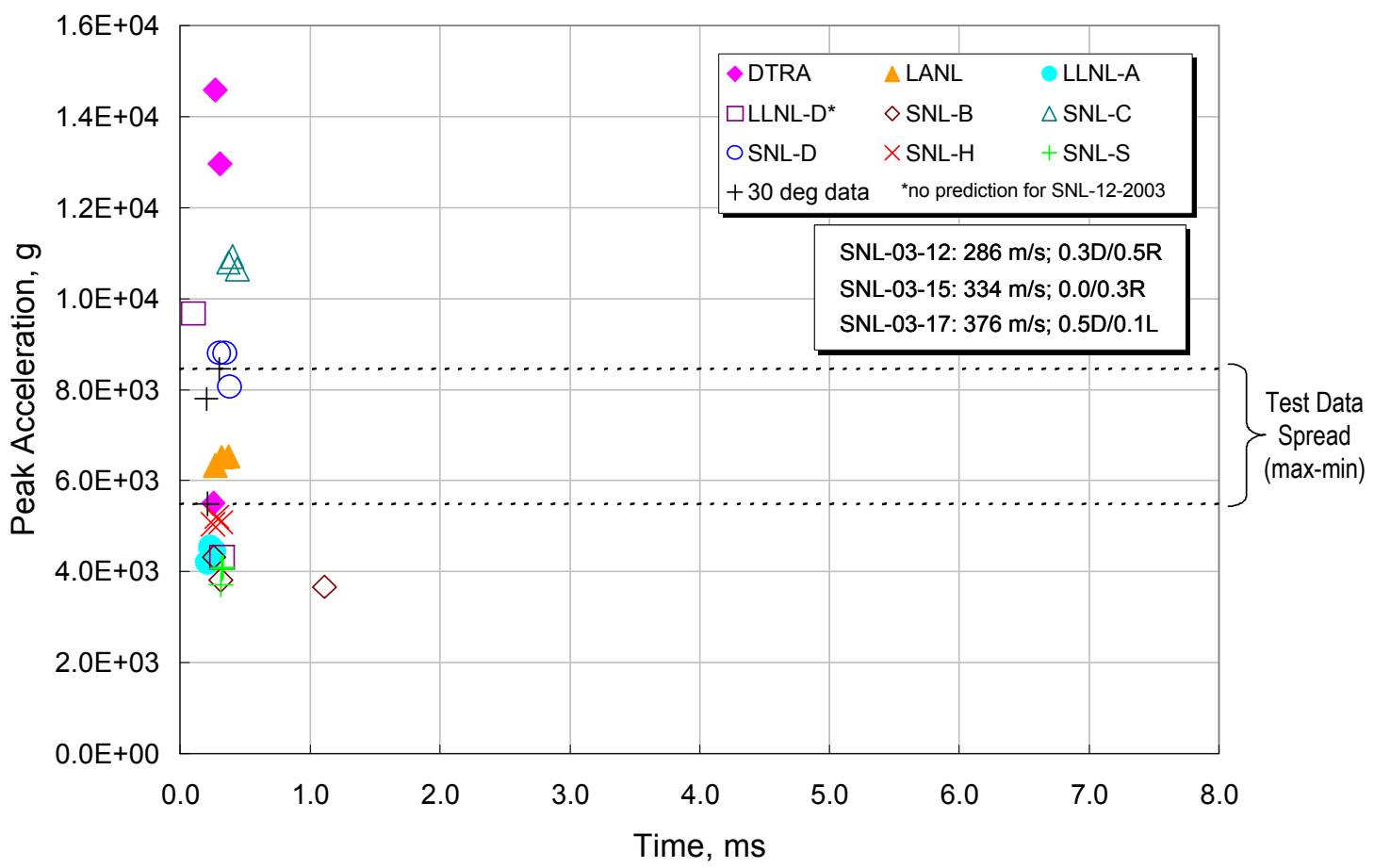

Figure 21. Peak Z-lateral acceleration, 30 degrees obliquity, 0 - 8 ms. 


\section{Appendix A . Prediction Code Descriptions.}

\section{A.1 PENCURV+ - Joe Renick.}

This overview of PENCURV+ addresses only features of interest to the penetration of concrete targets, as considered in the present study. A comprehensive description of PENCURV+ and its many features and capabilities can be found in Adley, M.D., et al, Methodology and User's Guide for PENCURV+, Version 1.0, US Army Corps of Engineers, Engineer Research and Development Center, Feb 2003.

PENCURV + is a three-dimensional projectile penetration code that calculates the trajectory of a rigid axisymmetric projectile impacting complex three-dimensional multilayered geologic and structural targets. The surface of the projectile is divided into discrete elements defined by a longitudinal and circumferential grid. Loads on each element are calculated in a time-marching scheme and the equations of motion solved for each time-step. Forces are determined through a linear function in velocity where for concrete the coefficients are functions of yield strength, density and angle between the velocity vector and surface for each element. This model is called the PENCO3D model and is preferred for calculating penetration solutions in concrete and rock. For soft concrete and rock or soil, the normal loads on each element are calculated using an Snumber formulation.

For non-normal impact of a projectile on a thick concrete layer, PENCURV+ incorporates an algorithm to account for the effects of impact surface spallation on load distribution over the nose of the projectile. Spall and cratering of surface material immediately downrange of the impact point serves to very quickly relieve loads on the upper surface of the nose of the projectile. Little or no spallation occurs on the underside of the nose of the projectile so full loading is retained. The result is nose-up rotation that can significantly change the trajectory of the projectile, especially for nose-up angle of attack. Implementation of the impact induced projectile rotation model was crucial for modeling the impact of actual warheads that in general impacted targets with non-normal trajectories and non-zero angle of attack.

PENCURV+ also utilizes "quills" to interrogate the target to find material interfaces and free-surfaces. This refinement is necessary because near-by material interfaces can have a significant influence on projectile nose loads. If the quills encounter a harder material the loads are increased to account for the effects of a reflected compressive wave. If the quills encounter a softer layer or free surface, the loads are reduced to account for the effects of a rarefaction wave.

Subsequent to the analysis of the results presented here, Joe Renick met with Dr. Mark Adley and Dr. Donald Cargile of the Engineering Research and Development Center (ERDC), U.S. Army Corps of Engineers, on 17 June 2004 to attempt to resolve issues concerning the modeling of the response of on-board tri-axial accelerometers installed forward of the projectile center-of-gravity. It was concluded that a modification to PENCURV is required to make the proper coordinate transformation to calculate the triaxial motions and output of those calculations in an output file. 
They determined that because the proper coordinate system transformations were not performed, the PENCURV pitch and yaw accelerations reported here were not correct. The magnitude of the errors are thought to be relatively small but are undetermined in magnitude. The calculated axial accelerations were unaffected and considered reliable.

\section{A.2 Abaqus (6.4.1)/Spherical Cavity Expansion (SCE), Richard W. Macek.}

The analysis methodology that LANL used to simulate the oblique penetration tests consisted of incompressible spherical cavity expansion coupled to conventional flexible body explicit dynamic finite element analysis (FEA). As such, the target itself is not explicitly meshed but rather is approximated by a spatially and temporally varying pressure on the penetrator that is derived from expanding a layered thick-walled spherical shell.The local pressure is computed using a damaged Mohr-Coulomb constitutive model for the target with the layer thicknesses measured along the local outward normal to the penetrator case. To complete the pressure calculation, the interior radial velocity of the cavity is taken from the outward velocity of the penetrator again measured along the local normal and the resulting pressure is then fed back to the FEA code to determine the structural response and trajectory of the penetrator. With this finite thickness variation on the cavity expansion solution, no empirical near surface or layer correction factors were used.

The properties for the damaged Mohr-Coulomb model used for the cavity expansion approximation of the concrete target were a combination of measured data and strength properties derived from simulations of the normal impact tests (ca 2000). The density was as measured and the modulus of elasticity was derived from the density and the measured sound speed. The tensile fracture strain was assumed to be 0.5 percent while the cohesion (yield strength at zero pressure) and the slope of yield strength as a function of pressure curve were obtained by simulation of the normal penetration tests where the maximum axial deceleration and depth of penetration from the simulations were matched to the corresponding test data.

The simulations of the oblique impacts were performed with a Lagrangian FEA structural model of the penetrator that consisted of about 20,000 8-node continuum elements with the elastic and strength properties of 4340 steel. The simulations were performed in a reverse ballistic manner with as measured impact velocities, angles of obliquity, pitch angles of attack and yaw angles of attack. The angles of attack were input in a velocity reference frame. Each simulation required about 3 hours of computer time for a $10 \mathrm{~ms}$ impact event. Depth of penetration was measured at the nose and the accelerations were computed in a post-processing mode by differentiating the spatially averaged velocities of the data package. Velocity differentiation rather than direct sampling of the computed accelerations was used to minimize aliasing which results from under-sampling of the computed response. Because the velocities were sampled at $100 \mathrm{KHz}$, there is implicit lowpass filtering (with a $50 \mathrm{KHz}$ cut-off frequency) of the reported acceleration data. No other filtering was performed before transmittal.

\section{A.3 ALE3D - Gregg Kay.}


SNL/ERDC oblique penetration tests were predicted using a methodology that discretized both the target and the penetrator. ALE3D, a closely coupled arbitraryLagrangian-Eulerian finite element code that was developed at Lawrence Livermore National Laboratory, was employed to make the predictions. The use of ALE3D allowed the target to be modeled using an Eulerian description and the penetrators to be modeled using Lagrangian descriptions. This avoided the severe mesh tangling that can occur when using a pure Lagrangian approach to model penetration targets.

ALE3D solves dynamic problems by breaking each time step into two parts. A Lagrangian step is performed for the entire mesh, followed by remapping (or grid relaxation) of portions of the mesh where significant distortions have occurred. Revised state variables are then advected onto the remapped mesh. In ALE3D, a user may also arbitrarily designate portions of the mesh to be treated in a purely Lagrangian manner. ALE3D has a special grid relaxation scheme for penetration problems that programs lateral and axial relaxation of the target mesh according to the motion of specified penetrator (Lagrangian) nodes. This programmed relaxation maintains the relative positioning of target nodes near the penetrator with the penetrator as it moves through the target.

The concrete target material was modeled using ALE3D material model 63 - Concrete with porous crush. This model is derived from a CALE material model and is described in both the CALE and ALE3D manuals. The constitutive model uses two pressuredependent surfaces, an initial inelastic surface and a fully damaged (rubblized) surface. Migration between the surfaces is controlled by a scalar damage variable that reflects accumulated material damage. This damage can account for tensile pressure failure, principal stress failure and effective plastic strain failure. Material model 63 has a porecrush capability that limits material pressure capacity as a function of current material porosity. Material model 63 also adjusts the shape of the failure surfaces for tensile or compressive strain-rate enhancement (in the principal stress versus pressure plane).

The ALE3D material model strength curve was obtained from published SNL/ERDC static low strength concrete laboratory test results. This data included triaxial and hydrostatic tests results. In the material model, the hydrostatic test results were assumed to represent the fully crushed hydrostatic response curves. A caveat: triaxial benchmark studies using this material model did not produce correct shear-enhanced compaction responses, though dilatational non-linear volume changes were observed, and the model was able to replicate the desired triaxial failure points. The overall ALE3D penetration methodology was validated using the SNL/ERDC low strength concrete normal impact test results.

For the oblique impact simulations, the pitch and yaw angles of attack were combined into a single angle of attack. The ALE3D meshes for these simulations contained approximately 1.5 million zones. The mesh resolution was 0.2 inches in a 1.35 diameter zone around the penetrator and 0.58 inches in regions surrounding the finer meshed zone. ALE3D run times, with 42 processors, averaged 12 hours.

Post processing in the simulations was initiated with computed velocities, as the calculated ALE3D accelerations were quite noisy. Nodal accelerometer 
velocities were numerically differentiated in time to determine the accelerations. The velocities were sampled every 10 microseconds. This resulted in a $50 \mathrm{KHz}$ Nyquist frequency to avoid aliasing. No filtering was performed on the calculated data that was submitted for evaluation. Acceleration time histories were rotated from computational global reference frames into local penetrator reference frames using a Matlab script and displacement time histories from four penetrator steering nodes.

\section{A.4 DYNA3D - Gregg Kay.}

SNL/ERDC oblique penetration simulations were predicted using a methodology that employed purely Lagrangian descriptions of the target and the penetrator. DYNA3D, a nonlinear, explicit three-dimensional Lagrangian finite element code, was employed to make these predictions. The use of a pilot hole or bore hole was employed to alleviate the mesh tangling that can occur when a purely Lagrangian approach is used to model penetration events. Underlying assumptions in this application are that the projectile trajectory is known a-priori, and that the results are independent of the pilot hole diameter and the target mesh resolution.

Solution variations with pilot hole diameter and mesh density were determined on simulations of the SNL/ERDC low strength concrete normal impact test results. From these studies, a pilot hole diameter equal to 15 percent of the penetrator diameter and element lengths on the order of 0.5 inches were determined to be acceptable. For the oblique simulations a trial penetrator trajectory was assumed and the initial calculation was allowed to proceed until the penetrator tip reached the surface of the pilot hole. At this point the calculations were stopped and the pilot hole trajectory was adjusted to keep the penetrator tip within the centerline of the pilot hole. This process was repeated until a pilot hole trajectory was obtained that minimized the penetrator tip run-out from the pilot hole centerline. This process took from four to eight iterations per test simulation. For the oblique impact simulations, the pitch and yaw angles of attack were combined into a single angle of attack. The DYNA3D meshes for these simulations contained approximately 75,000 zones. Single processor DYNA3D run times averaged 2 hours.

The concrete target material in these simulations was modeled using a two invariant, rate independent CAP model. This model is described in the DYNA3D manual. The failure strength curve for the CAP model was obtained from published SNL/ERDC static low strength concrete laboratory test results. This data included triaxial and hydrostatic tests results. Triaxial benchmark studies using this material model were able to produce both shear-enhanced compaction and dilational responses. The penetrator was modeled as a rigid material.

Post processing in the simulations used center of gravity acceleration time histories of the penetrator. Acceleration time histories were rotated from computational global reference frames into local penetrator reference frames using a Matlab script and displacement time histories from four penetrator steering nodes. No filtering was performed on the calculated data that was submitted for evaluation.

\section{A.5 PENCURV - Todd Broyles.}


PENCURV is a computer code for modeling the three-dimensional trajectory of a rigidbody projectile penetrating into geologic and structural targets. PENCURV was developed by the Geotechnical and Structures Laboratory at the Engineer Research and Development Center, US Army Corps of Engineers. It models the penetration of a threedimensional, rigid-body projectile into a target using a differential area force-law numerical algorithm for spatial integration and an automatic time-step algorithm for time integration. PENCURV contains a weapon failure algorithm to indicate when the rigidbody assumption is valid. PENCURV runs in a few seconds on a typical personal computer.

The projectile geometry modeled in PENCURV must be axisymmetric. The center of gravity and moments of inertia for the projectile are specified by the user. The projectile may be spinning or non-spinning.

The target modeled in PENCURV may be composed of an arbitrary number of curvilinear layers of material, including void (air). PENCURV contains four models for the resistance of target materials. One, a "soft rock" normal stress model based on Young's equation, is suitable for soils and frozen soils. A corresponding "hard rock" normal stress model, based on cavity expansion theory, is suitable for harder rocks and concrete. Both models are empirically based and suitable for multilayer targets. Another target resistance model is the ISAAC2 normal stress model for half-space soil targets for certain classes of penetrators with tapered bodies. A third model is the Empirical Forrestal Normal Stress model for normal impact on half-space concrete targets. The fourth model is the "hard rock" normal stress model with a jointed rock model. The jointed rock model reduces the strength of the rock by modeling user-defined planes of weakness which represent cracks and fissures in the rock.

Friction on the penetrator has been incorporated indirectly by determining the algorithm constants through comparisons with test results. However, in the case of a spinning projectile or a high-obliquity impact, circumferential and tangential friction can be added using the Coulomb friction model by specifying circumferential and axial friction coefficients.

For the oblique impact calculations, the penetrator was modeled as a hollow projectile with a 3CRH ogive nose and a slight flare in the body. The penetrator's weight was $128.643 \mathrm{~N}(13.11 \mathrm{~kg})$ and the principal moments of inertia were $0.0908332 \mathrm{~N}-\mathrm{m} 2$ about the longitudinal axis and $2.42208 \mathrm{~N}-\mathrm{m} 2$ about the transverse axes.

The target was modeled as a layer of concrete with an S number of 0.85 using the "soft rock" normal stress model followed by a layer of air. An S number of 0.85 was selected by calibration from a normal impact test. Specifically, the $\mathrm{S}$ number was varied in a simulation of a normal impact test (SNL-00-04) into the same concrete until the depth of penetration predicted by PENCURV matched the experimental measurement. The "soft rock" model was used instead of the "hard rock" model because the acceleration profile predicted by the "soft rock" model more closely matched the measured acceleration data than the acceleration profile predicted by the "hard rock" model. There was no friction between the penetrator and the target.

PENCURV predicts only translational accelerations in the lateral direction. It does not 
directly estimate accelerations in the lateral direction due to rotation of the penetrator. In some problems rotational acceleration can equal or exceed translational acceleration in the lateral direction over some periods of the penetration event. While PENCURV does not calculate rotational accelerations, it does calculate angular velocity about the pitch axis. Therefore, for the oblique impact calculations the rotational acceleration at the accelerometer was estimated by calculating the derivative of the angular velocity data via a spreadsheet and multiplying that by the moment arm of the accelerometer (its distance from the center of mass). This simple computation gives a reasonable first-order approximation as long as the axis of rotation is close to the penetrator's center of mass. (While it would be more accurate to also perform this analysis on the yaw angular velocity, PENCURV does not generate this data in its output stream. The yaw angle and yaw rate that it does generate are effectively measures of rotation about the centerline of the penetrator, not the yaw axis.) The total lateral acceleration at the accelerometers was then estimated by adding the pitch angular acceleration to the translational accelerations.

\section{A.6 PRESTO - Mike Chiesa.}

Simulations were performed on the complete set of experiments by WES using the Sandia Presto code. The code is identical to that used by Duong and Longcope for this study (see below) and the FEM model is different but about the same fidelity (approximately 50K elements). The case material was allowed to deform plastically and indeed did yield according to the simulations. The Spherical Cavity Expansion loading assumption was used as described by Longcope. The SCE method assumes the target is infinite in the radial direction, which was clearly not the case in the WES tests. For large obliquity angles it was obvious that the radial edge effects were important.

The differences between this set of simulations, and those performed by Duong and Longcope, result from assumptions of the input parameters for the SCE model. The three parameters for the SCE pressure loading on the nose were determined based on modeling of the previous set of WES data. The parameters were iteratively determined to predict the correct depth of penetration over the full range of impact velocities (all of these tests were normal to the target). These parameters were not changed for the newer material which was slightly different than the previous concrete. A reduction of 50 percent of the SCE loading was applied to the cylindrical part of the penetrator to account for lower material strength due to crushing and cracking of the concrete. A free surface parameter (FSP) of 13.2 was used at the upper surface to account for free surface effects during oblique impacts.

Additionally, parametric studies were performed using three other sets of SCE parameters, two other values for the afterbody load reduction and two other values for the FSP (plus and minus 10 percent). The parametric study showed the parameters had little effect on the penetration path length but had a major effect on the oblique loading and final resting

place of the penetrator. Plans are to use the Dakota optimization code to refit the five parameters to best fit the oblique WES data, and this set will be used in the upcoming WES angle of attack tests. Angles of attack and pitch were both included in the simulations, with values as reported for each test. The data were filtered using a four pole Butterworth filter of $15 \mathrm{KHz}$. 


\section{A.7 PRESTO v1.07 - PRESTO/SCE Simulations, Henry Duong and Don Longcope.}

The simulations of the five oblique penetration experiments that we submitted were done with the PRESTO v1.07 Lagragian solid dynamics code using a finite element model (FEM) of the penetrator to which SCE based loading was applied. The FEM, shown in the figure, was a full 3-D model using $51 \mathrm{~K}$ hex elements that represented seven components of the test penetrator. 4340 steel with elastic-plastic properties was used for the penetrator case and all other components except the battery (aluminum) and battery housing (polyurethane foam). Threaded joints were represented with tied contact and adjacent components with contact. The model accurately represents the geometry, mass $(29.3 \mathrm{lbm})$, and c.g. location (11.0 inches from tip) of the test penetrator.

On the nose ( $3 \mathrm{CRH}$ portion), the full cavity expansion pressure, $\mathrm{P}_{\mathrm{SCE}}$, was applied as a normal stress and the parameter $\mathrm{S}_{\mathrm{f}}$ was given a value that represented free surface effects; while on the aft-body, the applied normal stress was $0.25 \mathrm{P}_{\mathrm{SCE}}$ and $\mathrm{S}_{\mathrm{f}}=0$ ( no free surface effects) were used. The cavity expansion pressure is $\mathrm{P}_{\mathrm{SCE}}=\mathrm{C}_{1}+\mathrm{C}_{2} * \mathrm{~V}+\mathrm{C}_{3} * \mathrm{~V}^{2}$, where $\mathrm{V}$ is the normal component of velocity of a surface node and the $\mathrm{C}$ 's are constants, which fit the numerical SCE solution. The SCE solution and the $\mathrm{S}_{\mathrm{f}}$ parameter are defined by laboratory triaxial data provided by WES for the 3.4 ksi concrete target. We submitted results based on two sets of WES data:

$$
\begin{aligned}
& \text { Year 2000: } \mathrm{C}_{1}=1.78 \times 10^{4} \mathrm{lb} / \mathrm{in}^{2}, \mathrm{C}_{2}=1.70 \mathrm{lb}-\mathrm{s} / \mathrm{in}^{3}, \mathrm{C}_{3}=5.48 \times 10^{-4} \mathrm{lb}-\mathrm{s} 2 / \mathrm{in} 4 ; \mathrm{Sf}=13.3 \\
& \text { Year 2003: } \mathrm{C} 1=1.54 \times 104 \mathrm{lb} / \mathrm{in} 2, \mathrm{C} 2=1.76 \mathrm{lb}-\mathrm{s} / \mathrm{in} 3, \mathrm{C} 3=4.21 \times 10-4 \mathrm{lb}-\mathrm{s}^{2} / \mathrm{in}^{4} ; \mathrm{Sf}=11.9
\end{aligned}
$$

The differences in these parameters are primarily a result of differences in the isotropic compression data for the years 2000 and 2003.

Our penetrator model was oriented to account for both the measured pitch and yaw angles of attack (AoA) as well as the angle of obliquity. The pitch AoA, which was out of the plane of obliquity, had an insignificant effect on the results. We used forward and reverse, 
$2000 \mathrm{~Hz}$ low-pass, 4-pole Butterworth filtering on all the results.

\section{A.8 Zapotec v1.4 - Jeromy Hollenshead.}

Zapotec is a code developed at Sandia National Laboratories that couples CTH, an Eulerian shock physics code, and Pronto3D, a Lagrangian solid mechanics code. Both CTH and Pronto were also developed at Sandia. In the Zapotec analysis, both $\mathrm{CTH}$ and Pronto3D are run concurrently so that the Eulerian and Lagrangian calculations are tightly coupled. At each time step, Zapotec maps the current configuration of a Lagrangian body and its state onto the fixed Eulerian mesh. Any overlapping Lagrangian material is inserted into the Eulerian mesh and the updated mesh data passed back to CTH. Once the material insertion is complete the external loading on the Lagrangian material surfaces is then determined from the stress state in the Eulerian mesh. These loads are passed back to Pronto3D as a set of external nodal forces. Once the coupled treatment is complete, both $\mathrm{CTH}$ and Pronto3D are run independently over the next time step.

In the Lagrangian calculation, the steel components of the penetrator were described using an elastic-plastic hydrodynamic material model while an orthotropic crush model was used for the polyurethane packing material. The parameters required in these models were taken from previous simulations that used the same $3 \mathrm{CRH}$ penetrator design. For the target, the required material properties were determined from analysis of the tri-axial data provided with the normal impact data. The concrete is represented using a porous material model, the P-alpha model, for the volumetric response, and a pressure-dependent yield model for the deviatoric response. In the P-alpha model, the fully dense material characterizes the fundamental response, and the lower density (distended) porous reference condition defines the initial state. Parameters for upper and lower bound extremes of the concrete response were determined and used to characterize the uncertainty in the penetrator response due to the target properties. Once determined, the target properties are not modified with the exception of the fracture stress, which is the only free parameter.

The penetrator was discretized using approximately 16,000 hexagonal elements. This mesh size was sufficient for the current calculations although a much finer mesh could have been used without a large increase in the computational time. The target was modeled as a free-standing, oblique cylinder surrounded by void. The results of a grid refinement procedure indicated that a uniform grid of $5 \mathrm{~mm}$ in the immediate area of impact was satisfactory. The 5-mm grid extends out uniformly for about 5 penetrator diameters at which point the grid is graded out to the boundaries. In the direction of penetration, a $1-\mathrm{cm}$ uniform grid was used. The resulting Eulerian grid consisted of approximately 18 million cells.

Before the predictions of the oblique tests were performed, the computational model was calibrated to the normal impact acceleration response using the fracture stress of the target concrete. Several simulations were conducted using fracture strengths ranging from 1.0- 
3.0 MPa. The lower bound of 1.0 MPa was based on previous experience with stronger targets while the upper bound of 3.0 MPa was estimated from theoretical calculations based on the reported unconfined compressive strength. The calculation seemed to be fairly sensitive to the fracture strength. The final value used for the oblique penetrator computations was $1.25 \mathrm{MPa}$.

For each simulation, history data was written out at two-microsecond intervals. Post processing was done using a Matlab script to read in the penetrator displacement at four nodes located at the position of the accelerometer. These four points were used to form a basis for a local coordinate system within the penetrator. Since the accelerations reported by the computation are fairly noisy, the velocities predicted at the accelerometer were read in and numerically differentiated in time to determine the acceleration. These accelerations were then converted from the computational coordinate system to the local penetrator coordinate system using basis described earlier. They were then filtered, typically at $15 \mathrm{kHz}$, using a four pole Butterworth filter. Once filtered, the data was depopulated and the final data reported at 10 microsecond intervals.

\section{A.9 EMU 2.6c Peridynamic - Stewart Silling.}

Emu is a three-dimensional meshless Lagrangian code oriented toward modeling the response and failure of materials that fracture under load. It is based on the peridynamic theory of solid mechanics, which is formulated in terms of integral equations, rather than the classical differential equations. As a result of this mathematical formulation, interaction between Emu nodes takes place through pairwise interactions ("bonds") rather than through conventional stress-strain dependence.

Penetrators can be modeled in Emu as rigid bodies that interact with the target nodes according to an algorithm similar to a Lagrangian slideline. Alternatively, a deformable penetrator can be modeled as a three-dimensional grid. Because the code is meshless, it is easy to set up calculations with complex target geometries including tunnels, empty rooms, and geological layers.

A distinguishing feature of Emu is that it models the initiation and growth of individual cracks. Any number of cracks, together with their mutual interaction, can occur in a problem. A key advantage of Emu is its ability to model the global failure of a target by cracking, and it has successfully modeled the "target size effect".

Material models can be specified conveniently using Young's S-number. A constitutive model for concrete has been developed and tested against experimental penetration data for normal impact.

Postprocessors are provided that plot time histories of penetrator variables and threedimensional views of grid variables. Emu can run on a single processor or multiple processors using MPI. It has been implemented on HP Linux, Sun, Cplant, Janus, Altix, SGI, and other systems. A Windows version with a user-friendly graphical interface is also available. For more information see . 


\section{Appendix B Additional Validation Metrics.}

\section{B.1 Windowed accelerations.}

Windowed accelerations provide an additional metric that can be used to compare experimental and predicted acceleration histories. This metric characterizes the waveform over various time windows and thus a comparison of the amplitudes over the time of the acceleration waveform duration is obtained The first four milliseconds of each acceleration time history are divided into eight 1-ms wide windows. A gaussian-weighted integral of the acceleration, $Q$ is calculated over each window and compared with experimental results. Figure B1 illustrates the process.

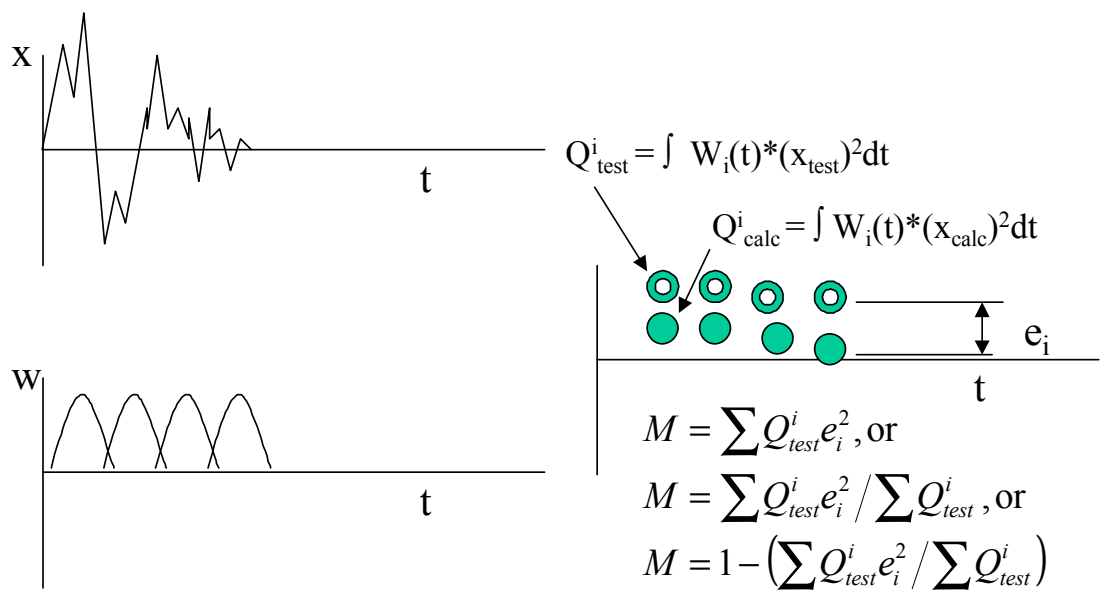

Figure B-1. Windowed acceleration metric.

A MATLAB $^{\circledR}$ function provided by SNL was used to calculate the windowed accelerations, $Q$. Graphs of axial and lateral windowed accelerations for all predictions versus test results were prepared. The scalar metric $M=\sum Q_{\text {test }}^{i} e_{i}^{2} / \sum Q_{\text {test }}^{i}$ was calculated in all three axes for each prediction. These metrics were tabulated and presented as bar charts. The results for the windowed metric are shown in Figures B2 through B11. 


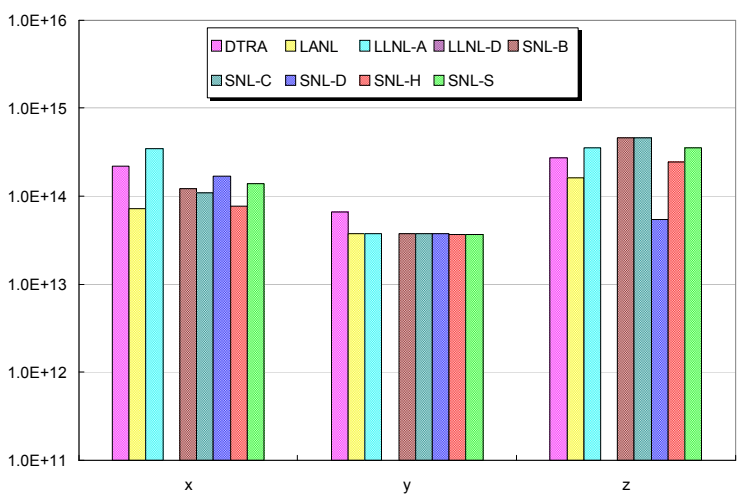

Figure B-2. Windowed metric SNL-03-12

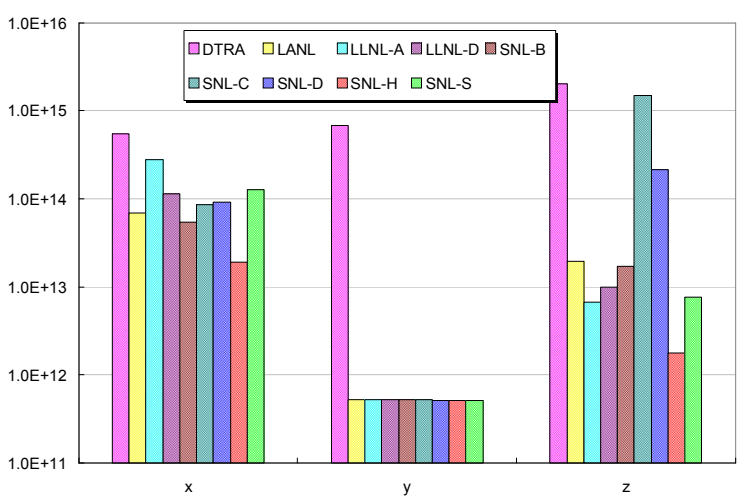

Figure B-4. Windowed metric SNL-03-15

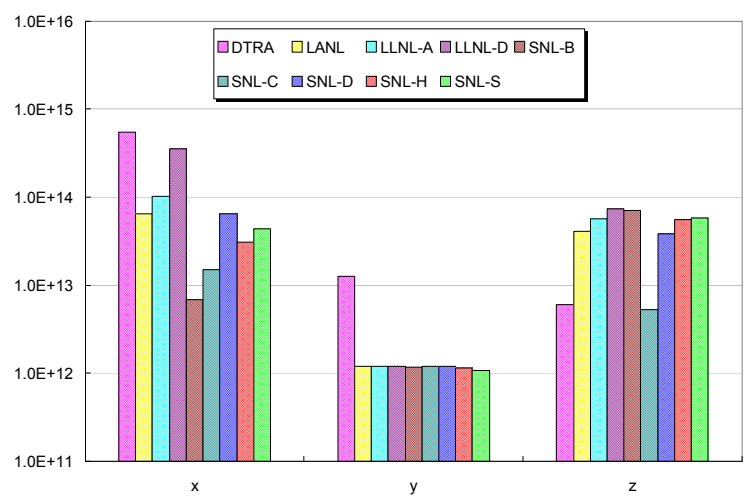

Figure B-3. Windowed metric SNL-03-14

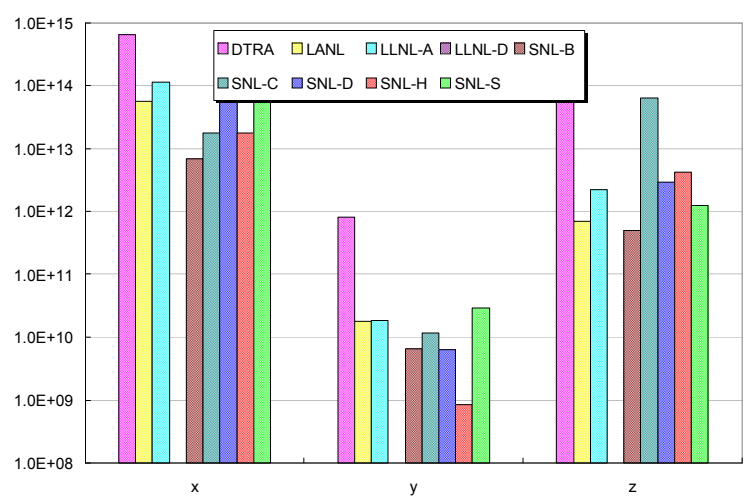

Figure B-5. Windowed metric SNL-03-16

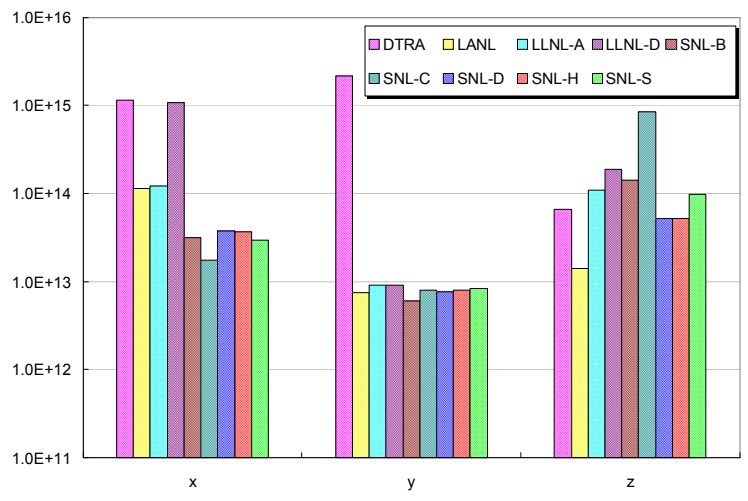

Figure B-6. Windowed metric SNL-03-17. 


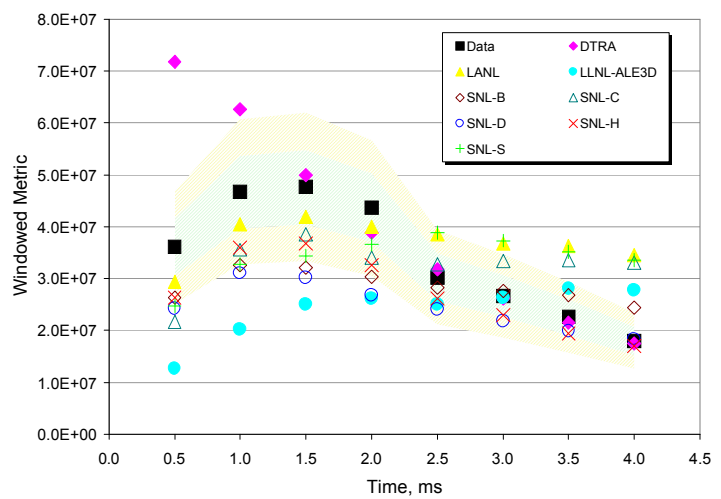

X-Axis

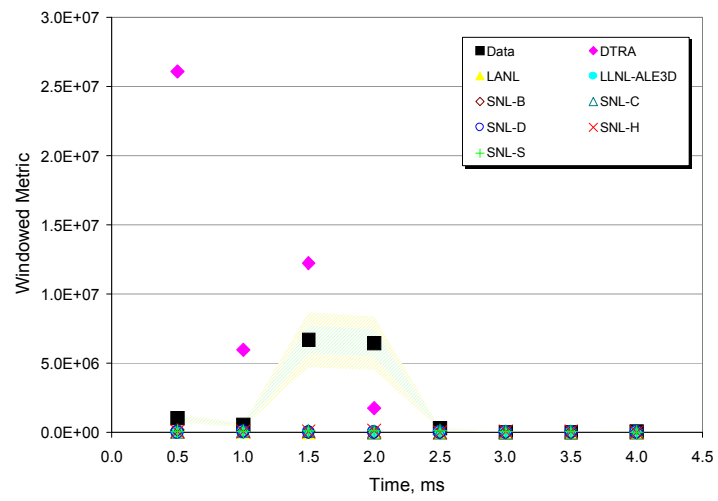

Y-Axis

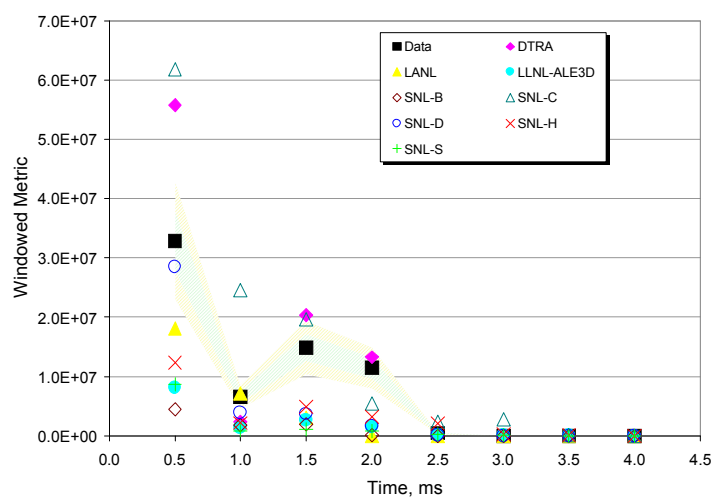

Z-Axis

Figure B-7. SNL-03-12 raw windowed metric. 


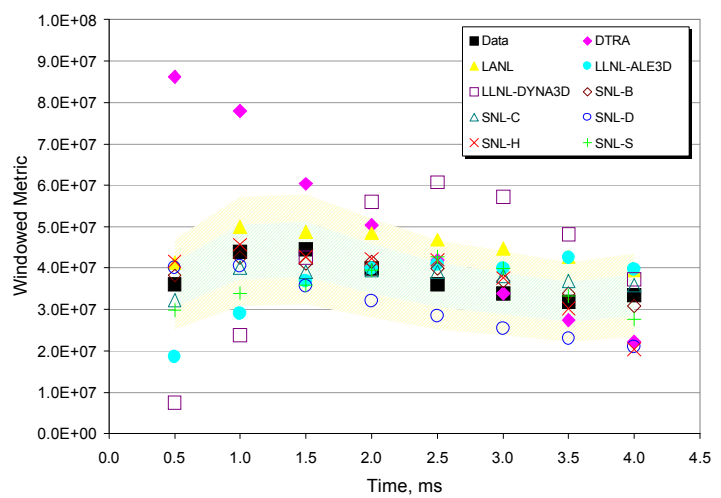

X-Axis

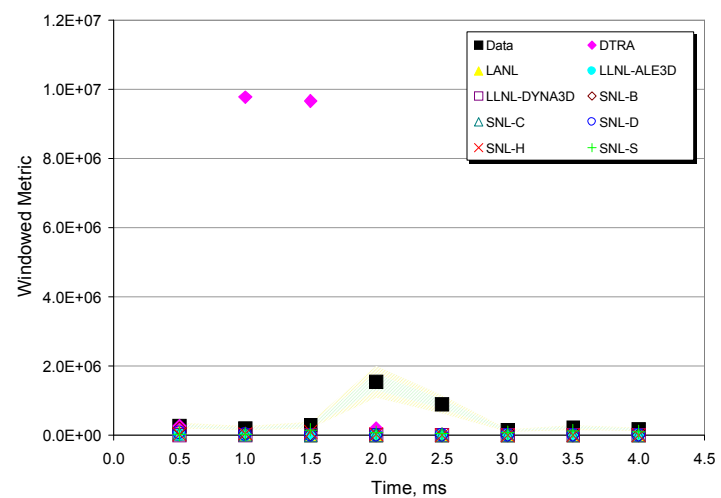

Y-Axis

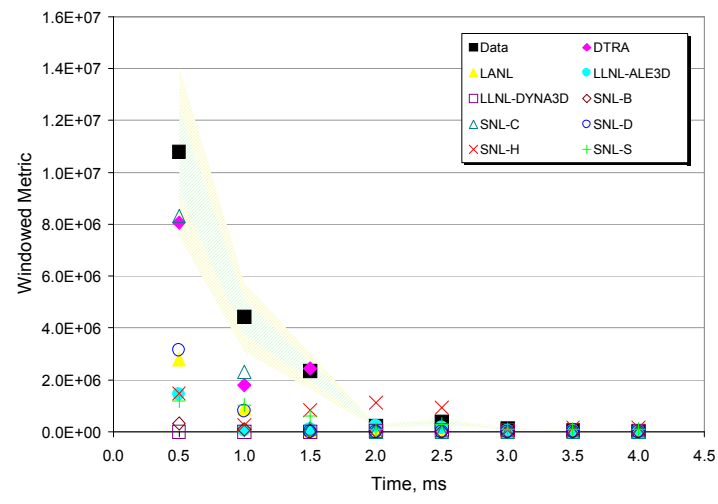

Z-Axis

Figure B-8. SNL-03-14 raw windowed metric. 


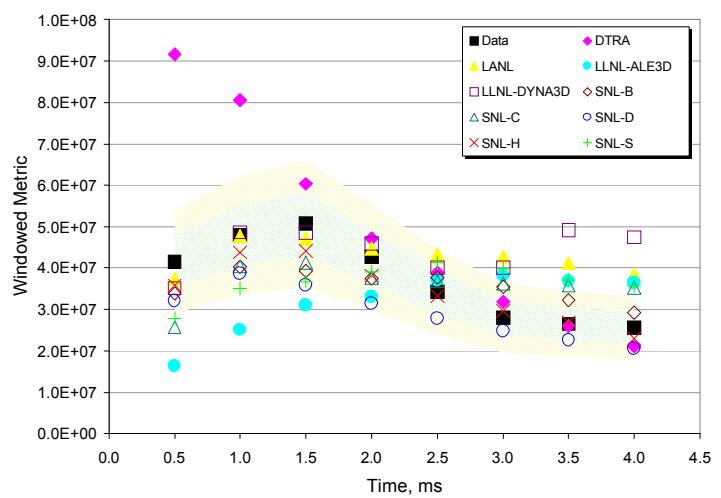

X-Axis

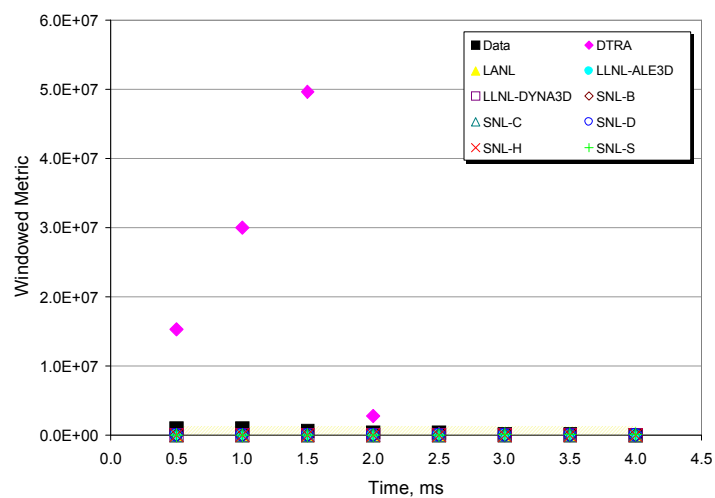

Y-Axis

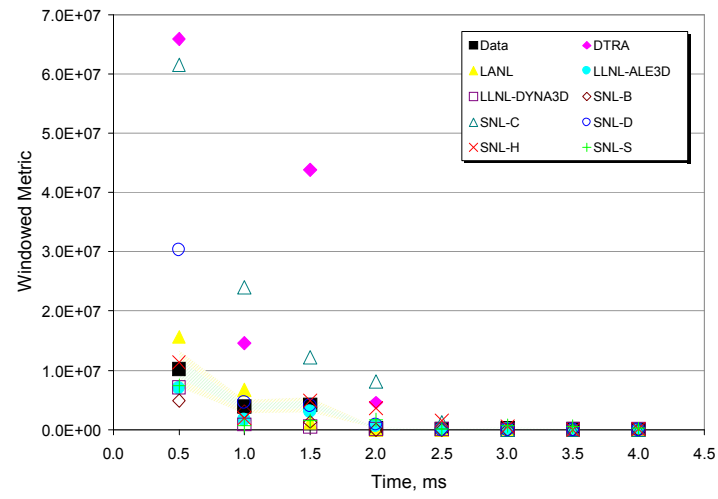

Z-Axis

Figure B-9. SNL-03-15 raw windowed metric. 


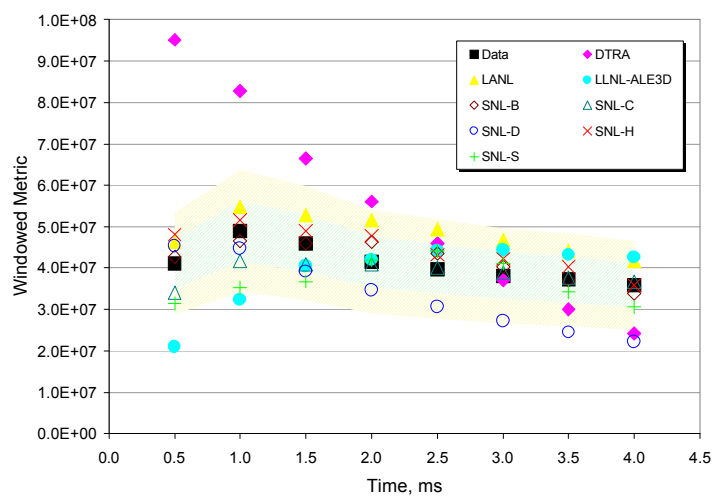

X-Axis

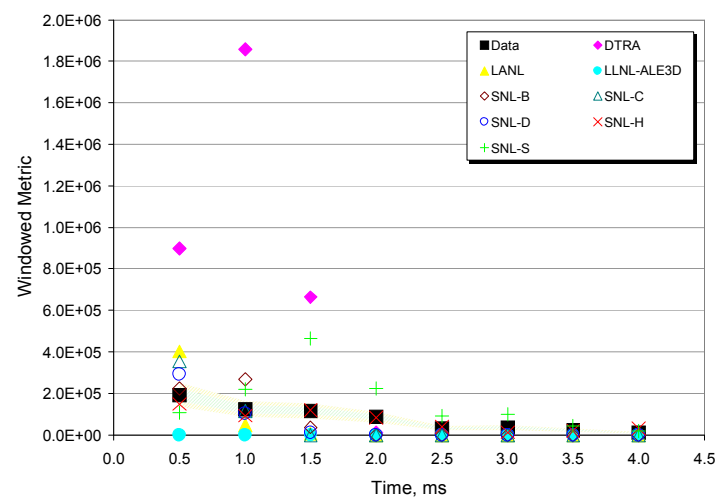

Y-Axis

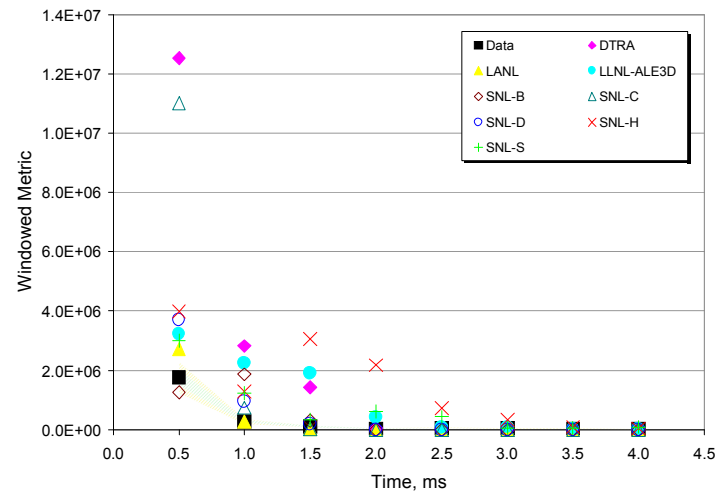

Z-Axis

Figure B-10. SNL-03-16 raw windowed metric. 


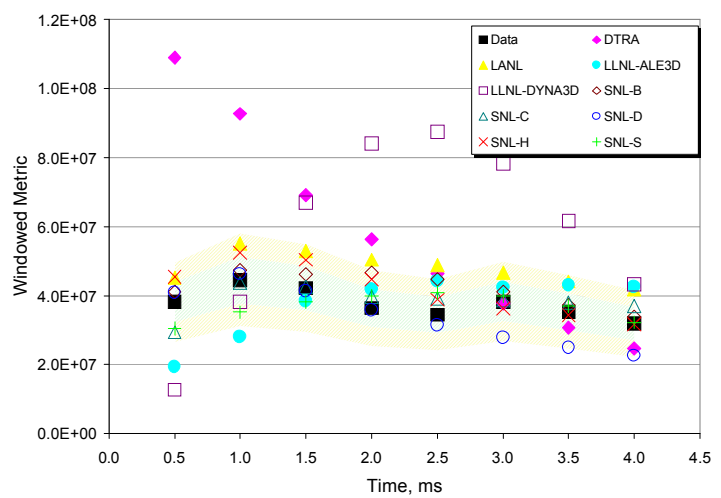

X-Axis

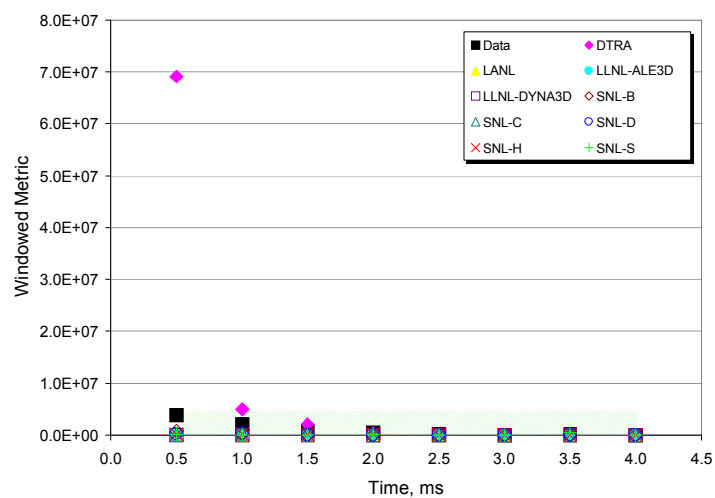

Y-Axis

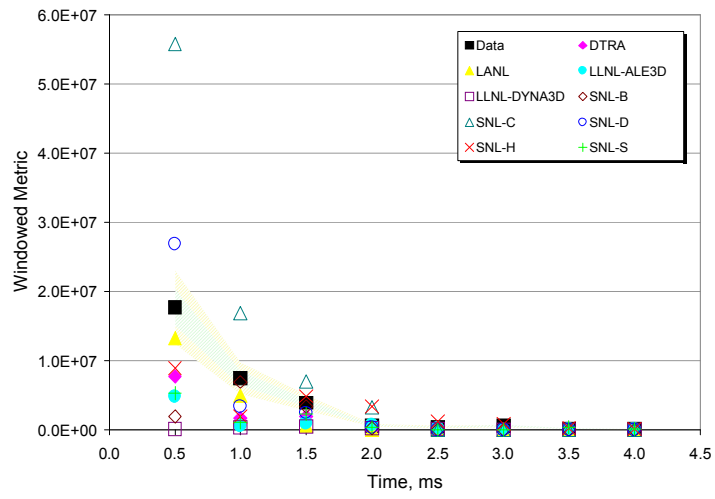

Z-Axis

Figure B-11. SNL-03-17 raw windowed metric. 


\section{B.2 Temporal moments ${ }^{3}$.}

Additional metrics for comparing data and validating code calculations are provided by temporal moments of the acceleration time-histories.

The $\mathrm{i}$ 'th temporal moment of a function $\mathrm{f}(\mathrm{t})$ about a time, $a$, is defined as

$$
m_{i}(a)=\int_{-\infty}^{\infty}(t-a)^{i}[f(t)]^{2} d t
$$

The $0^{\text {th }}$ temporal moment is the integral of the magnitude squared of the time history and is called the time history energy, $E$,

$$
E=m_{0}=\int_{-\infty}^{\infty}[f(t)]^{2} d t
$$

$E$ is independent of the time shift, $a$. The first temporal moment normalized by the energy gives the delay or time where the centroid of the energy is located.

$$
\tau=\frac{m_{1}}{E}
$$

Higher moments calculated about a time shift $a=\tau$ are called central moments. The $2^{\text {nd }}$ and $3^{\text {rd }}$ moments are used to calculate the duration and skewness of a time history.

The duration of the time history is defined as

$$
D_{t}=\sqrt{m_{2}(\tau) / E}
$$

$D_{t}$ describes the width of the energy pulse and is analogous to standard deviation for random variables. The duration can be used to normalize energy in units of amplitude, the root energy amplitude

$$
A_{r}=\sqrt{\frac{E}{D_{t}}}
$$

The cube root of the third central moment normalized by the energy is the skewness

$$
S_{t}=\sqrt[3]{m_{3}(\tau) / E}
$$

Skewness describes the shape of the function. Positive values indicate high amplitudes on left of the centroid, $\tau$, with a tail on the right; negative values indicate the reverse; and symmetric pulses have zero skewness.

Using a MATLAB ${ }^{\circledR}$ function provided by SNL, the delay, $\tau$, RMS duration, $D_{t}$, root energy amplitude, $A_{r}$, and skewness, $S_{t}$, were calculated for each prediction and compared

${ }^{3}$ Smallwood, D. O. "Characterizing Transient Vibrations Using Band Limited Moments." Proceedings of the 60th Shock and Vibration Symposium. Volume 3, pp93-112. Hosted by the David Taylor Research Center, Underwater Explosions Research Division. Portsmouth, Virginia. Nov. 1989 
with test results.

Column charts showing a comparison between the predicted and measured temporal moments are displayed in Figures B12 to B31. The moments considered included the delay to centroid, RMS duration, root energy amplitude and skewness. Consistently, the greatest variations from the values derived from the measurements occurred with the lateral predictions.

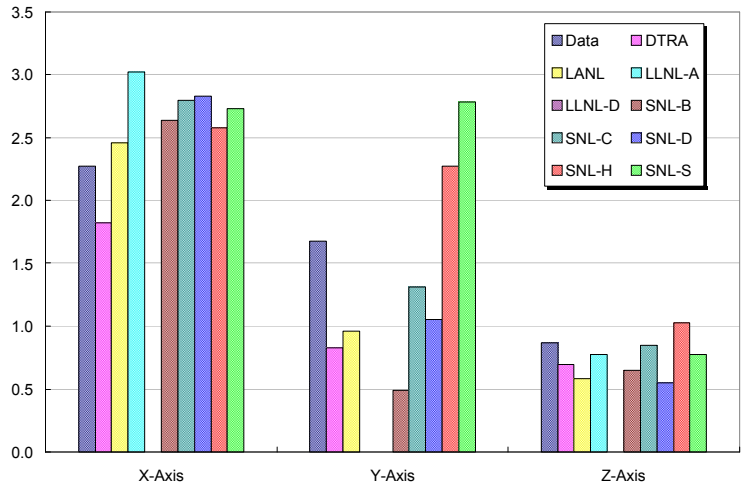

Figure B-12. SNL-03-12 delay to centroid.

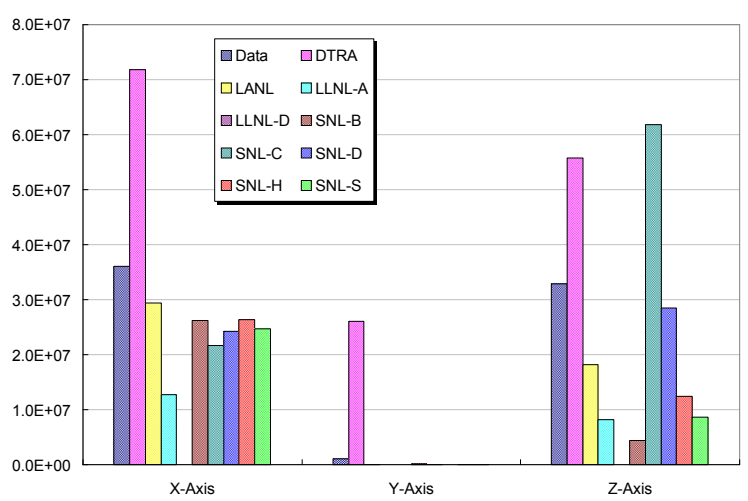

Figure B-14. SNL-03-12 root energy amplitude.

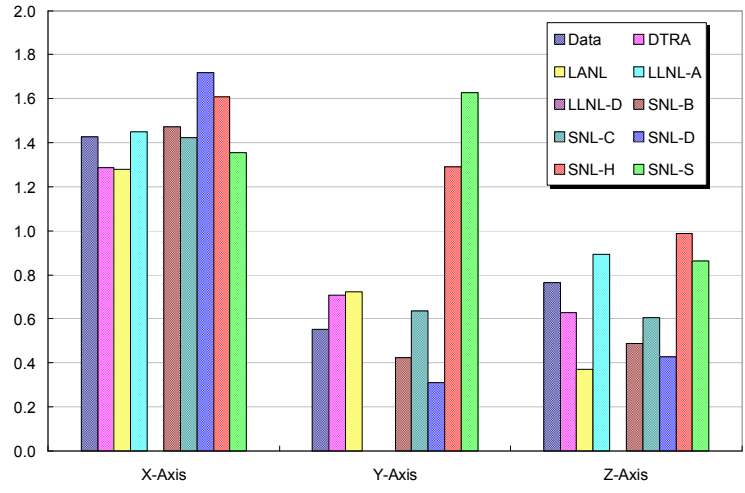

Figure B-13. SNL-03-12 RMS duration.

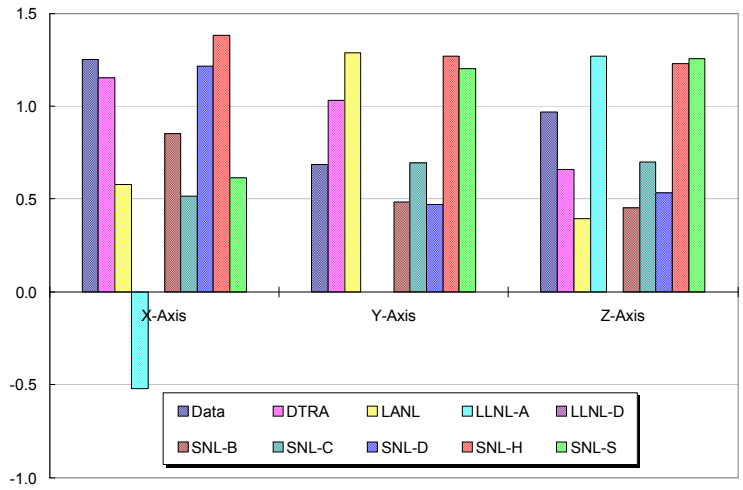

Figure B-15. SNL-03-12 skewness. 


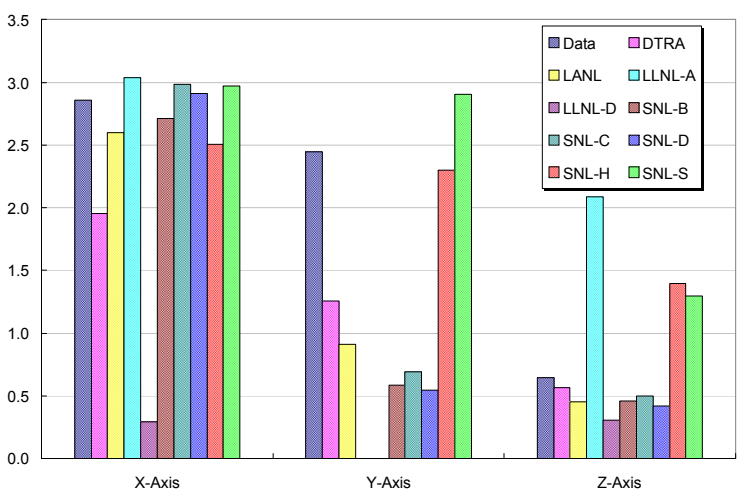

Figure B-16. SNL-03-14 delay to centroid.

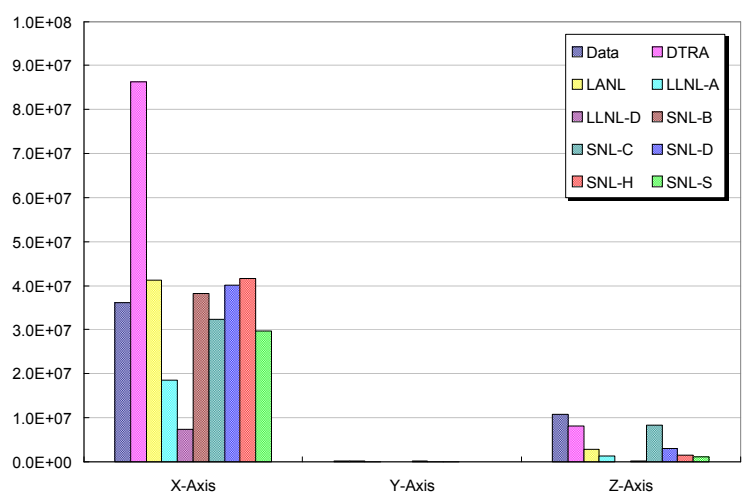

Figure B-18. SNL-03-14 root energy amplitude.

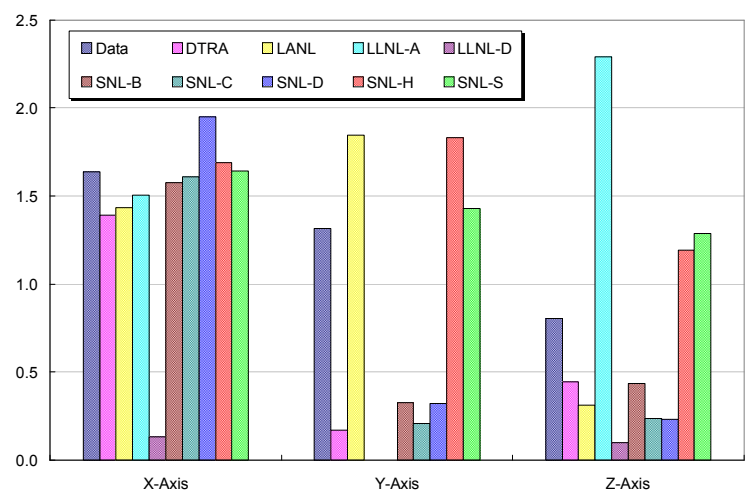

Figure B-17. SNL-03-14 RMS duration.

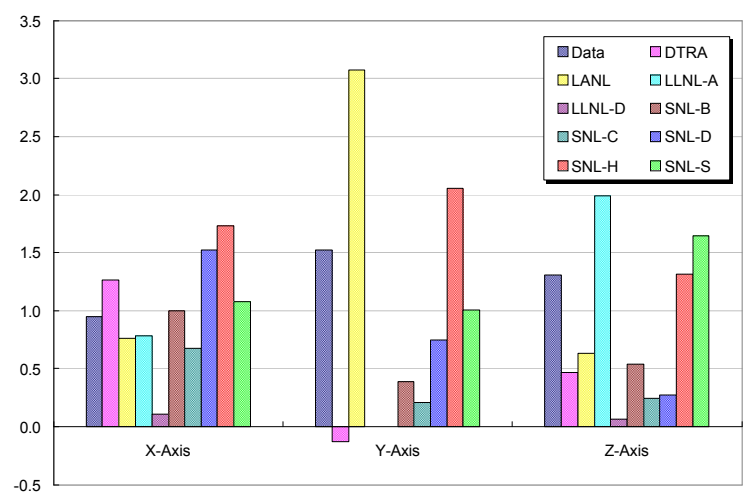

Figure B-19. SNL-03-14 skewness. 


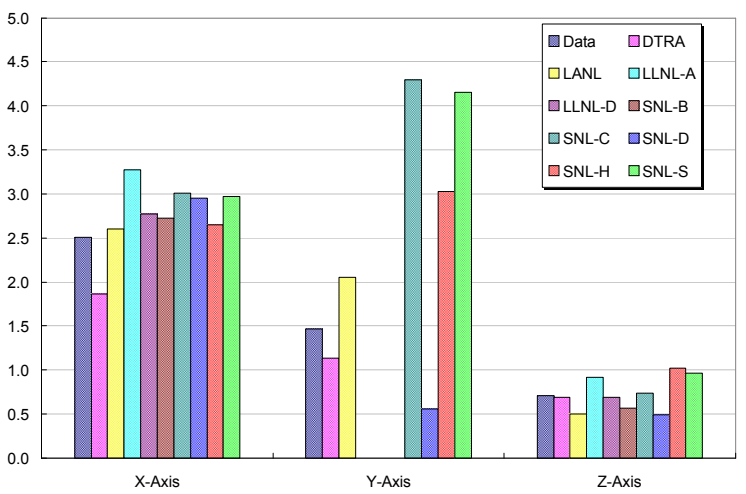

Figure B-20. SNL-03-15 delay to centroid.

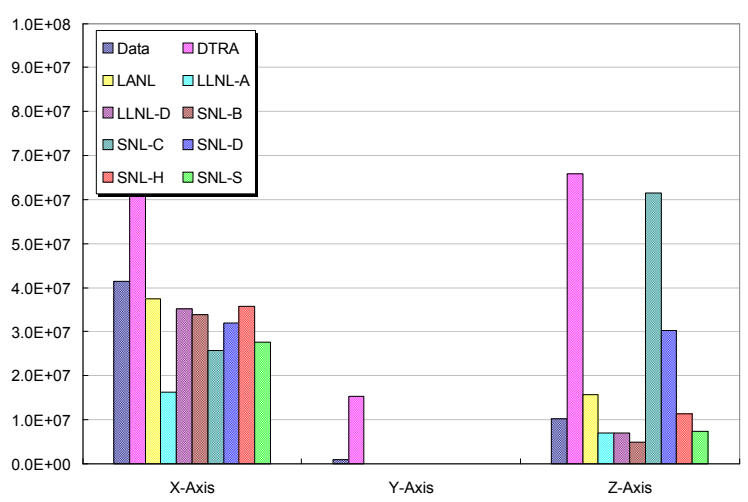

Figure B-22. SNL-03-15 root energy amplitude.

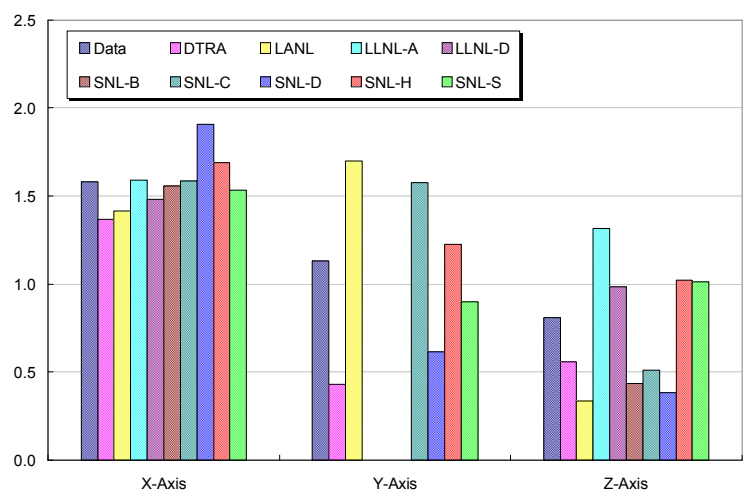

Figure B-21. SNL-03-15 RMS duration.

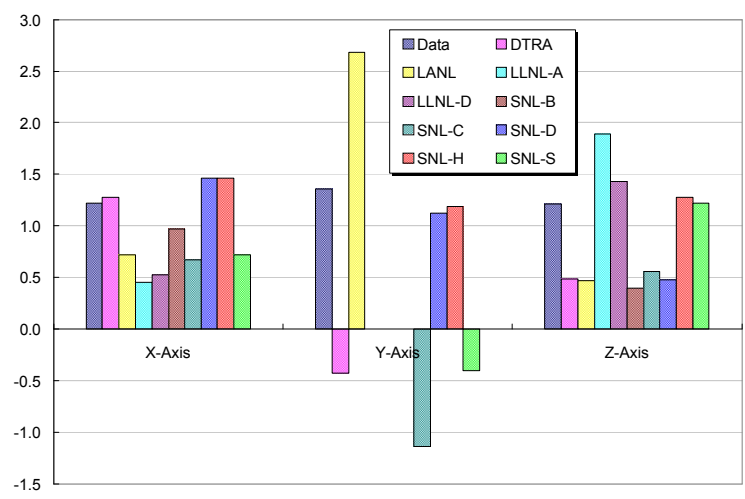

Figure B-23. SNL-03-15 skewness. 


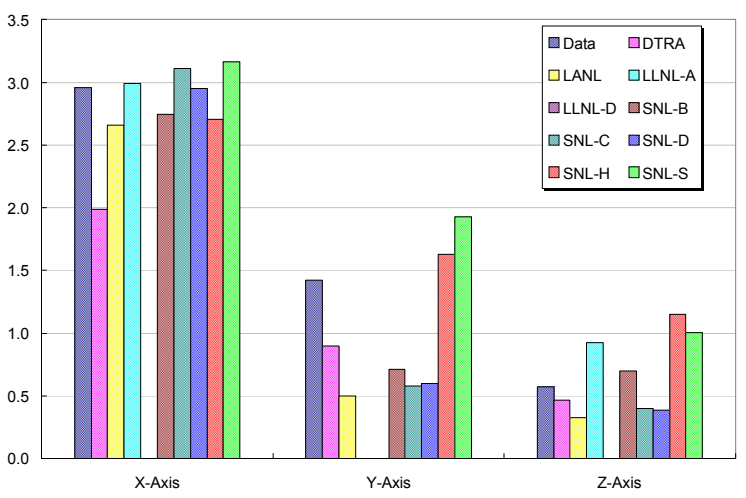

Figure B-24. SNL-03-16 delay to centroid.

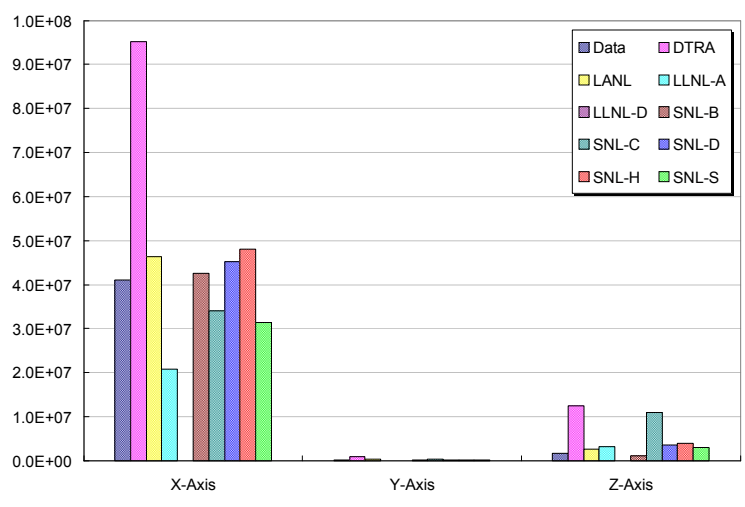

Figure B-26. SNL-03-16 root energy amplitude.

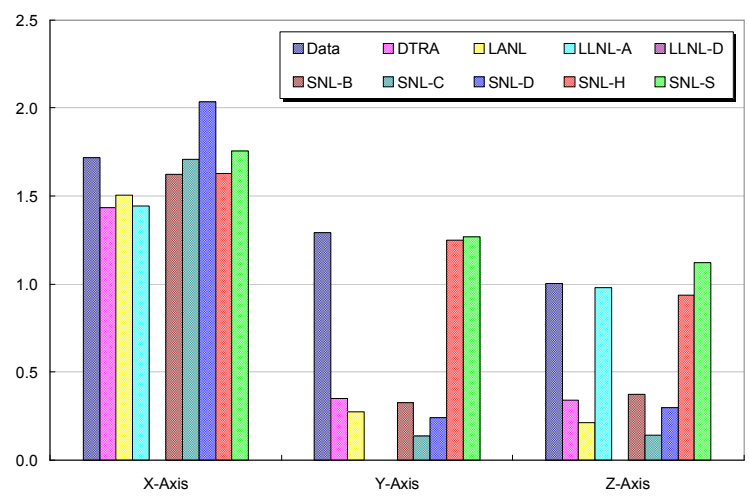

Figure B-25. SNL-03-16 RMS duration.

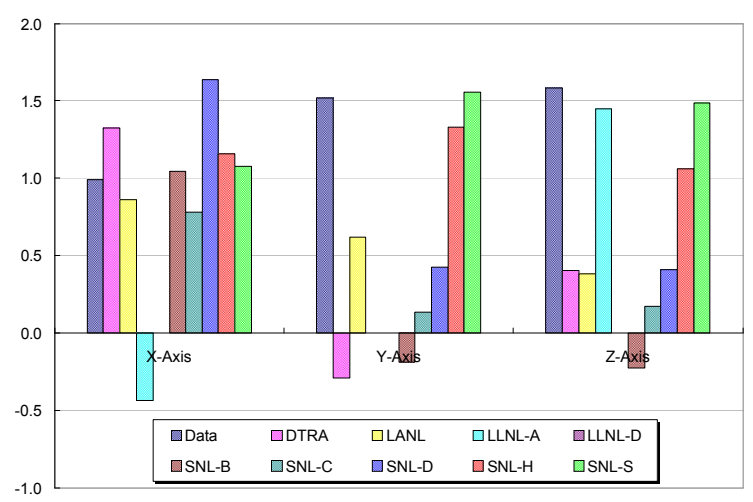

Figure B-27. SNL-03-16 skewness. 


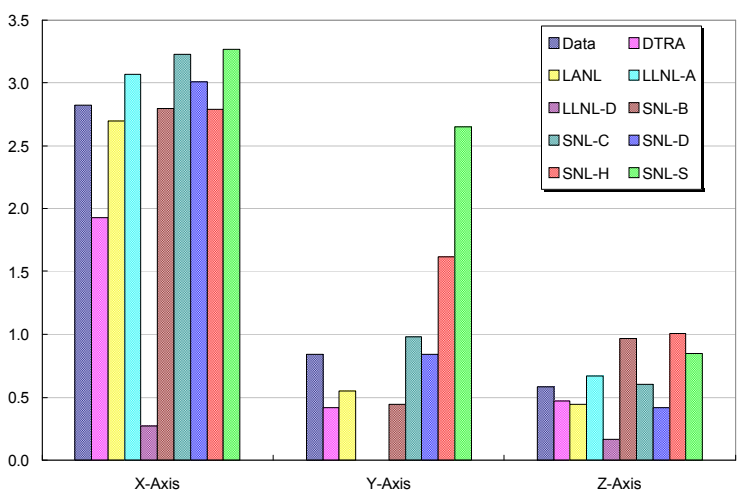

Figure B-28. SNL-03-17 delay to centroid.

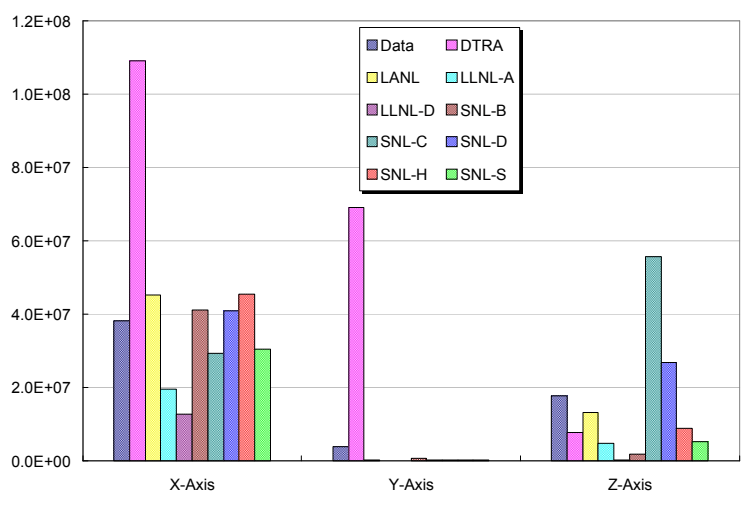

Figure B-30. SNL-03-17 root energy amplitude.

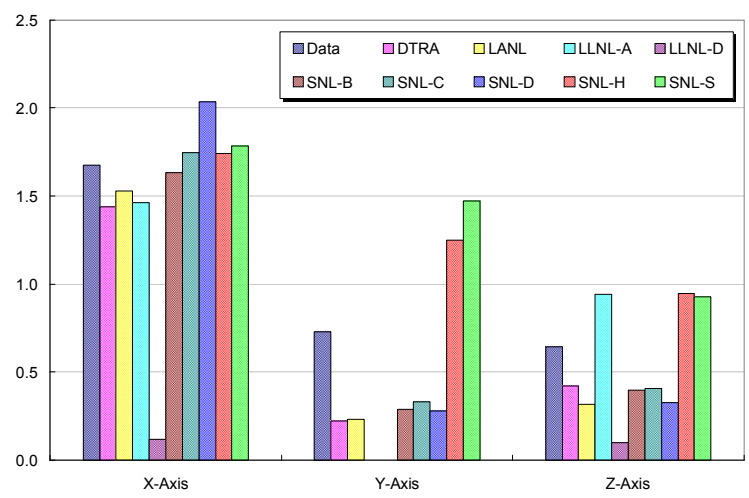

Figure B-29. SNL-03-17 RMS duration.

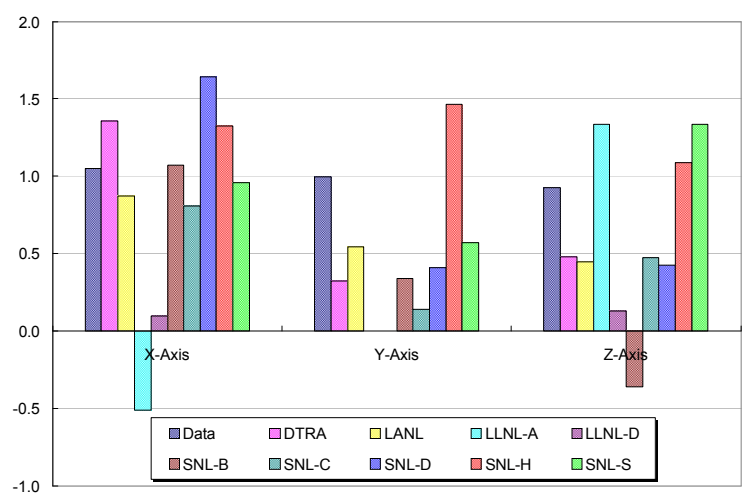

Figure B-31. SNL-03-17 skewness. 


\section{Appendix C Graphical Representation of Penetrator Rest Position.}

Penetrator displacements, rest position and angles were reported in the target-centered frame, x', y', z' illustrated in Figures 5 and 6. Final rest angles in the x'-z' and y'-z' planes are defined as illustrated below.

\section{Top View}

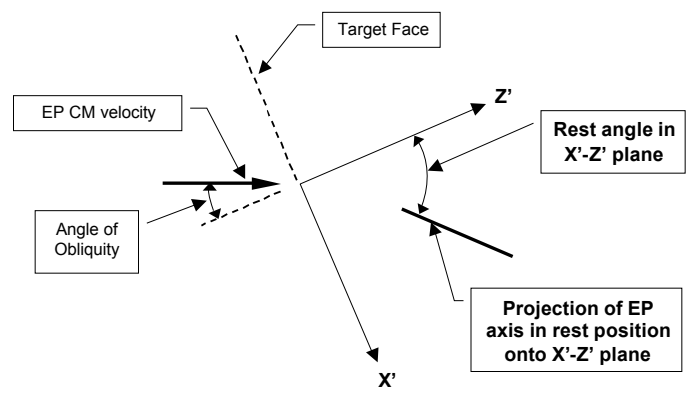

Side View

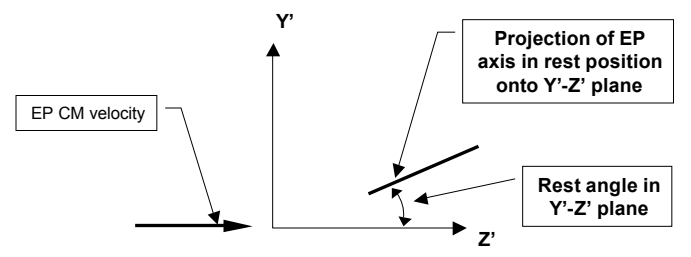

Figure C-1. Penetrator final position rest angles.

Final nose tip location in the x', y', z' target reference frame were tabulated and a pseudo penetration path length calculated

$$
r^{\prime}=\sqrt{x^{\prime 2}+y^{\prime 2}+z^{\prime 2}}
$$

The y' axis is normal to the target plane of symmetry, and both the calculated and the measured displacements along the y' axis were near-zero and were neglected for the purpose of comparing final rest position of the penetrator. End cap position of the penetrator was estimated using the $x^{\prime}$ and z' displacements and the final rest angle in the x'-z' plane.

Penetration data (end point and path length) predictions were in fairly good agreement with the measured data. See Tables C1 through C5. Graphical representations of the penetration data and predictions are shown in Figures C2 through C6, where the experimental result is indicated by an outline of the projectile. 
Table C-1. SNL-03-12, penetration data.

\begin{tabular}{|c|c|c|c|c|c|}
\hline & $\begin{array}{c}\text { Nose Tip } \\
\boldsymbol{x}^{\prime} \mathbf{( m )}\end{array}$ & $\begin{array}{c}\text { Nose Tip } \\
\boldsymbol{y}^{\prime} \mathbf{( m )}\end{array}$ & $\begin{array}{c}\text { Nose Tip } \\
\mathbf{z}^{\prime} \mathbf{( m )}\end{array}$ & $\begin{array}{c}\text { Path } \\
\text { Length }(\mathbf{m})\end{array}$ & $\begin{array}{c}\mathbf{X}^{\prime}-\mathbf{Z}^{\prime} \text { rest } \\
\text { angle }\end{array}$ \\
\hline Data & 0.54 & 0.02 & 0.48 & 0.72 & 50.00 \\
\hline DTRA & 0.49 & -0.02 & 0.43 & 0.66 & 48.28 \\
\hline LANL & 0.42 & 0.00 & 0.58 & 0.72 & 36.02 \\
\hline LLNL-A & 0.54 & 0.00 & 0.72 & 0.90 & 38.22 \\
\hline LLNL-D & & \multicolumn{3}{|c|}{ No Calculation } & \\
\hline SNL-B & 0.46 & -0.01 & 0.66 & 0.80 & 34.80 \\
\hline SNL-C & 0.60 & -0.01 & 0.52 & 0.79 & 49.30 \\
\hline SNL-D & 0.57 & -0.01 & 0.65 & 0.87 & 41.90 \\
\hline SNL-H & 0.55 & -0.01 & 0.63 & 0.83 & 43.66 \\
\hline SNL-S & 0.41 & -0.01 & 0.61 & 0.73 & 31.01 \\
\hline
\end{tabular}

Table C-2. SNL-03-14, penetration data.

\begin{tabular}{|c|c|c|c|c|c|}
\hline & $\begin{array}{c}\text { Nose Tip } \\
\boldsymbol{x}^{\prime} \mathbf{( m )}\end{array}$ & $\begin{array}{c}\text { Nose Tip } \\
\boldsymbol{y}^{\prime} \mathbf{( m )}\end{array}$ & $\begin{array}{c}\text { Nose Tip } \\
\boldsymbol{z}^{\prime} \mathbf{( m )}\end{array}$ & $\begin{array}{c}\text { Path } \\
\text { Length }(\mathbf{m})\end{array}$ & $\begin{array}{c}\mathbf{X}^{\prime}-\mathbf{Z}^{\prime} \text { rest } \\
\text { angle }\end{array}$ \\
\hline Data & 0.33 & 0.04 & 0.93 & 0.99 & 18 \\
\hline DTRA & 0.29 & 0.01 & 0.79 & 0.84 & 20.23 \\
\hline LANL & 0.26 & 0.00 & 0.90 & 0.94 & 16.19 \\
\hline LLNL-A & 0.31 & 0.00 & 1.04 & 1.09 & 15.98 \\
\hline LLNL-D & 0.29 & 0.00 & 0.90 & 0.95 & 16.45 \\
\hline SNL-B & 0.27 & 0.01 & 0.98 & 1.02 & 15.40 \\
\hline SNL-C & 0.30 & 0.00 & 0.98 & 1.02 & 16.50 \\
\hline SNL-D & 0.31 & 0.01 & 1.08 & 1.12 & 15.70 \\
\hline SNL-H & 0.34 & 0.01 & 1.04 & 1.09 & 19.42 \\
\hline SNL-S & 0.29 & 0.01 & 1.00 & 1.04 & 16.70 \\
\hline
\end{tabular}


Table C-3. SNL-03-15, penetration data.

\begin{tabular}{|c|c|c|c|c|c|}
\hline & $\begin{array}{c}\text { Nose Tip } \\
\boldsymbol{x}^{\prime} \mathbf{( m )}\end{array}$ & $\begin{array}{c}\text { Nose Tip } \\
\boldsymbol{y}^{\prime} \mathbf{( m )}\end{array}$ & $\begin{array}{c}\text { Nose Tip } \\
\mathbf{z}^{\prime} \mathbf{( m )}\end{array}$ & $\begin{array}{c}\text { Path } \\
\text { Length }(\mathbf{m})\end{array}$ & $\begin{array}{c}\mathbf{X}^{\prime}-\mathbf{Z}^{\prime} \text { rest } \\
\text { angle }\end{array}$ \\
\hline Data & 0.62 & 0.00 & 0.69 & 0.93 & 43.00 \\
\hline DTRA & 0.59 & -0.01 & 0.54 & 0.80 & 47.05 \\
\hline LANL & 0.51 & 0.00 & 0.74 & 0.90 & 34.49 \\
\hline LLNL-A & 0.61 & 0.00 & 0.86 & 1.06 & 35.70 \\
\hline LLNL-D & 0.51 & 0.00 & 0.72 & 0.88 & 32.52 \\
\hline SNL-B & 0.55 & 0.00 & 0.81 & 0.98 & 34.10 \\
\hline SNL-C & 0.69 & 0.00 & 0.72 & 1.00 & 43.80 \\
\hline SNL-D & 0.69 & 0.00 & 0.83 & 1.08 & 40.60 \\
\hline SNL-H & 0.64 & -0.01 & 0.78 & 1.01 & 41.90 \\
\hline SNL-S & 0.50 & -0.01 & 0.81 & 0.95 & 27.95 \\
\hline
\end{tabular}

Table C-4. SNL-03-16, penetration data.

\begin{tabular}{|c|c|c|c|c|c|}
\hline & $\begin{array}{c}\text { Nose Tip } \\
\boldsymbol{x}^{\prime} \mathbf{( m )}\end{array}$ & $\begin{array}{c}\text { Nose Tip } \\
\boldsymbol{y}^{\prime} \mathbf{( m )}\end{array}$ & $\begin{array}{c}\text { Nose Tip } \\
\mathbf{z}^{\prime} \mathbf{( m )}\end{array}$ & $\begin{array}{c}\text { Path } \\
\text { Length }(\mathbf{m})\end{array}$ & $\begin{array}{c}\mathbf{X}^{\prime}-\mathbf{Z}^{\prime} \text { rest } \\
\text { angle }\end{array}$ \\
\hline Data & 0.30 & 0.00 & 1.07 & 1.11 & 16 \\
\hline DTRA & 0.29 & -0.02 & 0.88 & 0.92 & 18.21 \\
\hline LANL & 0.29 & 0.00 & 0.99 & 1.03 & 16.39 \\
\hline LLNL-A & 0.37 & 0.00 & 1.13 & 1.19 & 18.94 \\
\hline LLNL-D & \multicolumn{5}{|c|}{ No Calculation } \\
\hline SNL-B & 0.33 & -0.02 & 1.06 & 1.11 & 17.40 \\
\hline SNL-C & 0.35 & -0.01 & 1.10 & 1.15 & 17.60 \\
\hline SNL-D & 0.37 & -0.02 & 1.19 & 1.25 & 17.50 \\
\hline SNL-H & 0.38 & -0.02 & 1.01 & 1.08 & 23.60 \\
\hline SNL-S & 0.30 & -0.01 & 1.12 & 1.16 & 12.41 \\
\hline
\end{tabular}


Table C-5. SNL-03-17, penetration data.

\begin{tabular}{|c|c|c|c|c|c|}
\hline & $\begin{array}{c}\text { Nose Tip } \\
\boldsymbol{x}^{\prime} \mathbf{( m )}\end{array}$ & $\begin{array}{c}\text { Nose Tip } \\
\boldsymbol{y}^{\prime} \mathbf{( m )}\end{array}$ & $\begin{array}{c}\text { Nose Tip } \\
\mathbf{z}^{\prime} \mathbf{( m )}\end{array}$ & $\begin{array}{c}\text { Path } \\
\text { Length }(\mathbf{m})\end{array}$ & $\begin{array}{c}\mathbf{X}^{\prime}-\mathbf{Z}^{\prime} \text { rest } \\
\text { angle }\end{array}$ \\
\hline Data & 0.69 & 0.00 & 0.89 & 1.13 & 38 \\
\hline DTRA & 0.64 & 0.00 & 0.68 & 0.93 & 43.38 \\
\hline LANL & 0.59 & 0.00 & 0.88 & 1.06 & 33.61 \\
\hline LLNL-A & 0.69 & 0.00 & 1.01 & 1.22 & 34.44 \\
\hline LLNL-D & 0.52 & 0.00 & 0.70 & 0.87 & 36.71 \\
\hline SNL-B & 0.62 & -0.02 & 0.96 & 1.14 & 32.60 \\
\hline SNL-C & 0.78 & -0.01 & 0.92 & 1.20 & 40.10 \\
\hline SNL-D & 0.78 & -0.03 & 1.02 & 1.28 & 38.00 \\
\hline SNL-H & 0.71 & -0.02 & 0.89 & 1.14 & 42.22 \\
\hline SNL-S & 0.62 & -0.01 & 1.01 & 1.19 & 29.27 \\
\hline
\end{tabular}



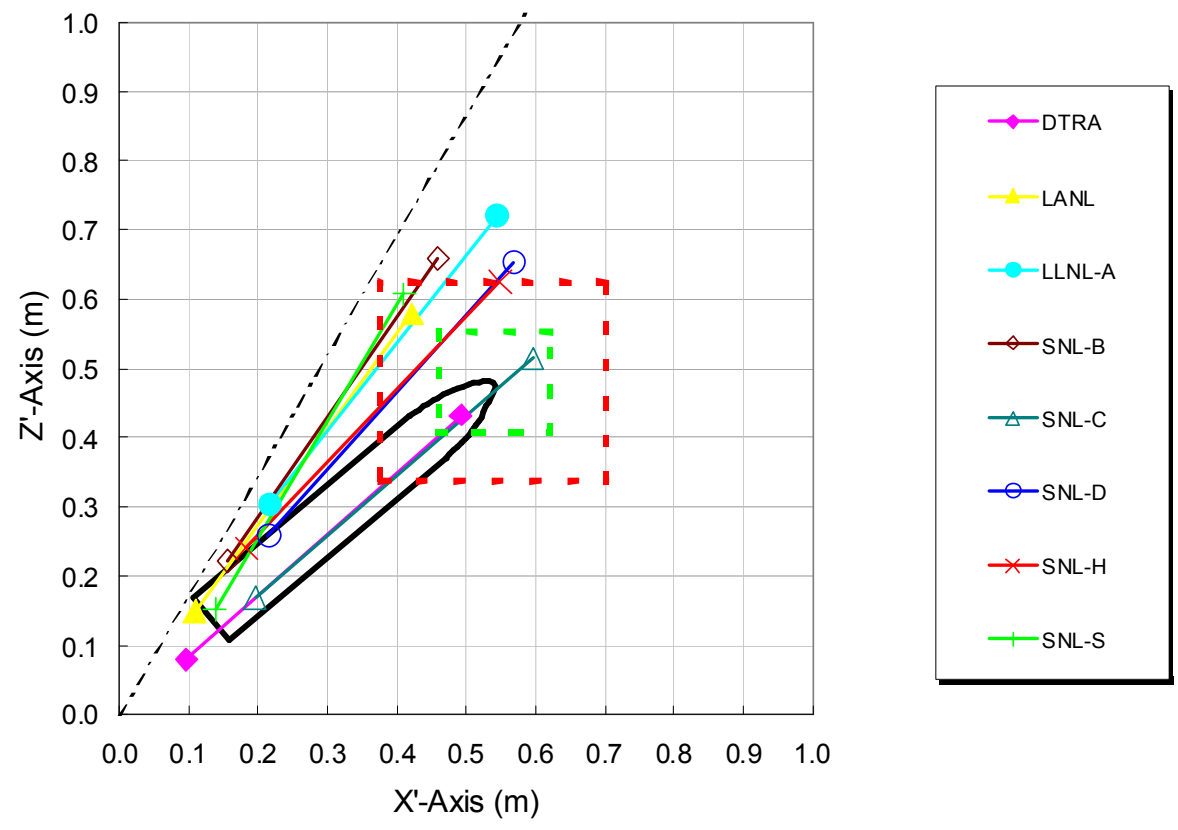

Figure C-2. Position in X'-Z' plane, SNL-03-12.
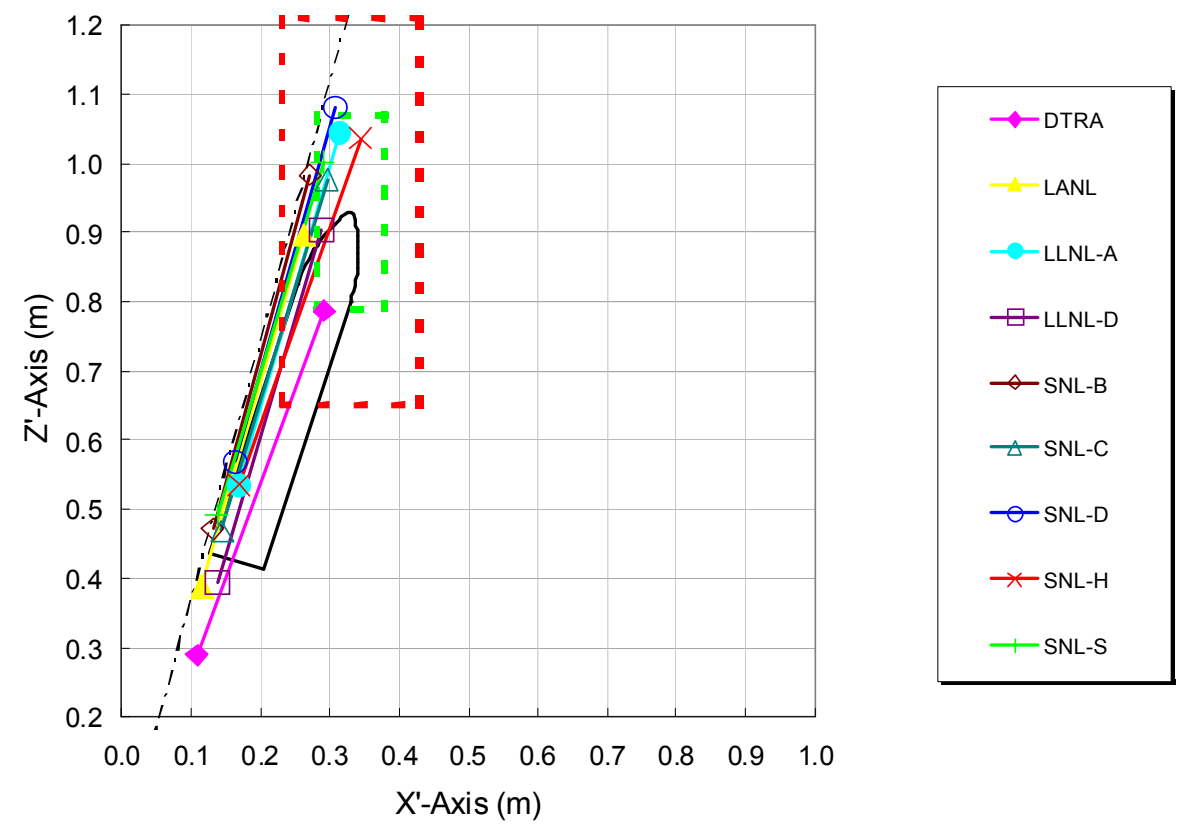

Figure C-3. Position in X'-Z' plane, SNL-03-14. 

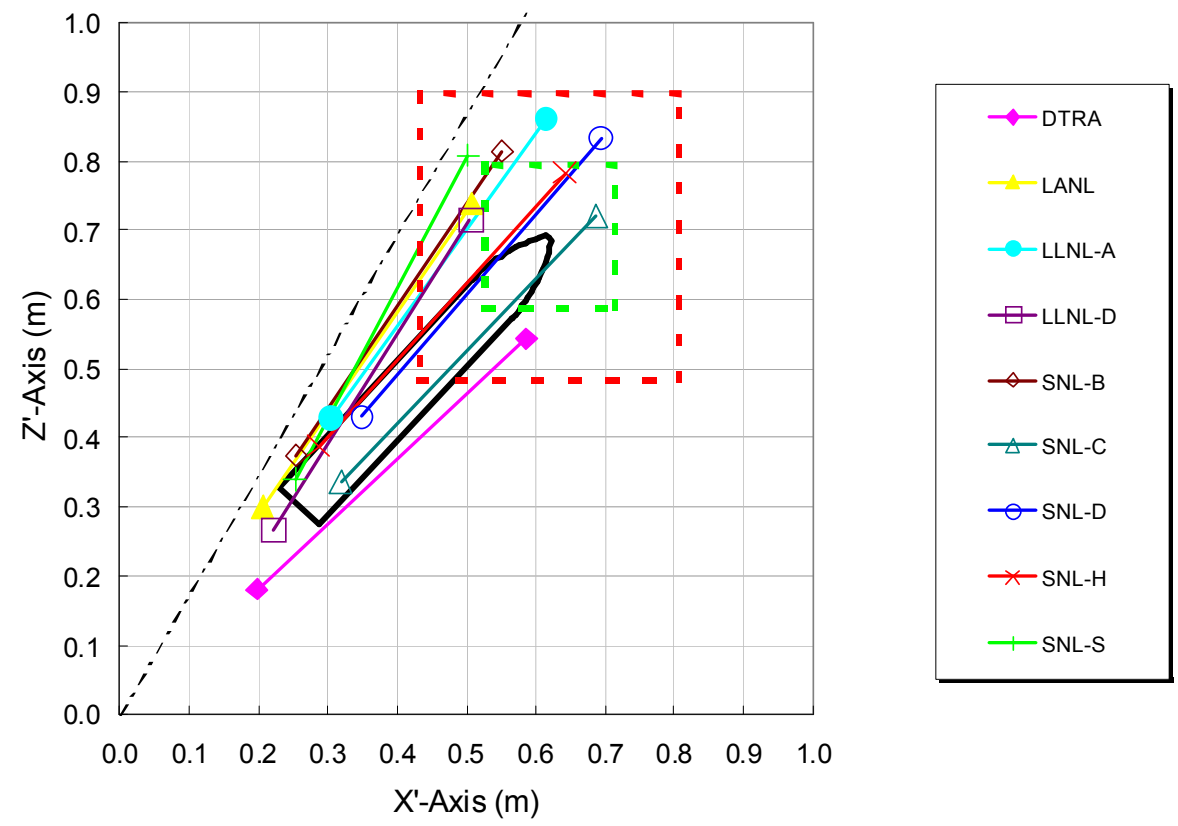

Figure C-4. Position in X'-Z' plane, SNL-03-15.
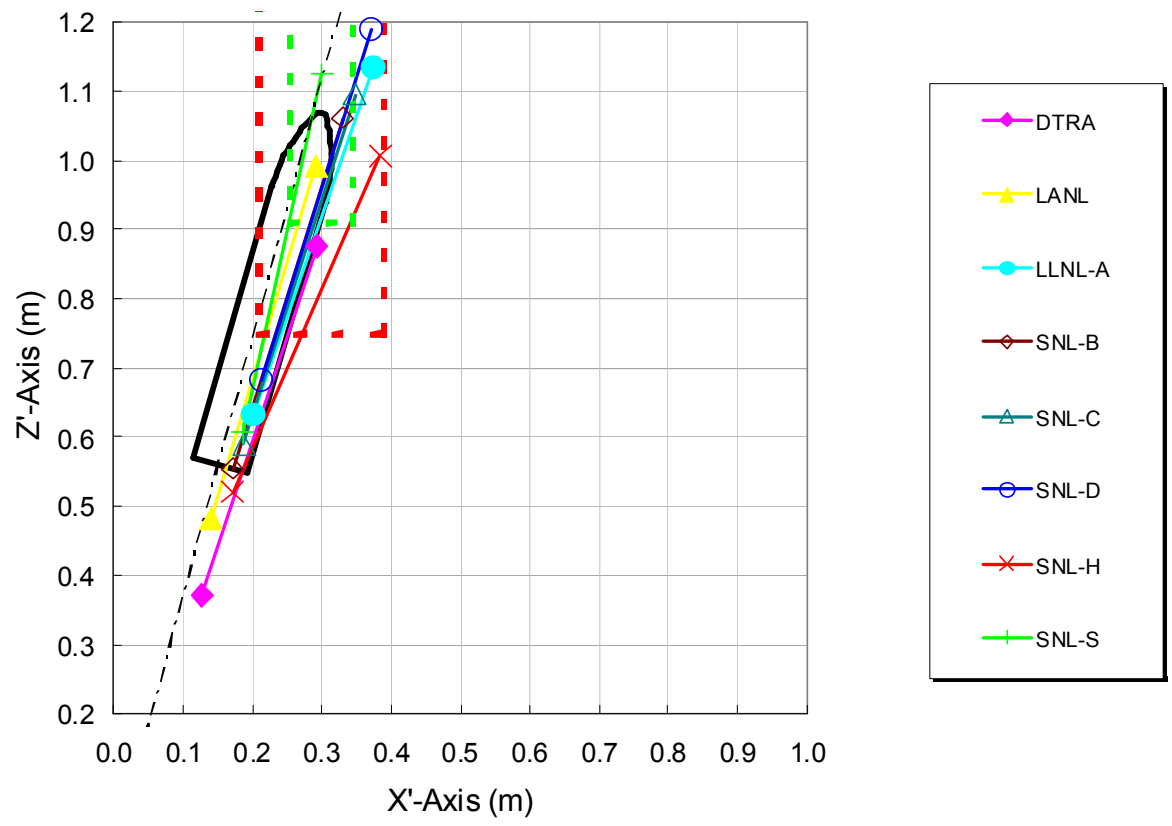

Figure C-5. Position in X'-Z' plane, SNL-03-16. 

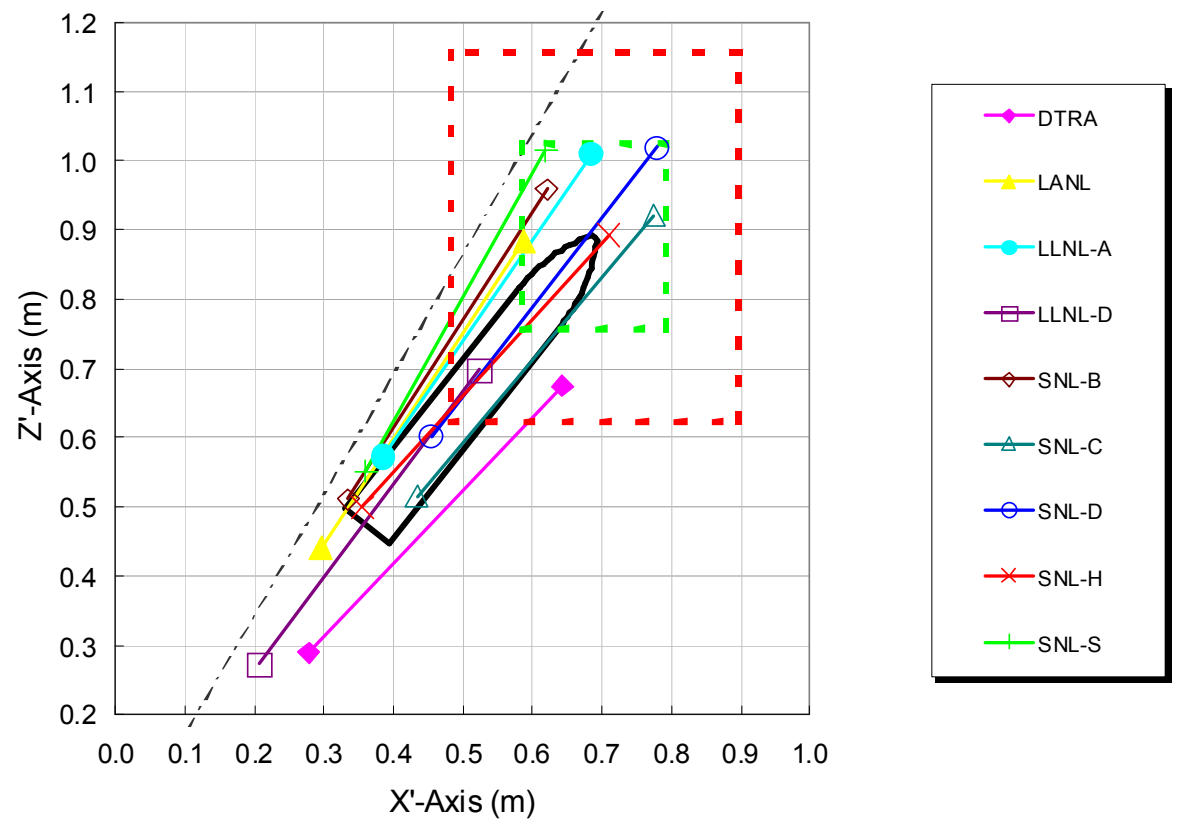

Figure C-6. Position in X'-Z' plane, SNL-03-17. 


\section{Appendix D Lateral Acceleration in the Y-Direction}

Table D1 shows the predicted and measured peak Y-lateral accelerations for each of the tests considered in this study. Figure D1 shows comparisons of the predicted and measured peak lateral accelerations in the Y-lateral direction.

The oblique impact tests considered here were designed to be symmetric with respect to the Y-direction, so the accelerations in that direction would be expected to be nearly zero. Since small angles of attack were present in the impact conditions, small accelerations in the Y-direction would not be surprising. However, the large amplitudes and high variability seen in the Y-lateral accelerations make those data questionable. Further investigation will be required to explain these results. Nevertheless, the data and calculational results for the Y-lateral accelerations are included here for completeness.

Table D-1. Peak Y-lateral accelerations for all tests and predictors.

\begin{tabular}{|c|c|c|c|c|c|}
\hline & SNL-03-12 & SNL-03-14 & SNL-03-15 & SNL-03-16 & SNL-03-17 \\
\hline Data & $4.01 \mathrm{E}+03$ & $1.57 \mathrm{E}+03$ & $1.12 \mathrm{E}+03$ & $6.36 \mathrm{E}+02$ & $2.41 \mathrm{E}+03$ \\
\hline DTRA & $8.00 \mathrm{E}+03$ & $5.39 \mathrm{E}+03$ & $1.01 \mathrm{E}+04$ & $2.16 \mathrm{E}+03$ & $1.42 \mathrm{E}+04$ \\
\hline LANL & $3.64 \mathrm{E}+02$ & $4.88 \mathrm{E}+02$ & $1.09 \mathrm{E}+02$ & $1.02 \mathrm{E}+03$ & $8.64 \mathrm{E}+02$ \\
\hline LNLL-A & $0.00 \mathrm{E}+00$ & $0.00 \mathrm{E}+00$ & $0.00 \mathrm{E}+00$ & $0.00 \mathrm{E}+00$ & $0.00 \mathrm{E}+00$ \\
\hline LLNL-D & No calculation & $0.00 \mathrm{E}+00$ & $0.00 \mathrm{E}+00$ & No calculation & $0.00 \mathrm{E}+00$ \\
\hline SNL-B & $7.55 \mathrm{E}+02$ & $7.44 \mathrm{E}+02$ & $0.00 \mathrm{E}+00$ & $6.43 \mathrm{E}+02$ & $1.65 \mathrm{E}+03$ \\
\hline SNL-C & $4.66 \mathrm{E}+02$ & $2.66 \mathrm{E}+02$ & $1.46 \mathrm{E}+00$ & $8.89 \mathrm{E}+02$ & $7.72 \mathrm{E}+02$ \\
\hline SNL-D & $3.52 \mathrm{E}+02$ & $3.12 \mathrm{E}+02$ & $2.28 \mathrm{E}+02$ & $7.87 \mathrm{E}+02$ & $7.93 \mathrm{E}+02$ \\
\hline SNL-H & $4.71 \mathrm{E}+02$ & $4.19 \mathrm{E}+02$ & $2.90 \mathrm{E}+02$ & $4.71 \mathrm{E}+02$ & $5.48 \mathrm{E}+02$ \\
\hline SNL-S & $5.17 \mathrm{E}+02$ & $5.40 \mathrm{E}+02$ & $8.37 \mathrm{E}+02$ & $1.04 \mathrm{E}+03$ & $1.09 \mathrm{E}+03$ \\
\hline
\end{tabular}




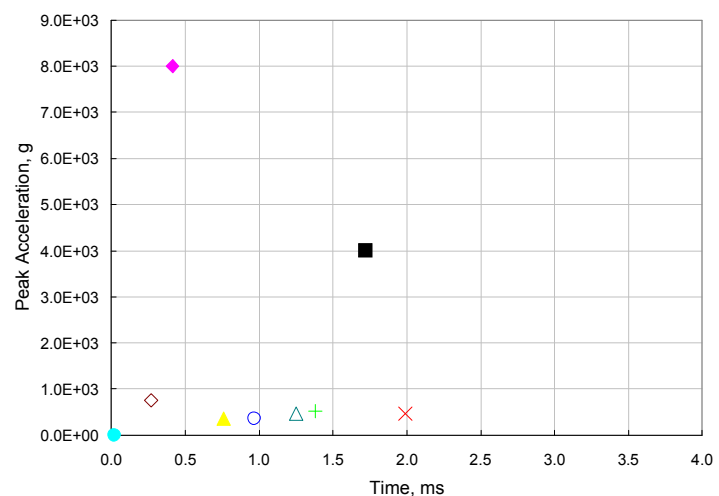

SNL-03-12

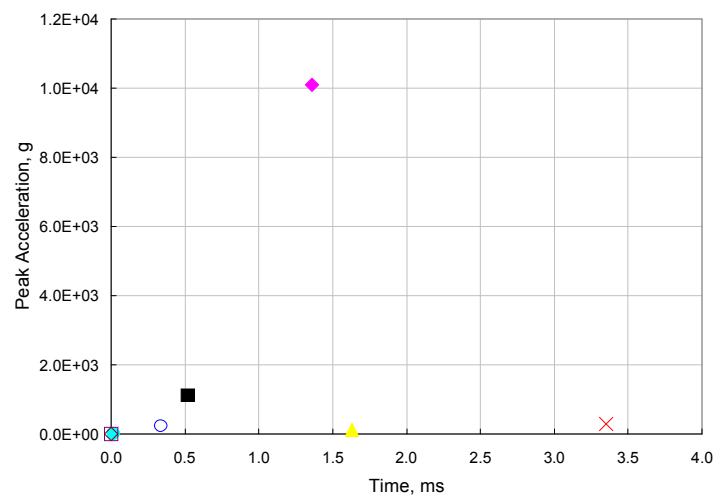

SNL-03-15

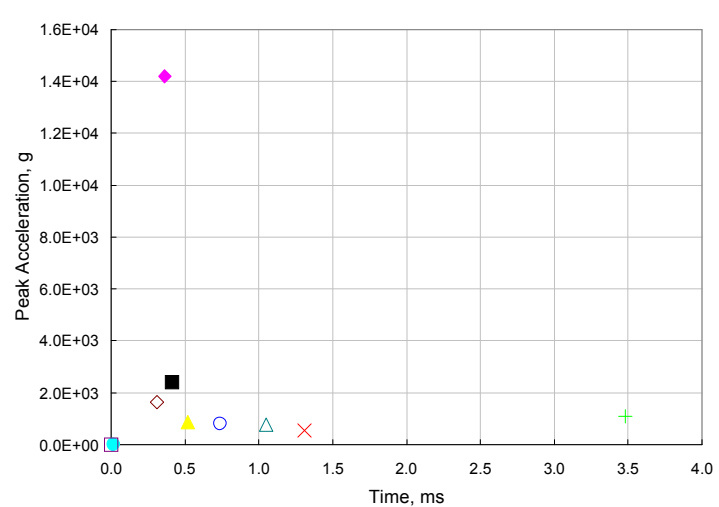

SNL-03-17

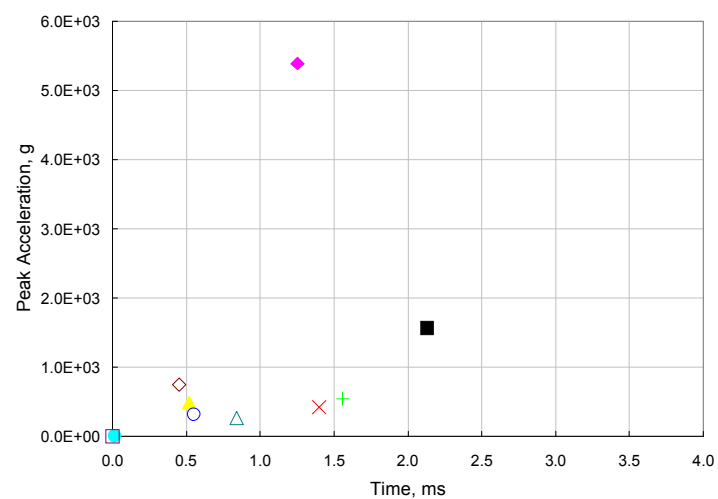

SNL-03-14

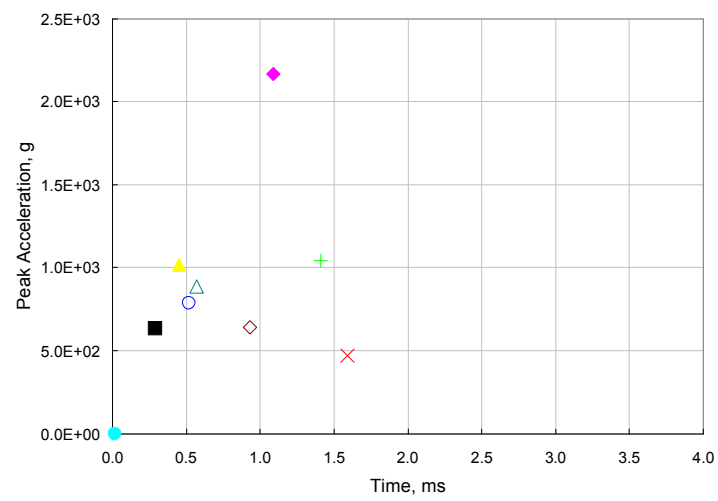

SNL-03-16

\begin{tabular}{|c|c|c|c|}
\hline Data & $\diamond \mathrm{DTRA}$ & $\triangle$ LANL & LLNL-A \\
\hline$\square^{\text {LLNL-D }}$ & $\diamond S N L-B$ & $\triangle$ SNL-C & OSNL-D \\
\hline$\times$ SNL-H & + SNL-S & & \\
\hline
\end{tabular}

Figure D-1. Peak Y-lateral acceleration for all tests. 


\section{Appendix E Test Variables}

\section{E.1 Material Properties ${ }^{4}$}

The following is a list of variables provided for the penetration tests at WES. Future tests will use high strength concrete and possibly two data recorders to measure rotation and other parameters.

Concrete Target Properties.

$\begin{array}{ll}\text { Aggregate size } & \leq 3 / 8 \mathrm{in} \\ \text { Porosity } & 18 \text { percent } \\ \text { Wet density } & 124 \mathrm{lb} / \mathrm{ft}^{3}\left(1.99 \mathrm{Mg} / \mathrm{m}^{3}\right) \\ \text { Water content } & 4.12 \text { percent } \\ \text { Dry density } & 119 \mathrm{lb} / \mathrm{ft}^{3}\left(1.91 \mathrm{Mg} / \mathrm{m}^{3}\right)\end{array}$

\section{E.2 Variables/uncertainties ${ }^{5}$}

Table E1 provides estimates of the variable control and measurement uncertainty for the experiments. Control refers to how well a particular variable could be controlled. Measurement refers to the precision of the measured data. The final resting position is measured by jack hammering the concrete away from the penetrator to expose the nose and tail. Body rotation was not measured during penetration.

Table E-1. WES experimental variable control and measurement precision.

\begin{tabular}{|r|c|}
\hline Variable & Control \\
\hline Angle of attack & $0.5^{\circ}$ \\
\hline Impact velocity & $\pm 20 \mathrm{ft} / \mathrm{s}$ \\
\hline Obliquity & $\pm 1^{\circ}$ \\
\hline Y and Z axis & $2^{\circ}$ \\
\hline Velocity & $\pm 10-15 \mathrm{ft} / \mathrm{s}$ \\
\hline Pitch/yaw & $<0.1^{\circ}$ \\
\hline Penetrator mass & $\approx 2 \mathrm{~g}$ \\
\hline $\mathrm{X}^{\prime}$ and $\mathrm{Z}^{\prime}$ axis & $1 / 8 \mathrm{in}$ \\
\hline $\mathrm{Y}^{\prime}$ axis & $1 / 4$ in \\
\hline
\end{tabular}

\footnotetext{
${ }^{4}$ Frew, Danny J. Instrumented Penetration Input Conditions for Oblique Penetration Experiments into Low Strength Concrete Targets. Sandia National Laboratories, 6 Apr. 2004.

${ }^{5}$ Frew, Danny J. Private communication. 23 Jun. 2004;
} 